


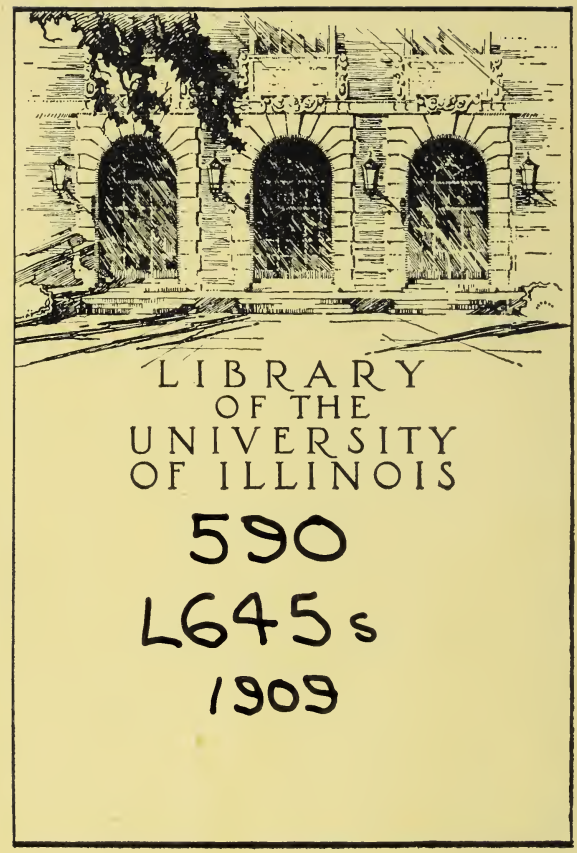



Digitized by the Internet Archive in 2017 with funding from

University of Illinois Urbana-Champaign Alternates 




\section{MSHAR! \\ UNIVERST OF ILLIWUIS}

URBANA 


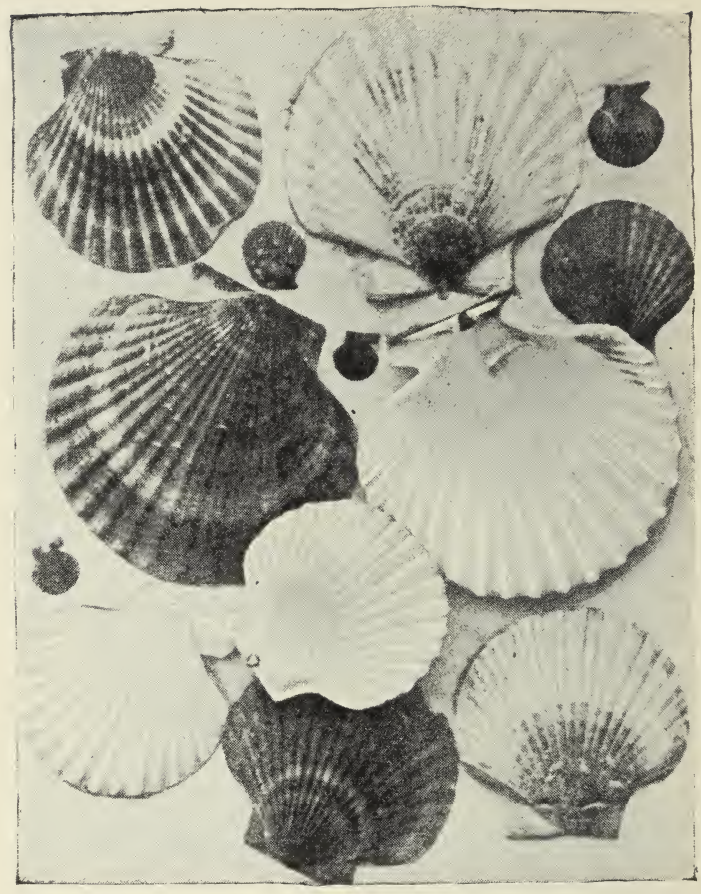

Fig. I.-The Scallop Shell, Pecten Opercularis (see page 107), SLIGHTLY REDUCED IN SIZE. THE LARger SHELls ARE FRom DOUglas, IsLe of MAN ; THE SMALleR SHELlS ARE YOUNG SPECIMENS FROM LlaNdUdNo, NORTH WALES. 


\title{
THE STORY OF ANIMAL LIFE
}

\author{
BY \\ B. LIN DSA Y
}

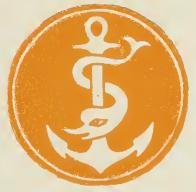

WITH FORTY-SEVEN ILLUSTRATIONS

NEW YORK

S. S. MCCLURE CO.

MCMIX 
Copyright, IgO2

BY D. APPLETON AND COMPANY

All rights reserved 


\section{PREF A C E}

OF the diagrams which illustrate this little volume, the majority were prepared by Miss E. C. Abbott (formerly Bathurst Scholar at Newnham College, Cambridge): the sketches were made from specimens in the South Kensington Museum of Natural History, which has kindly granted permission for their use. In addition to these, there are several figures that are taken from specimens in my possession, photographed by the publishers; two or three cuts are diagrammatic; and I owe to the kindness of Mr. J. Craggs, formerly president of the Northumberland Microscopical Association, the drawings of Polycystina and of the scales of the Sole.

B. L. 


\section{O N T E N T S}

CHAPTER

PAGE

I. The Story of Animal Life.

II. How ANImAls ADAPT THEMSElves TO CiRCUMSTANCES • • • • • • • . . I3

III. Classification: the Sorting of the Animal

KINGDOM • • • • . • • • 30

IV. The One-celled Animals, or ProtozoA • 45

V. The Ceelenterata - . . . • 53

VI. The Sponges • . • . . . . 63

VII. THE Vermes OR WORMS • • • • • 68

VIII. The Arthropoda: Lobsters, Spiders, AND

INSECTS . • . . . • • 76

IX. The Mollusca, or Shell-Fish • • 98

X. The Brachiopoda, or Lamp-Shells • . II7

XI. The Moss-Corals, or Polyzoa • • . II

XII. The Echinodermata • • • • • I22

XIII. The Chordata . . . . . • . I35

XIV. The Vertebrata . • • • • . 138

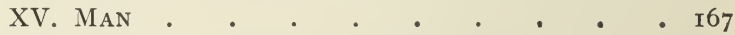

XVI. How Zoologists DO THEIR WORK... . I80

INDEX . . . . . • • • • I93 


\section{LIST OF ILLUSTRATIONS}

FIGURE

I. The Scallop-Shell . . . . Frontispiece

2. Limpets and Periwinkles . . . . . . I9

3. Diagram of $A$ maba . . . . . . . 35

4. Section of Hydra . . . . . . . 36

5. Diagrammatic Section of Earthworm . . . 38

6. Diagram of a Gastrula . . . . . 。4 4 I

7. Diagram of a Trochosphere . . . . . 42

8. Shells of Radiolarians (Polycystina) . . . . 47

9. A Coralline . . . . . . 58

Io. Gorgonia . • • . • . . 59

II. Corals . . . . . . . . 60

I2. Marine Worms . . . . . . . 73

13. A Centipede . . . . . . . 77

I4, I5. Shells of Barnacles . . . . . 79,80

I6. Hermit Crabs • . . . . . . . 8 I

I7. A Land Crab . . . . . . . 82

I8. A Sand-hopper . . . . . . . 83

I9. A Spider . . . . . . . 84

20. Nest of Trap-door Spider . . . . . 85

21. Galeodes . . . . . . . . 86

22. A Tick . • . . . . . 87

23. A Scorpion . . . . . . 88

24. Larvæ of Insects . . . . . . . 90

25. Larva of the Bee . . . . . . . 92

26. Ants . • . . . . . . 92 


\section{FIGURE}

PAGE

27. White Ants

28. Cocoons of Moths

29. A Moth and its Larva

30. Nest of a Gregarious Caterpillar

3I. Development of an English Water-beetle (Dytiscus) 96

32. Insect Pests • • • • • • • 97

33. Branchy Murex . . . . . . . 102

34. Shell of the Common Venus . . . . 104

35. Eggs of Molluscs . • • • . . . II5

36. The Five-holed Sand-Cake . . . . . 125

37. A Brittle-Star • . . . . . . . I29

38. A Sea-Cucumber . . • • • . . I30

39. A Stone-Lily or Encrinite . . . . . I3I

40. A Feather-Star. • . . . . . . I32

4I. Sections showing Position of the Vertebrate Noto-

chord . . . . . . . . . I39

42. Scales of a Sole . . . . . . . 143

43. Tadpoles . . . . . . . . . I53

44. Eggs of Reptiles . . . . . . . 155

45. Skull of Kangaroo . . . . . . . . 162

46. Skull of Rodent . . . . . . . . 163

47. Slide with Rows of Sections for the Microscope . 185 


\section{THE STORY OF ANIMAL LIFE}

\section{CHAPTER I}

\section{THE STORY OF ANIMAL LIFE}

IF the microscope had never been invented, the Story of Animal Life, as it is related by modern science, could never have been told. It is to the microscope that we owe our knowledge of innumerable little animals that are too small to be seen by the unassisted eye; and it is to the microscope that we owe the most important part of our knowledge about the bodies of larger animals, about the way in which they are built up, and the uses of their different parts. The earlier opticians who toiled, one after another, to bring the microscope to perfection, never dreamed, in their most ambitious moments, of the value of the gift that their labour was to confer upon mankind. For the microscope alone has made it possible for men of science to study the world of living things. This is the value of honest and thorough work in almost every department of intellectual labour; that it builds a firm and sure though perhaps hidden foundation for the loftier and more perfect work of after days.

The microscope has shown us the intimate structure of every organ of the animal body; and 
thus, in most cases, the uses of the organ, and the steps by which it performs its tasks, have been made clear. The microscope has also shown the true nature of the sexual functions, and all the steps of the processes of growth in young animals. None of these things could ever have been rightly understood without the microscope, for all their most important details are invisible to the naked eye. To the microscope, too, we owe our knowledge of the essential kinship between plants and animals; to it, also, our understanding of the oneness, the "solidarity," as the French would say, of the animal kingdom, for it is in the structure of microscopic parts that resemblances are revealed under the most strikingly different circumstances of outward form.

Let us inquire a little into the history of the animals that can only be seen by the aid of the microscope. Most of them live in water, especially dirty water, containing decaying remains of plants or animals. The naturalists who first discovered them studied them in "infusions" of hay, and so on, and hence these little creatures were named Infusoria-a name that has since been somewhat restricted in its application. By an "infusion" is meant that water is poured on some substance and allowed to stand; the more ancient and evilsmelling the infusion becomes, the more of these little animals do you find living in it. Nature provides dirty water ready made, in ditches and in ponds, and these are full of microscopic animals. And not only do they appear in dirty water, but kindred kinds appear in clean water also, and many in the waters of the sea.

It will easily be understood that when the existence of microscopic animals was discovered, 
zoologists had greatly to modify their ideas of the animal world. Still more was this the case afterwards, when it was found that all animals were built up of minute parts much resembling these microscopic animals in their main features. To these unit parts, of which all animal bodies are composed, the term "cell" is applied. The name of cell is not very descriptive of these units in the animal body, but correctly describes the unit of plant structure. In certain important essential particulars both, however, are alike. Nowadays we are not content to describe the grouping and external features of cells; their minute structure also is made a subject of research and inquiry, and affords a field for most of the fashionable speculations of our own day.

How great has been the progress made by the science of zoology since the eighteenth century may be estimated from the following quotation:-

"I remember," says the late George J. Romanes (in his book called "The Scientific Evidences of Organic Evolution "), "once reading a very comical disquisition in one of Buffon's works on the question as to whether or not a crocodile was to be classified as an insect ; and the instructive feature in the disquisition was this, that although a crocodile differs from an insect as regards every conceivable particular of its internal anatomy, no allusion at all is made to this fact, while the whole discussion is made to turn on the hardness of the external casing of a crocodile resembling the hardness of the external casing of a beetle; and when at last Buffon decides that, on the whole, a crocodile had better not be classified as an insect, the only reason given is, that as a croc- 
odile is so very large an animal it would make 'altogether too terrible an insect.'

How different is the state of knowledge now, when every part of a crocodile or a cockroach is described in print in the minutest detail, and set before even the beginner in zoology as a necessary lesson.

But in spite of the labour necessary to master such detailed lessons, the study of the animal world is far from prosaic. The Story of Animal Life, indeed, bids fair to be the only element of romance left in the modern world for those who stay at home in their own land. The traveller of days of yore, when he ventured into the woods and fields, or upon the water, expected to meet with all sorts of strange things-fairies and elves and ugly gnomes; giants, ogres, and dragons; mermaids and water-witches. With the spread of education all these things have vanished now; it is quite certain that no Board-School-boy has ever met any of them: and one's walks abroad would be in these days as prosaic as they are safe, but for the world of animal life. If you have eyes for this, every field has its inhabitants, and every hedge its marvels. Instead of a fairy, you may be well contented to meet a dragon-fly with shining wings; instead of an ogre you will find the fierce spider, which not only makes away with every harmless fly that blunders into her net, but in many cases destroys her own kind also. Many a plant may be met with which has its own special caterpillar or other dependent insect, with ways of its own, which may amuse your idle hours. As for the change of a caterpillar or a tadpole into its adult form, it would be taken for a miracle if it were observed for the first time. 
The reader may have noticed that there are some unfortunate people who have no eyes for these things; from childhood upwards they have been so absorbed in money-making or in reading books - the one case is as bad as the other-that they have never learnt to observe the facts of nature. Some cannot even recognise the different kinds of plants that they see in the hedges, or in a country walk. Such natures are intellectually defective; they are much to be pitied, and require a special training to remedy their stupidity. I mention this, because the occurrence of this form of stupidity is one of the dangers resulting from town life and bookish education, which we have to guard against at the present time.

But for all healthy people accustomed to the outdoor world, the study of animal life has always possessed an interest. Its interest has, however, been increased a hundred fold by the progress of modern discovery, which has taught us to see in the animal kingdom one large family, working its way upwards from humble beginnings, to more perfect structure of body, and more complete intelligence of mind.

\section{CHAPTER II}

HOW ANIMALS ADAPT THEMSELVES TO CIRCUMSTANCES

WE all know what it is to adapt ourselves to circumstances. Suppose two lads, fresh from school, go out into the world to earn their living; 
one becomes a navvy and one a clerk. In five years' time these two young men will probably be very different in appearance from one another. The navvy will have developed his muscles; he will be broad-built, broad-chested, and strong. The clerk, on the other hand, will probably be comparatively weak and slim, his chest will not be so broad, his muscles will not be so well developed. The navvy, too, will probably be of a fresh complexion, while the clerk will be pale. All these differences are due to the fact that their bodies have adapted themselves to circumstances. Both men may be equally healthy, and equally long-lived. Let us take another example. Let us compare two other youths, of whom one becomes a cobbler and one an Alpine guide. The latter, in five years' time will have become a perfect specimen of muscular humanity-active, agile, and hardy. The cobbler will be comparatively stiff in his limbs and unable to undertake any singular feat of muscular exertion, although he may be able to do a very hard day's work at his own trade. The mountaineer, too, will probably differ in disposition from the cobbler. He will be daring, rescurceful, and not afraid of danger under circumstances which would terrify the cobbler. Now let us suppose that the sons and grandsons of the navvy are brought up to be navvies, and the sons and grandsons of the clerk are brought up to be clerks; - that the children and grandchildren of the Alpine guide follow his own calling, and the children and grandchildren of the cobbler do the same;-we shall probably have four families differing very much in type of physique from one another. Yet take one of the navvy's sturdy grandchildren and bring him 
up as a clerk, and he will lose much of his sturdiness. Let the mountainecr's grandsons be brought up as cobblers, and by the time they are thirty they will not be remarkable for their muscular capabilities.

Just in a similar way the bodies of animals adapt themselves to circumstances. It is not always possible to trace the steps by which this has been done. But sometimes it is so; and we may find a whole series of varieties that are plainly due to adaptation. When we see an animal which is in some way especially fitted for its surroundings, we are therefore justified in concluding that it has become so by degrees.

The way in which animals adapt themselves to their surroundings in the matter of colour would afford material for several volumes each as large as this one. Those who have not travelled in foreign countries may perhaps find it difficult to realise that brilliant colouring and showy patterns can ever enable an animal to hide itself successfully. But an instance may be taken from an animal common on our own shores which will illustrate how this principle works.

In the spring there may be found in large numbers upon our rocky coasts a little oval shellfish, about one-third of an inch long, sticking to the fronds of the tangle and other broad-leaved seaweeds. The animal is of a very pale brown colour; its shell brownish and semi-transparent, with several stripes of brilliant turquoise blue down the back. These stripes are not continuous, but interrupted at intervals so as to give them a beady look. Taken in the hand and looked at closely, the shell, with its contrast of blue stripes on a brown ground, is extremely conspic- 
uous; brown being, in fact, the contrast-colour which shows blue in its greatest brilliancy. Yet, when perched upon the tangle, the creature is almost invisible, and might easily be mistaken for a natural irregularity of the surface of the seaweed. While the brown is the colour of the seaweed itself, the brilliant blue is indeed the exact colour of the spring sky at that season, everywhere reflected from the sea-water and from the wet surface of the seaweed. By matching that brilliant colour the animal therefore is rendered invisible. This little creature is the young of the Semi-transparent Limpet, Patella pellucida. This, at least, was the old-fashioned name for it, though it has received others. Its young and its adult form are so different in the appearance of the shell, that they have been described under different names. English readers who search for it in the spring will learn by experience that bright colouring may help to make a creature invisible. But this is not all that is to be said about the protective colouring of this little shell-fish. There are many creatures whose young live at the surface of the sea, and afterwards migrate to deeper water as they attain adult age. In early life they are transparent, because thus they best escape notice in the clear water of the surface, especially when seen from below, by the many enemies on the watch to devour them. But in their later life they become opaque, because thus they best escape notice from enemies watching from above, as they crawl along the bottom of the sea. Now this is the case with the little Patella. For this also migrates to the bottom-in this instance a comparatively short journey-when it is ready for adult life. Both 
shell and animal, therefore, are at first nearly transparent, but in older life both become more opaque; the blue stripes, too, are almost or quite obliterated in the after-growth of the shell, slight traces of them alone remaining at its apex. This change of colour fits the animal for the new home in which it settles, for it moves down from the leaf of the tangle to its root, and there finds a snug shelter among the coral-shaped branches of which the root is composed. Not many reflections of the blue sky are likely to reach the recesses of the tangle-root, so the creature has no longer any need of its protective colouring of blue.

The adult shell, however, retains a certain degree of translucency, which matches very well with the colouring of the tangle-root; and thus presents a great contrast to the shell of the common Limpet, which is found on rocks. The rugged surface of the latter is usually more or less irregularly speckled in harmony with the surfaces on which it lives, though this shell also presents when young occasional touches of blue, which suggests a family likeness in colour tastes on the part of the two kinds of Limpet. The blue in this case, however, is of the dullest and dingiest shade. The Patella pellucida is common on the more rocky portions of our coasts; in spring the young may be seen in thousands on the seaweeds of the Isle of Man; here its habits were first observed and described in detail by the Manx naturalist Forbes, who noticed its peculiar way of finding a hiding place among the roots of the tangle. The same shell-fish, in contrast with the commoner. Limpet of the rocks, affords another instance of the way in which 
shells adapt their forms to their surroundings. In each case the shell is a plain conical cap, and the animal within keeps the shell firmly attached to the base on which it rests. The Limpet can move about at a very creditable snail's pace when it wishes to do so, and at low-water mark, when the tide is beginning to rise, you may easily find them moving about and off their guard; but during many hours of the day, when the tide is out, the main object of the Limpet is to keep its shell as firmly fixed to the rock as possible. It will at once be seen that if the margin of the shell were smooth like that of a tea-cup, and the surface of the rock to which it clung very irregular, many chinks would be left between the margin of the shell and the surface of the rock through which unwelcome visitors might find entrance. The loss of moisture through the crevices, too, would be a serious thing to the animal during the hours when the shell is uncovered by the tide and exposed to the rays of a hot sun. On the other hand, if the margin of the shell were irregular, and the surface on which it rested smooth, unprotected crevices would in the same way be left. So the Limpets adapt the shape of their shell to their surroundings; the Patella pellucida, which lives on the smooth branches of the tangle-root, has a shell with a smooth regular edge; while the Patella vulgata, which lives upon rocks, has a shell with an irregular, indented edge, whose irregularities fit into those of the rock on which it rests. (See Fig. 2.)

Probably every reader will be able to appreciate the above instances of creatures adapted to their surroundings. For there are few people who are not familiar with the common Limpet of 


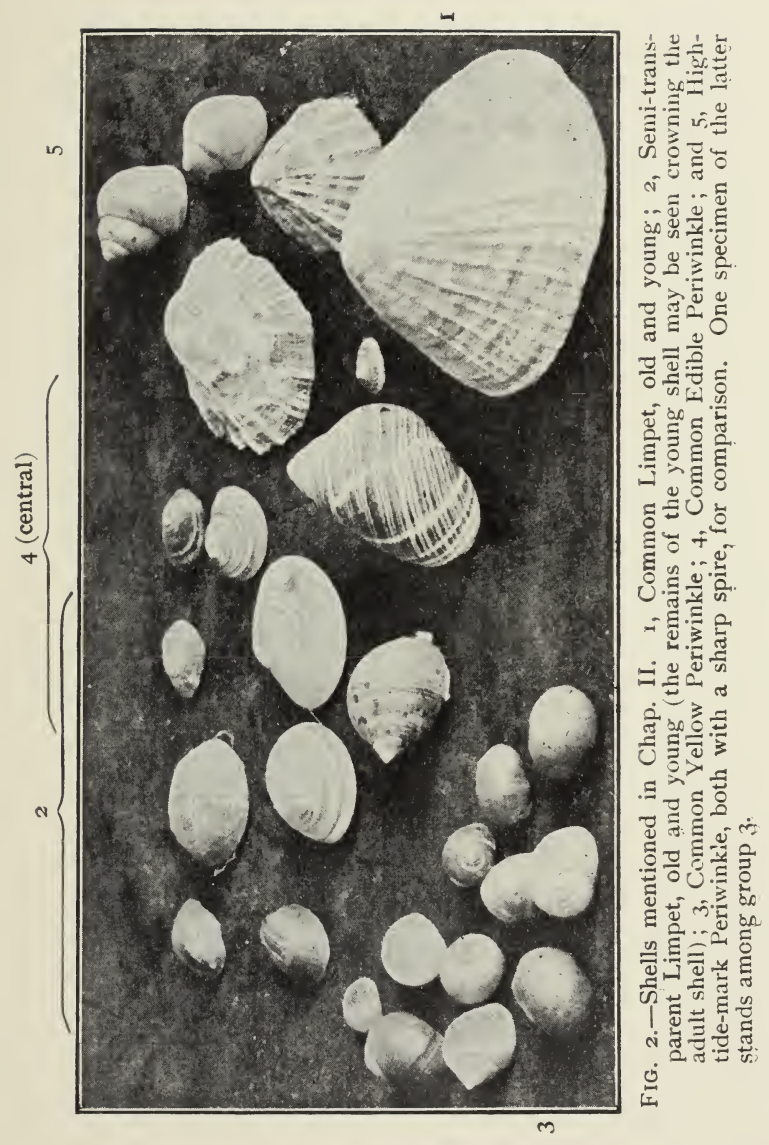


the shore between tide-marks, and with the great seaweed called Tangle, which has its habitat a little lower down, and forms great sea-meadows, whose upper limits alone are ever laid bare by the tide. The Patella pellucida, too, is fairly common, and the dead shell may be found on most rocky parts of our coast all the year round. As for the blue-striped young shell, floating on the blades of the tangle, those who have leisure to visit the seaside during the months of spring and early summer, may have seen it as I have described it; and the mention of it will recall pleasant memories of clear spring skies, and fresh sea-winds, and fields of heavy tangle swaying gently on the swell that comes in from the open sea. It is interesting to know something of the habits of the creatures whose forms we study, and we have already spoken of the snug little hiding-place that the Semi-transparent Limpet finds for itself in the tangle-root. It is of interest to remember that the Common Limpet, too, is a home-loving creature, which knows and prefers the spot of rock on which it habitually rests; and can find its way back to it, aided by its two eyes and two smelling patches. This has been proved by Professor Lloyd Morgan, who has recorded the result of his observations, made on the coast of Dorsetshire. It is not easy to detach a Limpet from the rock without injuring or exhausting it, but these specimens were caught when moving of their own accord, and were therefore uninjured and brisk. They were removed to short distances, and the following table shows the result of the experiment, clearly proving that the Limpet prefers home, but regards a distance of two feet as a very long journey. 


\begin{tabular}{c|c|c|c|c}
\hline $\begin{array}{c}\text { Number } \\
\text { Removed. }\end{array}$ & $\begin{array}{c}\text { Distance in } \\
\text { Inches. }\end{array}$ & $\begin{array}{c}\text { Number } \\
\text { Returned } \\
\text { in Two } \\
\text { Tides. }\end{array}$ & $\begin{array}{c}\text { In Four } \\
\text { Tides. }\end{array}$ & Later. \\
\hline 25 & 6 & 2 I & 0 & \\
2 I & I 2 & I 3 & 5 & 0 \\
2 I & I 8 & I0 & 6 & 2 \\
36 & 24 & I & I & 3 \\
\hline
\end{tabular}

Similar observations were made at an earlier date, by Mr. George Roberts, at Lyme Regis.

Let us now take an instance of adaptation in form. And this time we will take a shell so common that everybody will know it.

Everyone who has spent a little time in naturalising on the shore, has noticed how often you may find univalve shells, such as those of the whelk and periwinkle, with the top of the shell knocked off. This is nearly always the case with the dead shells that you find strewn along the tide-line; and after a storm, on a rocky coast, you may find shells that still contain the living tenant, in the same sad condition. And you may also meet not infrequently with shells, dead or living, that bear evidence of the owners' efforts to repair them after an accident to the spire. A piece has been broken, and you find it cemented on again by a patch of shell, serviceable no doubt to the owner, but crooked and unsightly in appearance. Now there is a very common shell, the little yellow periwinkle, which has practically done away with its spire, the coils of the shell being so curved that the earlier part of the spire 
does not project beyond the later-formed coils, and the whole shell has a rounded outline. This little creature lives on the long seaweeds which grow at low-water mark or near it; and when the sea is rough it is obviously liable to be dashed from its foothold on the seaweed and flung violently down, as the huge seaweeds sway about in the shallow waves. We may easily satisfy ourselves that this is an accident that frequently happens, by examining the shore when the tide is going out, on some stormy spring or autumn day. Numbers of the yellow periwinkles are then to be found crawling on the sand, and striving to regain their place in the seaweedy rocks as soon as possible. On a calm day you will rarely see one crawling on sand above low-water mark, for it is a place they do not choose by preference; those that are to be found there on the stormy day have lost their foothold, and have been washed about by the tide. Had they, like some other kinds of periwinkle, a sharp spire, how many would be the casualties under these circumstances! But as it is, you do not see a single specimen with a broken top: the rounded spire is an adaptation to circumstances, required for the protection of the tenant of the shell. (See Fig. 2.)

It may be added that the yellow Periwinkle is not only protected from mechanical sources of danger by its form, but is also in some degree protected from living enemies by its colour. This, at first sight, seems exceedingly conspicuous. We must remember, however, that the animal often lives in that part of the shore where the Bladder Seaweeds, or Fuci, are extremely abundant. The flowering ends of these are of a yellow 
colour, fairly bright. When seen from below, with the sunlight streaming through them, they no doubt appear much brighter than when seen, as we see them, from above, with the sunlight falling on them. Now protection from foes below is what the yellow periwinkle needs most: for fishes are quite ready to swallow it whole, and are not in any way deterred by the thickness of the shell, which is (by-the-way) in a measure a protection against birds when the tide is out; fishes habitually swallow shell-fish whole, although the inmate only is digested. The bright yellow, then, that seems to us so conspicuous, is probably a good means of hiding for the periwinkle when under water. Its common variations in colour, too, are probably protective in their use: some are a dull purplish brown, some drab. These are good colours in which to lie hidden, respectively, under darker tracts of seaweed, or upon the rock itself. This little shell is so abundant on rocky coasts that on some beaches the dead shells are as numerous as pebbles. No wonder, with all these adaptations for protection!

Another instance of adaptation to circumstances is described in the sea-urchin shown on p. 125 . This is one among many instances where animals that live on sand or mud acquire a flattened shape, so that their weight is distributed, and the danger lessened, of their sinking in a quick-sand. The flat-fish, such as soles and flounders, are a familiar example; and the same principle is illustrated by the flattened forms of many of the bivalve shell-fish, whose flat shell, when closed, can lie safely on the loosest sand. Equally is their form adapted for their circumstances, when, in their slow way, they begin to 
move. For the flat valves of the shell are placed to the right and left of the animal's body. So that when it stirs, or floats quietly in the current of the tide, the shells present their sharp edges to the resistance of the water, thus enabling the creature to move like a ship through the sea, or like a knife-blade through bread, with the least possible friction: and specially is this provision for the lessening of friction important, when we consider that many of these bivalve shell-fish have to move, not only through water, but also through sand and mud.

It may be assumed that every reader is familiar with the common forms of the bivalve shell-fish. The frontispiece shows one of them, considerably flattened in shape.

So far, however, we have not explained how animals adapt themselves to circumstances; we have only pointed out the fact that they do so.

Take the case of our little Limpet. It cannot say: "I will paint myself with blue and brown, so as to be mistaken for a bit of seaweed reflecting the blue sky"; nor can the periwinkle say: "I will paint myself with yellow, so as to pass unnoticed among the yellow ends of the Fucus; and I will build my spire low, so that it will not be broken." The bivalve shell-fish and the Sand-Cake sea-urchins do not say to one another, "Let us alter our shells, and build them a little flatter, so that we shall not sink in too deep when we lie upon the ooze and sand of the sea."

How then do these adaptations take place? Darwin has explained this for us. Individuals often have some little peculiarity, in which they differ from the average of their kind. The establishment of such little marks of individuality 
is spoken of as Variation. If among these individual peculiarities there is one which is in any way disadvantageous, e.g. one which tends to make the creature conspicuous in the sight of its foes, the owner will be quickly eaten, and of that peculiarity there will be an end. If, on the contrary, the peculiarity gives the owner some advantage over its fellows, that individual will survive, and probably transmit its peculiarity to some of its descendants.

We have seen, for instance, that it is of advantage to our little periwinkle to be yellow, when it lives in certain situations; and that it sometimes presents other colours, likely to be favourable in other cases. If we gather together a large number of specimens, we shall find a surprising range of variation in colour. Some present a tint of bright orange, nearly red; some are a dull brown; the dark purple shade and the drab have been already referred to. The very young shell usually presents an unmistakable shade of pink; and we may find innumerable half-grown specimens in which we may trace the gradual establishment of the advantageous yellow colour, from an original shade of unmistakable pink, presented by the earlier whorls. Kindred varieties of the shell, too, may be found with stripes or speckles. Since this very common shell may be found in abundance on any rocky shore in the British Isles, the reader may easily study its colour-variations, both in the dead and the living shell. Study also the ground on which the creature lives, with its sharp colour-contrasts of rock and seaweed patches, and it will be easy to understand why the colours are thus varied, with a preponderance, on the whole, of the yellow 
shades. It is all a question of the survival of the fittest-the unfit being represented by colours too easily seen, and therefore quickly snapped up. As for the spire, it has already been shown how that is adapted to circumstances. It is worthy of remark that in the kindred Edible Periwinkle, Littorina littorea, which has a sharp spire, elderly specimens may be seen with the end of the spire damaged.

Turn again for a moment to our first instance-the adaptation of men to a sedentary or an outdoor occupation. Here we dwelt upon the change produced by their mode of life; we left out of sight the "survival of the fittest." Yet here it is equally surely at work. How often does the young mountaineer, less agile than his fellows, come by a violent death? Only those who are equal to the necessities of the life survive-many are lost. How often does the clerk, tied to his desk, fail in health and die? How often, hating a sedentary life for which he is unfitted, does he throw his energies into athletics, lose interest in his office work, and get dismissed? Here again comes in "the survival of the fittest"-for a desk: alas! perhaps the only means of livelihood.

But why do variations occur? This is the question first asked by a child, when you try, to explain the working of "natural selection." It is also the last question asked by scientists, who are still industriously engaged upon studying the problem.

In the above instances from human life, we have considered the occurrence of changes brought about in the organism by the circumstances of life; or as scientists say, by the "en- 
vironment." Scientific men are busily hunting for instances of variation of this sort. Take for example, an animal which lives sometimes in salt water, sometimes in water that is only brackish; there are cases in which small differences can be noticed, according to the difference in the habitat. Notice the marine shell-fish, for instance, near the estuary of a river: they are often less robust specimens than are found at a point free from the influence of fresh water.

Not until the effect of known causes on the rise of variations has been studied much more fully than at present, will it be possible to judge regarding the nature of those variations which appear to be spontaneous; for which, at present, no predisposing cause can be assigned.

A very large number of variations, however, fall into the class of "Atavistic" variations; that is to say, those which show a return to an ancestral type. These are variations which are very rarely welcome. If, for instance, a boy has a pair of handsome black rabbits, he is not much pleased to find among their progeny, every now and then, one of the colour of the original wild Bunny. The probability, in this case, is that the atavistic variety will find its way into a pie, instead of being kept as a pet. Equally unsatisfactory to the owner, is the incorrigibly savage and intractable dog or horse-a reversion to the mental type of an ancestor which knew not the authority of a master.

Atavistic variation often occurs when members of two well-marked varieties are mated; so that in some of the offspring produced, each parent seems to cancel out the more extreme characteristics of the other, leaving only the character- 
istics of the more generalized ancestral type, from which both parents have alike been derived.

When the ancestral type is in some way inferior to the modern one, variation which consists in reverting to the former is often referred to as Degeneracy. There is reason to believe that discomfort and hardship of existence tend to produce variation of this kind-a fact of supreme importance, when the problem of Degeneracy is considered in connection with human life. When creatures begin to degenerate, it is, in fact, as if the species were saying to itself, "I have gone astray; let me retrace my steps along the road by which I came, and maybe I shall find comfort and safety; step by step I will try to go back to my ancestral form."

Very rapid variation of any sort is indeed often a sign that the struggle for existence is too hard for the type in question. The palæontologist can tell us of types that present numerous variations before becoming extinct; while others, comfortably holding their own in the struggle for existence, remain practically unchanged during age after age of the geological record, and survive even up to the present day. We may borrow from commercial life a homely illustration that will explain this aspect of variation. When competition in trade is keen, the seller must have novelties; he will try all sorts, and find some good, some bad, some indifferent. If he now revives an out-of-date pattern of goods, for the sole sake of change, this is Degeneracy. But where, on the contrary, competition is dull, the same firm will turn out the same goods for a long period of time. There is an optimum in trade competition: a reasonable 
competition results in the production of sensible novelties, and consequent progress; but competition over-keen results in the production of rubbish, leading to eventual failure. So in the world of animal life; a certain degree of struggle for existence results in variation, establishment of new varieties, progress. A greater degree results in too rapid variation, new varieties that speedily perish, and finally, the extinction of the type.

We have spoken of "varieties." Each of the domestic animals presents varieties, which are the cumulative result of the breeder's artificial selection of natural variations. Thus the Pug and the Collie for instance, are varieties of the Dog; the Bantam and the Dorking of the Fowl. Among wild animals, varieties are similarly produced by natural selection, resulting from the "survival of the fittest." By degrees, intermediate forms are lost; and new species are established by the greater and greater divergence of varieties originally derived from one ancestral type.

Table Showing the Position in Classifica. tion of the Animals Named in the Fore. GOING CHAPTER

Phylum MOLLUSCA, or Shell-fish.

Class GASTEROPODA, or Snail-like Shellfish.

Sub-Class Anisopleura, or Unequal-sided Gas. teropods.

Branch Streptoneura, or Unequal-sided Gasteropods with nerves twisted into the shape of a figure of 8 . 
Order

Genus

Species

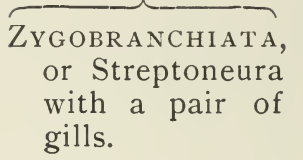

Patella, the Limpet, with gills obliterated, and only indirectly represented; breathing is performed by folds of the mantle.
AZYGOBRANCHIATA, or Streptoneura, with only one gill.

Littorina, the Periwinkle, or Shore Shell.

\section{Vulgata, the Com-} mon Limpet.
Littoralis, the (Yellow) Periwink!e that lives above low-tide-mark.

\section{CHAP'TER III}

\section{CLASSIFICATION, OR THE SORTING OF THE ANIMAL KINGDOM}

Give a child a few handfuls of shells. Probably the first thing he will do with them is to sort out the various kinds and separate them from one another. Each will go into a little heap by itself ; and next, our young friend will find names for them. These are Cap-shells and those Swordshells; these Saucers and those Plates; these Yellow-shells and those Pink-shells-according as some special character or form or colour strikes his fancy.

Now this is what zoologists have been doing 
with the animal kingdom from the earliest days of science; trying to recognise each distinct kind of animal form, and to give it a name of its own. Unfortunately for the reader, zoologists have been obliged to choose names of Latin and Greek origin, and therefore in writing about animals we are often obliged to burden our pages with long words. This is a disadvantage, but it is a very slight one compared with the great advantage gained by using the learned tongues, which consists in this, that learned men from all countries of the globe can equally understand the names thus brought into use. One particular kind of creature may have one name in English, another in French, another in German, and so on; but the learned world does not trouble itself with this multiplicity of names-it gives the creature a couple of names in Latin, and these names stand good for learned readers in every part of the globe. The importance of this will be fully realised when, in a later page, we shall have to speak of the work done by zoologists, and the way in which they do it. Meantime we must ask our readers to have patience if now and then some long names must be used. These learned names sometimes convey a description of some important characteristic possessed by the animal, and sometimes they are merely fanciful names, such as the child we have spoken of gives to his zoological playthings. It does not greatly matter whether the name is descriptive or nor; zoologists describe each animal kind in its most minute details, and the most commonplace or inappropriate name serves its purpose quite efficiently as a means of referring to published descriptions.

We have spoken of sorting the animal kingdom 
into its various kinds. But how do we know when a number of animals are all of one kind? No two individual animals are ever exactly alike, any more than two persons are ever exactly alike. "It is a matter of common observation that no two individuals of a species are ever exactly alike; two tabby cats, for instance, however they may resemble one another in the general characters of their colour and markings, invariably present differences in detail by which they can be readily distinguished. Individual variations of this kind are of universal occurrence" (T. J. Par'ser).

Among a host of animals that present so many differences, how do we determine what shall be considered as belonging to one and the same kind? This is a point that nature usually settles thus. If two varieties when mated produce offspring which are perfectly fertile when mated again with another set of offspring similarly produced, then the two varieties, however differing in appearance, belong to one species. If on the other hand, the two belong to a different species, the offspring will be what is called a mule or hybrid, and will not produce offspring if mated with another mule. One of the most familiar examples of a mule is the animal, commonly so-called, which results from mating a horse and an ass, and partakes of the characteristics of both.

Every animal receives two Latin or Latinised names, the first that of the genus, the second that of the species; this system of naming, often referred to as the "binary nomenclature," we owe to the industry of Linnaeus the great Swedish botanist and zoologist. Genera are groups consisting of a number of different species which 
closely resemble one another. Similarly genera which are somewhat alike, are again formed into larger groups, and so on. The names of families, orders, and classes used to be given to these groups in ascending order; but it is now generally recognised that such names are arbitrary, and that the divisions into which animals may naturally be grouped are altogether irregular, and not comparable with one another. Those who know a little of botany will readily understand, from their knowledge of wild flowers, that natural groups cannot be arranged in a formal series.

The main branches of the animal kingdom, the largest groups of all, used formerly to be called sub-kingdoms. Now the main divisions are often spoken of as phyla or races. Classifications, although they differ much in detail, according to the preferences of individual zoologists, yet agree as to the main branches of the animal kingdom, the chief of these are :-

I. The Protozoa, or One-celled Animals.

2. The Cœlenterata or Two-layered Animals.

3. The Sponges or Porifera.

4. The Vermes or Worms.

5. The Arthropods or Jointed Animals, viz., Insects and Crustacea.

6. The Mollusca or Shell-fish.

7. The Brachiopoda or Lamp-Sheils.

8. The Bryozoa or Moss-Corals.

9. The Echinodermata or Sea-Urchins.

Io. The Chordata, including- $(a)$ the Hemichordata ; $(b)$ the Ascidians ; $(c)$ the Vertebrata. 
Within recent years an attempt has been made to express the relationship these groups bear to one another, by placing them in separate divisions or grades. The first grade includes only the Protozoa, or unicellular animals. The position of second grade has been assigned to the Cœlenterata or diploblastic animals, whose bodies consist typically of two layers of cells. A third grade includes only a few groups of the lower worms, among which three body-layers may be distinguished, but no body-cavity is present. While the fourth grade, including practically the rest of the animal kingdom, have three body-layers (see p. $\left.3^{8}\right)$, and a body-cavity surrounding the internal organs (see p. $3^{8}$ ).

This arrangement of groups is an extremely convenient one; all the more convenient because it easily admits of modification. Already, indeed, we might find room for a grade intermediate between I. and II., consisting of what might be termed monoblastic animals, namely, animals consisting of a single layer of cells. For the frequent occurrence of Larvæ of this kind, consisting of a hollow ball of cells, renders zoologists on the alert to find a grown-up organism built in the same way. It is doubtful whether any of the forms that have been supposed to answer to this description really do so. Certain forms of these often claimed as plants by the botanists are, however, in the meanwhile, invited in to fill the blank.

There are also animals in which the internal layer of the body is very much reduced, consisting sometimes in fact of one cell only. Those are the Dicyemidæ and Orthonectidæ, both of them parasitic forms. They differ so completely from all other forms that it has been proposed 
to make for them a special group, the Mesozoa, or Midway animals, between the Protozoa and all the rest of the animal kingdom. It is, however, possible to group them under the head of Diploblastic animals; but nothing more different from the Colenterata could well be imagined, and some regard them as a degraded form of worm.

The animals which are higher in structure than the Protozoa, viz. our divisions 2 to 10 , are of ten grouped under the name Metazoa. The Metazoa thus include Grades II., III., and IV.

The meaning of the division of the animal kingdom into grades will be more apparent if we give an example of each.

GRADE I. The OneCelled Animals.-Amo$b a$, the Mobile animal,

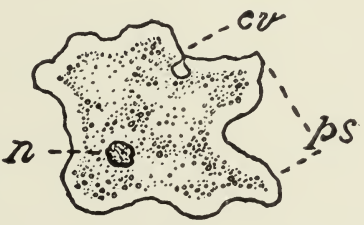

FIG. 3.-Amoba, a typical unicellular animal : $n$, nucleus; $c v$, contractile vacuole; $p s$, pseudopodia ; highly magnified. This represents Grade I. of animal existence. is the typical example of these. It consists of a single microscopic cell. In this cell is seen a dark irregular speck, the nucleus, which is an essential character of cells, whether they are independent or form part of the body of a larger animal. There is often visible also a clear rounded space, called the "contractile vacuole," which squeezes out fluid, disappears, and reappears again, serving the purpose of excretion. The cell-substance, called protoplasm, is prac-ically identical in this and in cells of all other kinds. It is jelly-like, and capable of a slow movement, which may be watched under the microscope. It suggests the flowing of treacle or 
thick gum. The movement may be traced by the change in outline of the cell and by the change in position of any granules that it may have taken in ; for particles which touch the creature sink in and are surrounded; thus it obtains its food. These slow flowing movements of the protoplasm result in continual changes of shape; hence the name, Amœba, the mobile animal. Sometimes

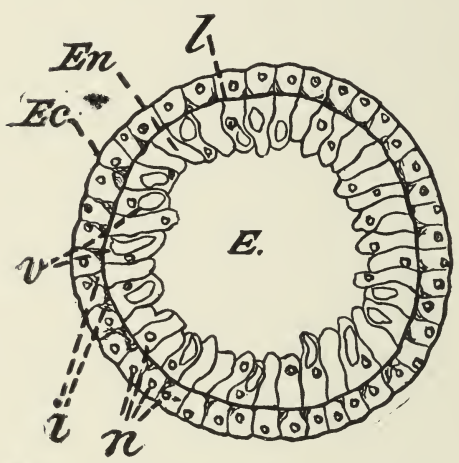

FIG. 4.-Section, highly magnified, of a two-layered animal, Hydra (Grade II.). Ec, outer layer of Ectoderm; $E n$, inner layer of Endoderm; $l$, lamella dividing the two, represented by a line; $n$, nuclei of the cells; $v$, thin vacuoles of small interstitial cells ; $E$, the Enteron or digestive cavity. the island of protoplasm, as it changes its shape, throws out, as it were, capes and headlands. These projections, which are present 1 y drawn in again, are called pseudopodia or false feet. They are characteristic of the whole group of Amœba-like animals, which are con s equent 1 y called Rhizopoda, the root-footed. The production of new individuals is accomplished by the division of the old cell into two. Thus it may be said that there is always a bit of the old cell remaining, though divided into fragments; and for this reason the Amœba-like Protozoans have been fancifully called "immortal."

Grade II. The Troo-layered, or Diploblastic 
Animals.-The type of these usually chosen is Hydra, a two-layered animal, which is further described on p. 54. A section through Hydra (Fig. 4) shows (I) the outer or skin layer of cells, called the ectoderm, and (2) the inner or stomach layer of cells, called the endoderm (literally outer skin and inner skin). The clear recognition of the primary body-layers of the simpler invertebrates as identical with the primary body-layers of the embryo of higher forms, is largely owing to the teaching of Professor Huxley, the importance of whose work on this and in many other respects, is little guessed at by many readers who know his name merely as a popular exponent of scientific ideas. The two-layered body of Hydra encloses a hollow digestive space; from this the Coelenterata receive their name, which means " possessing a hollow space only, by way of intestines." The name of Acœlomata, animals without a body-cavity, has therefore been given to the Cœlenterata and sponges. The meaning of the term body-cavity will be explained in the next paragraph but one. The Hydra, like all animals of its grade, and all those of the succeeding grades, reproduces itself by means of ova or egg-cells, and spermatozoa which fertilize them.

Grade III. The Triploblastic Animals without Body-Cavity.-This is a small section including only some of the lowest worms, such as the forms called Planarians. Between the Ectoderm and Endoderm lies an intermediate layer the Mesoderm. There are the beginnings of this in the Cœlenterata and Sponges, but here it is further established. It includes a very thick layer of muscles.

Grade IV. The Colomata or Triploblastic Ani- 
mals with a Body-Cavity.-This grade includes all the remainder of the animal kingdom. As an example of it, we may take the Common Frog. If we open from the lower surface the dead body of a frog, we first cut through the skin, next the muscles; then we come to the viscera, lying neatly packed in a cavity from which we can dislodge them. This cavity is the Body-Cavity.

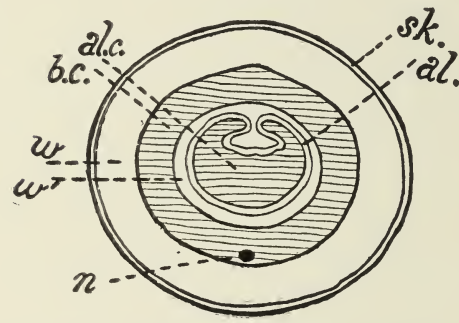

FIG. 5.-Diagrammatic plan of section cut through an Earthworm to show the position of the three body-layers and the body-cavity (Grade IV.). $S k$, skin; $a l$, glandular lining of the alimentary canal; $w$, muscular wall of body ; $w$, muscular of intestine, both belonging to the third layer or mesoblast; b.c., body - cavity (shaded); al.c., cavity of alimentary canal (shaded); $n$, nerve.

The skin corresponds with the ectoderm of $\mathrm{Hy}$ dra, although it is a vastly more complic a ted affair. The glandular lining of the alimentary canal corresponds with the endoderm of $\mathrm{Hy}$ dra; although this, too, is a more complicated affair. The mass of the body, lying between these two layers, is considered to correspond somewhat with the mesoderm of Grade III., and has received the collective term of Mesoblast. This description applies equally to the earthworm, for the higher worms differ immensely from the lower worms, and stand on a level with more important members of the animal kingdom (see Fig. 4I, p. I39). The body-cavity may be formed in different ways in different animal groups; but there is 
reason to believe that in certain cases it originates by a folding off of part of an original cavity corresponding with that of Hydra; so that part went to form the intestine, and part the cavity surrounding it.

The above arrangement of the main great groups of animals into four grades is that given by Professor Arnold Lang.

It should be added, that there are a few exceptional forms that present a departure from these broad rules of structure. They are, however, so few that they need only be named as curiosities. For instance, there are parasites in which the inner body-layer is practically done away with, because they are fitted to absorb food through the outer layer. And in one division of the Moss-Corals there is no body-cavity to be seen, although it is to be found in the other division.

What is the outcome of all this sorting of the animal kingdom? This most important result: that a classification of the animal kingdom into the four grades we have named, presents, in serial order, the stages through which young animals of the higher forms pass in the course of their growth. Every creature begins as a unicellular organism-the fertilised egg-cell. A vast number of creatures belonging to the higher groups present, later on, a two-layered condition, comparable with that of Grade II. Later on they acquire a third layer, and therefore correspond with Grade III. By degrees the body-cavity is formed, and they then present the adult bodystructure of Grade IV. The development of the chicken in the egg, for instance, presents these four stages. 
It will be sufficiently apparent that this coincidence is too striking to be without a meaning. Zoologists are all agreed in their interpretation of this meaning: it is, that the history of the individual presents a summary of the history of the race, and goes through the stages of structure which its ancestors presented in their adult forms. The story of the gradual upward struggle of the animal kingdom, from its humble beginnings to its present wonderful complexity, is written in the growing tissues of every young creature.

The principle that ancestral traits betray themselves is accepted as a truism in common life. Do we see young people rude and stupid? We say, perhaps, "No wonder ; their grandfather was a drunken, worthless lout." Do we see a family of the poorest class clever, and industrious, and refined? We say, "They come of a good stock." When we speak in this way, we reason from the common experience of mankind, that children resemble their ancestors. Similarly, when zoologists find an embryo starting its existence from one cell, they say, "No wonder ; its ancestors were unicellular." And when they find it assuming a two-layered form, they say, "Its ancestors were two-layered creatures." So certain are zoologists of the existence of an ancestral two-layered form, the parent at once of the existing Cœlenterata and of the higher forms, that Professor Hæckel has given it a special name-Gastræa. The two-layered young stage of higher creatures, when it has a free-swimming existence, is called a Gastrula (Fig. 6). Both names, meaning stomach-animal, refer to the structure, which is, in a still simpler form, that of 
Hydra-a two-layered bag of cells, of which the inner layer, lining the cavity, performs the work of digestion. The lowest of the Vertebrata, the Lancelet (see p. I40), has a larva of this kind. The same reasoning which suggests the existence of an ancestral Gastræa-animal, suggests that of an ancestral Planulaanimal; for the two-layered animals, on their part, present us with a monoblastic larva of the form already described (p. 34), called a Planula. Hence it is that zoologists look with such eagerness for forms, of which it can be said that they consist of one layer of cells only. The name Planula signifies "wandering animal," because the Planula larva swims about by means of cilia.

Mention has been made above of larval forms. It is

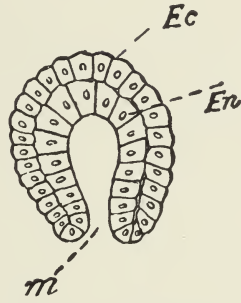

FIG. 6. - Diagrammatic representation of a typical Gastrula, or two-layered larval form, highly magnified ; optical section, longitudinal. Ec, Ectoderm or skin layer; $E n$, Endoderm or stomach layer; $m$, mouth leading into the enteric cavity. The dots are the nuclei of the cells. perhaps advisable to explain clearly what is meant by this term. It is a matter of every-day knowledge that in some animals the young form presents an appearance and structure very different from that of the grown-up form, and adapted for a different mode of life; the commonest instances are the caterpillar of the butterfly and the tadpole of the frog. We are apt to think of these creatures as somewhat exceptional in this respect. But the zoologist, in viewing the whole range of the animal kingdom, finds a vast number of animals with larvæ, differing much from the 
adult, and adapted for a different mode of life. It is, in fact, a very common arrangement; but often these larvæ are very minute, perhaps absolutely microscopic, therefore only known to the scientific observer. The two familiar instances we have named are fortunately big enough to be known to everyone. Now it is an axiom with

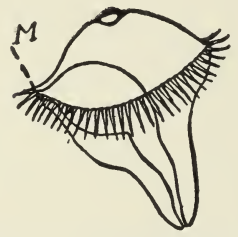

FIG. 7.-Diagrammatic representation of a typical Trochosphere, or ciliated larva, considerably magnified. $M$ is the mouth; the stomach and intestine are seen showing through the transparent body.

modern zoologists (as has been explained above), that the history of the individual is a summary of the history of its ancestors; larval forms are therefore of special interest in this connection. A very wide-spread form of larva, more advanced in its structure than the little Gastrula that has been already named, has received the name of 'Trochosphere or Wheel-ball (Fig. 7), because it swims round and round, by means of cilia, usually distributed in bands.

Its inner or stomach-layer, forms a definite alimentary canal, and is separated by a very simple mesoderm from the outside ciliated layer, which presents certain differences in form, according as the creature belongs to one group of animals or to another. The main characters of the Trochosphere are, however, the same in very widely differing groups. These little larvæ give rise to one of the most eagerly debated problems of zoology. Are we to suppose that animals which possess a Trochosphere larva are all descended from one common ancestor? Or are we to think that the Trochosphere is a form of body very convenient for the necessities of juvenile 
existence in the sea, and therefore independently evolved by animals which are not directly related to each other? Some authorities take the latter view; the former is perhaps more widely accepted, and has even been expressed by the application of the name Trochophora (Wheel-carriers), as a general term for those groups in which such larvæ are found. These include some of the higher worms, which present the typical Trochosphere, the Brachiopoda, and the Polyzoa; while variations of the Trochosphere type are shown by the earliest larvæ of Mollusca, the larvæ of the Echinoderms, and those of the Hemichordata (see p. 33), the latter bringing us, as it were, within eye-shot of the Vertebrata themselves. It will be seen, therefore, that the range of the Trochosphere larva covers a large portion of the ground occupied by our Grade IV. There is, however, one marked exception : the Arthropoda, which seem to have a prejudice against cilia in any form (since they include but one animal which possess any) have no example of a ciliated larva. Even their simplest larval forms belong to a higher type of structure, in which the shelly, jointed structure characteristic of the group is already indicated.

When we speak, however, of the occurrence of the Trochosphere throughout a wide range of animal life, it must be understood that its presence is not necessarily uniform throughout a group in which it occurs. Larval forms are adaptations which conform with the conditions of life for the particular animal in question : and nearly related kinds of animal may be without a larva. The Trochosphere larva is, of course, only adapted for aquatic existence, and is necessarily absent in the case of terrestrial forms. 
()

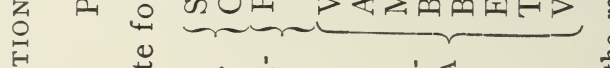

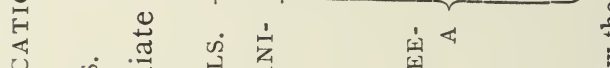

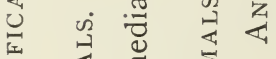

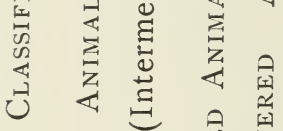

되 $x$ बि 되

至

约 药

4

质弪

건

近

0 无

$\because F$

분

过

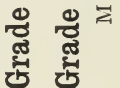

$\stackrel{2}{=1}$

3

○

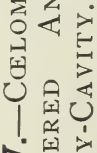

$\sum \geqslant \frac{1}{2}$

๑) 
When an animal has no free larva, but quits the egg in a form practically identical with that of the adult, the development is said to be "direct." But changes equally startling with those displayed when a larva develops into the adult form, may take place while the young animal is enclosed within the egg itself. To these also zoologists apply the axiom referred to above, that the history of the individual summarises the history of the race. Thus, for example, the Amphibian larva, e.g. the tadpole of a frog (p. 153) has gills, which disappear in the adult form: the young reptile, bird, or mammal, which has no larval stage, has gills during a comparatively early stage; and loses them at a later period of its development. In each case zoologists conclude that the animal is descended from a fishlike ancestor, which possessed gills all its life, and that the more immediate ancestors in the family tree, have lost their gills by degrees.

The study of the progressive changes of young forms, whether larval, or enclosed within the egg, is called Embryology, and constitutes, in these days, the major branch of zoological science. That it is of paramount importance to the student of classification, engaged upon the sorting of the animal kingdom, will be apparent from what has been stated above.

\section{CHAPTER IV}

\section{THE ONE-CELLED ANIMALS OR PROTOZOA}

Some idea of the general characteristics of the Protozoa has already been given by the description of Amaba. We may now say something 
about special groups of the Protozoa, which have minor characteristics of their own.

Amœba belongs to the class Rhizopoda, as has been already stated; but there are many of the Rhizopoda that greatly differ from Amœba in appearance. The possession of a shell or skeleton gives a special importance to several groups. For, as the reader has no doubt already learnt from an earlier volume in this series, such skeletons or shells have played an important part in the history of the earth's surface, building up geological strata of vast extent, by the accumulation of the shells left after the decay of the owners' tiny bodies, during long periods of time. The chalk rocks that form the "white cliffs of Albion," and that are so widely distributed in other parts of the globe, are formed in this manner; while the ooze of the Atlantic and other oceans, similarly composed of Protozoan débris, is now at the present time building up what will be the chalk rocks of future ages. Some of these Protozoans attain a remarkable size, instead of being microscopic, as is the case typically with the one-celled animals. Some forms of the Foraminifera found on the coast of North America measure as much as one-fifth of an inch across, while in warmer seas there are kinds which attain, as did the extinct Nummulite of Egypt, the size of a bean. Two inches across is mentioned as the maximum diameter, however, of either extinct or living forms. The Foraminifera are sometimes named Reticularia, because their pseudopodia interlace.

The Foraminifera have shells composed of carbonate of lime, but there are other forms that build up geological deposits, in which the shell is 
flinty. The diagram (Fig. 8) shows some fossil shells of Protozoa from the marl of Barbadoes. These constitute a deposit which was named "Infusorial earth," in the earlier days of microscopic observation, when all Protozoans were spoken of as Infusoria. The name, Infusoria, it must be

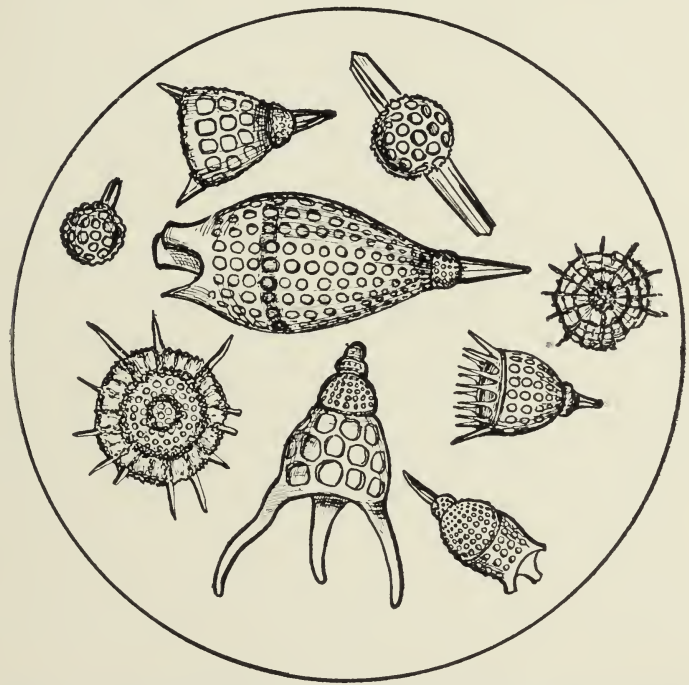

FIG. 8. -Fossil Skeletons of Polycystina, from the so-called "Infusorial Earth" of Barbadoes, highly magnified.

recollected, is now restricted to a special class, to which the forms in question do not belong. These fossil forms were named Polycystina, and are still often spoken of under that name, although the animals that present the peculiar feature of possessing "more than one cyst" now are 
called Radiolarians. The "cyst" consists of a basket-work supporting skeleton of flint; there may be several, one inside the other, and connected by radial bars. A living species named Actinomma has three such layers of basket-work, one in the outer layer of protoplasm, one in the inner layer, and a central one. It will perhaps be remembered by the reader that the animals of this group, Radiolaria, are forms described in a previous volume of the series, as so curiously associated in Symbiosis with the algæ known as Yellow Cells.

The famous polishing slate of Bilin in Bohemia consists of flinty Protozoan shells; it is 14 feet thick, and a cubic inch has been estimated to contain $4 \mathrm{I}, 000,000,000$ of the shells.

While the Radiolarians are marine, the Heliozoa, a group in which the skeleton is also present, but not usually so greatly developed, are predominantly fresh-water forms. Both classes take their name (Ray-animals, Sun-animals) from the stiff radiating rods of the skeleton.

Strongly to be contrasted with the above groups belonging to the Rhizopoda are the Infusoria proper, which are characterized by the usual possession of cilia. Cilia (literally "eyelashes") are fine hair-like processes of the proto. plasm of the cell, which fringe its exterior; by their constant movement they enable the animal to swim, and at the same time they create a current in the water, which washes up to the region of the mouth particles which may serve for food: for these creatures have this very great advantage over Amœba, and the other forms above referred to, that they possess something which may be called a mouth. That is to say, there is one par- 
ticular spot of the surface where particles are taken in. This may seem to be a restriction, when we compare the Infusorian with Amœba, which is apparently able to take in food at any part of the surface. But it is a restriction which is associated with an advantage; the Infusorian cell, namely, has a firm exterior with a definite outline, instead of being soft and mobile all over. The firmer exterior layer of protoplasm, which is in turn covered by a thin cuticle or limiting membrane, is called the cortex or rind. For this reason the name Corticata is sometimes given to the group, i.e., Protozoa with a rind.

Vorticella, the Bell Animalcule, is a stalked form living in ditches, which is usually selected as a typical form of the Infusoria. It receives its name, the Whirlpool Animal, from the current which its cilia create in the water. The purpose of this current is to wash food particles into the mouth. Associated with the Infusoria under the name of Corticata are the Gregarina and some other parasitic forms.

It is interesting to note that the main types of the unicellular animals are repeated again in the cells of different parts of the bodies of multicellular animals. Amœboid cells, so called because of their mobility and general resemblance to Amœba, are found in various parts of the higher animals. The lymph corpuscles of vertebrata, and the white corpuscles of vertebrate blood, as well as the biood corpuscles of invertebrates, are among the instances of this. There are cells, on the contrary, such as those that line the mucous tracts, which are of a Vorticella type, so to speak; fixed to their bases, and presenting cilia on the free aspect. 
Two things must be noticed before we leave the subject of the Protozoa. One is, that some forms present the beginning of a multicellular condition. Several units sometimes join together, and in this way a complex object may be formed, in which there are several nuclei; or the original unit may keep on growing till it consists of many successive portions, and in some of them a fresh nucleus may arise. This occurs in some of the Foraminifera.

The next thing to be noticed is, that there are a number of organisms which constitute a debateable ground, and are claimed now by the botanist, and now by the zoologist. While the latter insists on calling them Protozoa (Primitive Animals) the former would have them Protophyta (Primitive Plants). The fact is that in these organisms of the first grade, the distinction between "plant" and "animal" has not become a hard and fast line; and the disputed forms may be best described as links between the two. The chemistry of nutrition is probably more to be relied upon as a distinction, than the difference of structure. It is here that the two groups, plants and animals, start upon different roads, and many of the differences in structure must be regarded as the direct result of the fundamental difference in the mode of nutrition. The following very instructive remarks on the subject are taken from Professor Hertwig's valuable book "The Biological Problem of To-Day," * pp. I I I, I I 2 .

"The different mode of nutrition of animals

* "The Biological Problem of To-Day, Preformation or Epigenesis," by Professor O. Hertwig. Translated by P. C. Mitchell. Heinemann, 1896 . 
results in a totally different structural plan. Animal cells absorb material that is already organised, and that they may do so their cells are either quite naked, so affording an easy passage for solid particles, or they are clothed only by a thin membrane, through which solutions of slightly diffusible organic colloids may pass. Therefore, unlike plants, multicellular animals display a compact structure with internal organs adapted to the different conditions which result from the method of nutrition peculiar to animals. A unicellular animal takes organic particles bodily into its protoplasm, and forming around them temporary cavities known as food vacuoles, treats them chemically. The multicelluiar animal has become shaped so as to enclose a space within its body, into which solid organic food-particles are carried and digested thereafter in a state of solution, to be shared by the single cells lining the cavity. In this way the animal body does not require so close a relation with the medium surrounding it; its food, the first requirement of an organism, is distributed to it from inside outwards. In its further complication the animal organisation proceeds along the same lines. The system of internal hollows becomes more complicated by the specialisation of secreting surfaces, and by the formation of an alimentary canal, and of a body-cavity separate from the alimentary canal. In plants it is the external surface that is increased as much as possible. In animals, in obedience to their different requirements, increase takes place in the internal surface. The specialisation of plants displays itself in organs externally visible-in leaves, twigs, flowers, and tendrils. The specialisation of animals is concealed 


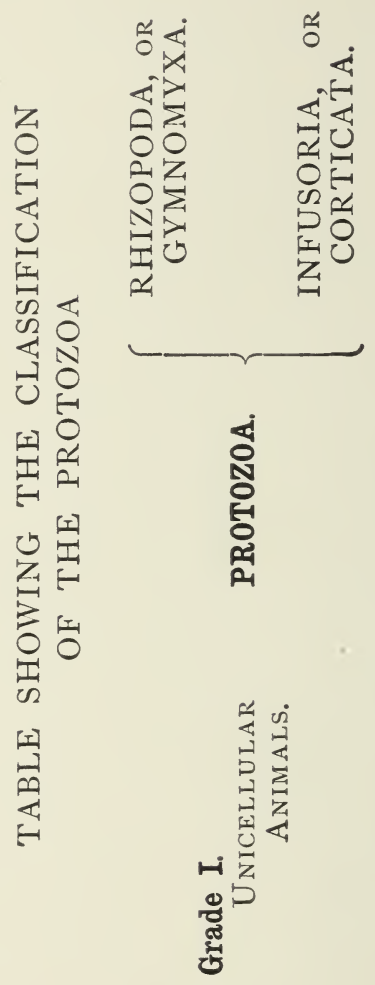


within the body, for the internal surface is the starting-point for the formation of the organs and tissues."

\section{CHAPTER V}

\section{THE CELENTERATA}

Next after the animals that consist of one cell only we have to consider the group of animals among which the lower kinds, at any rate, consist of a number of cells arranged in two layers. The representative of this group that the reader is most likely to meet with is the SeaAnemone, the Coral animal probably he will be content to know from pictures.

Everybody who has been accustomed to take a little interest in natural history, remembers the use of the old-fashioned term "Zoophyte." It was a name given to animals like those named above, which have a flower-like appearance, due to the possession of a set of petal-like arms or tentacles, placed all round the mouth; its literal meaning was animal plant, in allusion to the flower-like form. The great French zoologist, Cuvier, gave the group name Radiata to animals of this kind. This name is now not much used, because we have learnt to emphasize other peculiarities possessed by these animals, as well as that of radial symmetry, viz., their two-layered bodywall and simple digestive space (see p. 36 ). The group called Radiata by Cuvier, included, too, a number of animals which are widely separated from the "Zoophytes" in modern systems of classification. 
Sea-Anemones may be found on almost every rocky part of the English shores. Look for them in pools towards low-tide mark; if uncovered by the water, they will be found with the arms drawn in, so that the animal looks merely like a small round knob of shiny opaque coloured jelly ; if covered by the water, they will usually be found open, that is to say, with the arms (often called Tentacles) spread out. In the middle of the circle of arms is the mouth; and the apparent "flower" possesses an excellent appetite, as will readily be seen if any unfortunate little shrimp or sea-snail should come within reach of the arms. The latter will then at once contract upon it, and draw it into the mouth. Touch any of the common Sea-Anemones, and you will find that it is firmly fixed to the rock; at an early period of life it becomes fixed, and practically it remains always in one place, although a slight movement of the base is sometimes possible. Hence the advantage of the "radial "structure, for the arms reach equally in all directions round that most important centre of activity, the mouth. The most common kind of Sea-Anemone is of a dull dark red colour, and small in size; but others are large and brilliant in colouring. No uncoloured drawing would convey much idea of their beauty: the reader should consult the works of the late P. Gosse, an authority on Sea-Anemones, in whose books many beautiful illustrations will be found.

A much smaller animal than the Sea-Anemone is found in fresh water and is called Hydra. Its arms or tentacles are longer in proportion to its body, especially in one species, than is the case in the Sea-Anemones. Hence its name, fancifully 
derived from the seven-headed serpent of Greek Mythology, the Hydra killed by Hercules, which may be supposed to have presented a similar straggling appearance. The diagram on page $3^{6}$ represents a section through the middle of the body, only without the arms.

Unlike the Sea-Anemone, the Hydra can walk about. This it does in a very awkward manner, much in the same way as the Caterpillar known as the "Looper," clinging first with the front and then with the back extremity of the body (for head and tail they can hardly be called in so simple an animal as the Hydra, although the Looper caterpillar boasts both head and tail).

The Hydra is so small an animal that it appears to the unaided eye merely as a tiny speck. It may be found anywhere in British ponds and ditches, standing on water-weeds. Like the SeaAnemone it preys on animals smaller than itself. Nature has provided it with minute stinging cells, which benumb its prey; and in this all the animals of the Cœlenterate group resemble it.

One of the most curious things about the Hydra is, that it often throws out buds. It can, of course, produce eggs which are fertilized and hatched in the usual way of eggs; the buds are an additional way of multiplying itself.*

These buds are at first merely swellings, in which both of the layers of the body join: they grow larger; become provided with tentacles and a mouth, like the parent, and finally are cast off as independent animals.

* We may recall in comparison the way trees may be propagated by slips independently of flowers producing the seeds of the trees. 
For this reason the group to which Hydra belongs has received the name of Eleutheroblasteæ, the animals with free buds. But Hydra has many near relations in which these buds are not so cast off, but remain attached to the parent; and they in turn may produce others which also remain attached.

In this way, groups or colonies are formed, consisting of large numbers of individuals, and possessing a common stalk or stock which is formed by degrees as the process of multiplication goes on. The corals and the corallines are familiar examples of this.

The matter is complicated by the fact that either the separate animals or the flesh of the stock, or both, may secrete within themselves a hard supporting structure forming what is known as Corals. This may be developed in such a complicated manner, that instead of the coral appearing to be the product of the animal, the animal seems to be inserted in the coral, into which indeed it can retract itself for shelter.

The Corallines, on the contrary, secrete a leathery coating or sheath outside themselves and the stock. The leathery case is fairly transparent, so that on magnifying the creature the flesh of the common stock, as well as of the stalks of individual animals, may be seen inside. The "heads" of the animals poke out at the end of each branch (see Fig. 9).

The Hydra, with which we started, had always the power of producing eggs; each animal could do so, besides producing buds. But in our Colonial Coralline this is not necessarily so. Some individuals lose the power of producing eggs. Others can do nothing else, and become greatly 
altered in structure, often losing the power of developing tentacles, and exhibiting other changes. So much are they altered sometimes that they seem to be mere buds, not separate animals at all.

In other cases a still more surprising thing happens. The bud that is destined to produce eggs falls off, and becomes quite independent of the colony; more than this, it becomes quite different in appearance from the members of the colony: and instead of being a Hydra-like animal it becomes a jelly-fish. But the eggs of this jelly-fish do not produce jelly-fishes: they produce a more or less Hydra-like animal which gives rise by budding to a fresh colony. This is what is known to Zoologists as "alternation of generations."

Now comes a puzzling question-Which part of this family group shall we select and call it an "animal"? Is each Hydroid of the colony an animal, and the jelly-fish another animal? Zoologists say "No": from the development of one egg, to the production of another, is the cycle that constitutes an individual animal. So we have the puzzling result in nomenclature, that an "individual" consists of a very large colony of creatures in one place, together with a perfect shoal of creatures quite unlike it, floating miles away from it on the ocean. What name must we give to the units, so curiously connected with one another? Zoologists call them "Zooids" (animallike parts) or "persons."

This is the story of the jelly-fish as originally told. But there are innumerable variations upon it. There are kinds of jelly-fish that produce jelly-fish and have no Hydroid stage at all. Sometimes the "persons" of the colony present 
many varieties, each taking up some different task for the community. Some may be "nutritive persons," i.e. commonplace Zooids that have mouths and eat food; some "protective persons,"

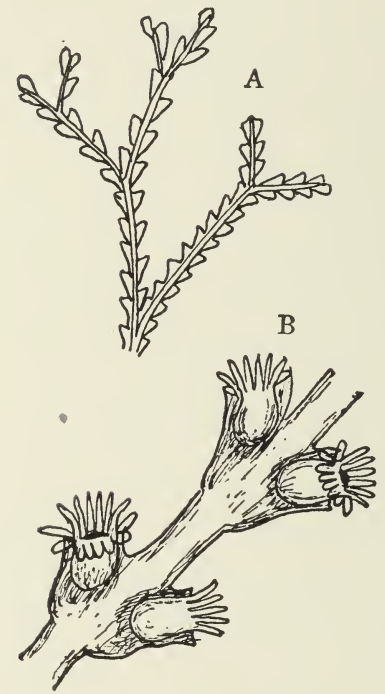

FIG. 9.-An example of the $\mathrm{Hy}$ drozoa. A, branch of a Coralline, Sertularia Ellisiz, magnified. B, the same, more highly magnified. reduced to mere folds or sheathing processes to guard the others; some are "stinging persons" armed with enormous quantities of thread cells. Then the whole colony may be like the jelly-fish, a floating affair, and not fixed at all.

We have several times above referred to the animals known as corallines. It may almost be assumed that the ordinary reader knows what these are; if not, a little search among the treasures of the sea-shore will almost certainly reveal some of them, living or dead. The texture and appearance of the dead stemsremind one of soft horn or dried gelatine; the branching arrangement of the stems and the little cells disposed at the ends of the branches will easily be shown under slight magnification. Most people will remember the rage for dyed corallines, by 
which all the fancy shops and florists were possessed a few years ago. The corallines, dyed a bright emerald green, or a dull red, which were used for decorations at that time, were usually a variety of the Bottle-brush Coralline, found on English shores; but sometimes commoner kinds were employed.

Fig. 9 shows an example of a coralline, slightly magnified in $A$, and in $B$ much more highly magnified, so as to show the individual hydra-like zooids, each with its circle of tentacula.

The Sea-Anemone and the Hydra respectively represent the two great groups of the Cœlenterata, named after them, the Anthozoa (Floweranimals), and the Hydrozoa (Hydra-animals). The corals are forms of the Anthozoa, single or colonial, which possess a skeleton.

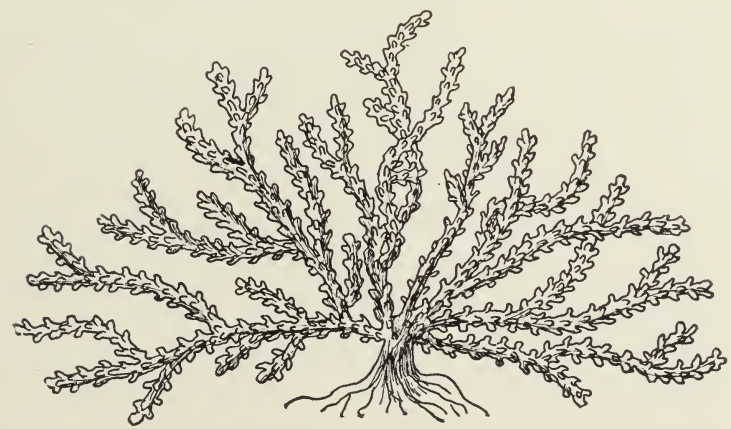

FIG. 10.-Gorgonia verrucosa, from Guernsey, nearly one-third of the natural size.

The above diagram shows examples of the Anthozoa. Fig. Io is Gorgonia, the Sea-Fan; 
while Fig. I I represents corals of six different kinds.

Besides the two great groups we have named, the Hydra-like animals and the Sea-Anemone-like
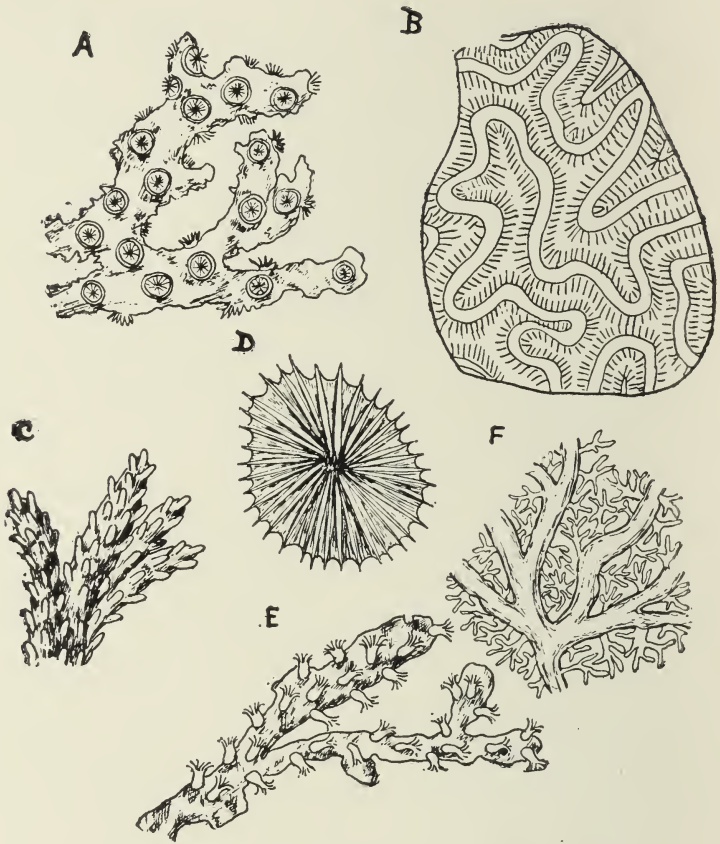

FIG. II.-Corals. A, Acanthoporia horrida. B, Meandrina strigosa. C, Madrepora divaricata. D, Fungia papillosa. $E$, Red Coral, Corallium rubrum. F, Stylaster sanguineus.

animals, the Colenterata contain a third group, the Ctenophora, or Comb-bearers, so called on 
account of their possessing bands of cilia, fancifully compared to the teeth of a comb. At first sight most of them somewhat resemble jellyfishes, being transparent forms swimming near the surface of the sea. They are carnivorous, and some of them highly phosphorescent at night. The gastric cavity is divided up into branches. The representatives of the Ctenophores, most often seen on our own coasts, are small rounded forms.

Two remarks must be added before quitting the subject of the Colenterata.

Firstly, the description of them as two-layered Animals is one that only applies typically and to the simpler forms. In others, such as the jellyfishes, there is an intermediate layer of jelly, which appears to acquire a cellular structure by the immigration of cells derived from the primary layers. Thus we see, within the group of the Cœlenterata, the gradual establishment of that third body-layer, which is found in all animals of higher structure. Scarcely indicated in Hydra, as a faint trace of a boundary-line (lamella) between the ectoderm and endoderm, it attains a good thickness in the Jelly-fish and Ctenophora. In animals of higher structure the third body-layer, being now fully established, is cellular from its beginning in the embryo; in the Colenterata its gradual formation is to be traced.

Secondly, it must be remarked that the colonial structure and the arrangement sometimes concomitant with it of "alternation of generations," is by no means confined to the Colenterata. Both are seen in other forms of life, in which the units, or zooids, differ greatly in structure from those of this group. 


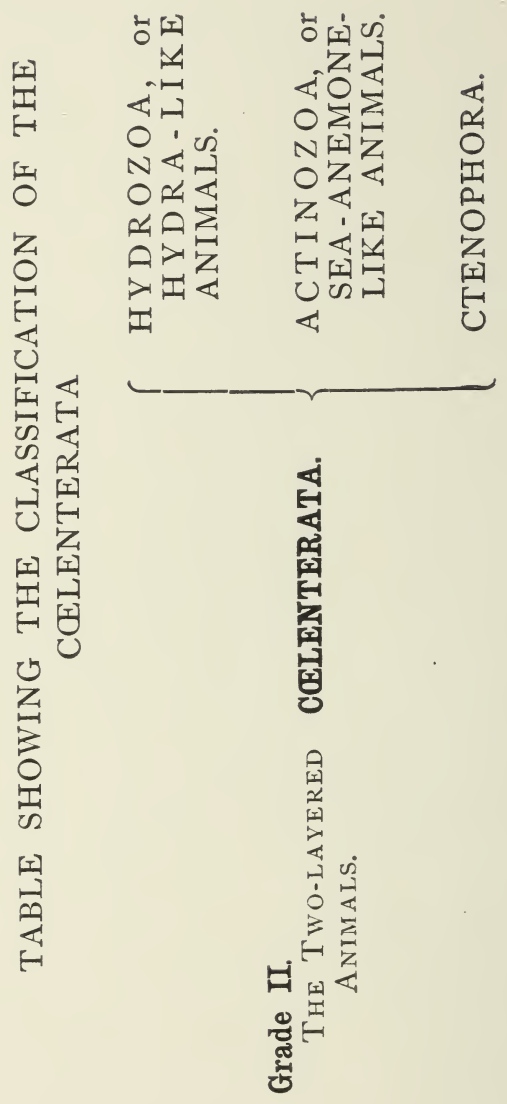




\section{C.HAPTER VI}

THE SPONGES

MANY who are familiar with the domestic sponge have never seen a sponge in a growing state, and would find it almost impossible to realise that a sponge may be a thing of beauty. And yet sponges are quite common on the rocky shores of our own country. It is true that they do not form large masses, like the sponges grown in warmer seas, which we import; but the smaller growths, massed together, often cover a considerable space of rock, and are conspicuous by their beautiful colouring. Some sponges are crimson, and some green; while one of the commonest is a brilliant orange-yellow. The latter may often be found near low-tide mark, on a shelf of rock under growing seaweed. If the explorer has any doubt what the object is, it may easily be identified by the touch, which though moist and firm in the growing state, is still the unmistakable "feel" of sponge. Where the receding tide exposes a large surface of steep rock, for instance in caves, sponges may be found covering the rocks as thickly as mosses do on land. Masses of dead sponge, consisting of branching parallel fingers a few inches long, may often be found in the dead state, washed up on the shore; these are the usual drab colour of a dead sponge.

The encrusting sponges which grow on rocks present a mass, so to speak, of little hillocks : in kinds which attain a larger growth, these may almost be described as branches. Each little hillock or branch has a hole at the top; and on the 
exterior of the rounded mass of the bath-sponge may be found numbers of such holes. We should naturally suppose that these holes were the mouths of the various sponge branches, especially since they lead to the central cavity of the branch, and thus to that of the whole sponge; and indeed they are known by the Latin name of "oscula," little mouths. They are, however, nothing of the sort; the sponge once had a mouth, a single one, when it was young, but the adult sponge has lost it. For the young sponge is at first a little free-swimming, two-layered animal of the type which has been described above as the gastrula larva. When it gets old enough to settle down in life, it sinks upon some suitable surface, and becomes fixed to it, mouth downward: the mouth is thus lost. How, then, is the animal to be fed? As it grows, there is developed in its substance a system of hollow spaces, which communicate with the exterior by means of $\mathrm{mi}$ croscopic pores. Through the latter, water is drawn in, and passes, after devious wanderings, to the central cavity of the animal, whence it is expelled by the so-called osculum. At first, the young sponge has but one cavity and one osculum; but by degrees the sponge branches and spreads, the cavity of each new portion remaining in connection with the main cavity. If, as they grow in size, the branches touch one another, they sometimes coalesce-a fact which renders the growth of the sponge in some cases a very complicated matter.

It will be seen from the above description that the sponge is a sort of living filter. As the water passes in through the pores, it deposits in the substance of the sponge all the little or- 
ganisms that it contains; on these the sponge feeds.

It will naturally be asked, how does this living filter work? WVater will not pass through small holes to flow out again at large ones in an upward direction, unless helped by some mechanism. How is this supplied? By the industry of the cells of the sponge. Its canal-system includes a set of wide chambers, lined with cells which have long cilia, called flagella. These flagella, constantly moving in one direction (like the fan of a ventilator), create a current, which passes the water on with such force that it reaches the central cavity, whence it is expelled through the oscula. These chambers do not communicate directly with the exterior. They are closed, except at certain small holes, the "prosopyles," where they take in the water that enters from spaces connected with the pores. At the main end of the chamber is an aperture called the "apopyle," capable of being partly closed, and leading into an excurrent passage. This last communicates with the central cavity of the sponge.

It will be seen that the topography of the sponge is a very complicated business. All its details have been studied by means of thin sections specially prepared and placed under the microscope (see p. 183 ); in these the labyrinth of canals and chambers is seen cut through at various points; the cells lining them and dividing them may be individually studied. The passage of water through the sponge was first observed by Robert Grant ; many of the most recent discoveries regarding the structure of sponges we owe to Professor Sollas.

We have not yet explained what our living 
filter does with its food when it gets it. The ciliated cells of the internal lining take in solid particles just as Amœba does; and from these they may be passed on to the cells of the middle layer, amœboid cells, which can move about. These cells are considered to be derived from the primary layers of the body, especially the inner one, and to have wandered into a cellless middle layer, comparable in nature with that of some Colenterates.

The sponge is full of firm or gritty particles, which form its skeleton, and remain when the sponge is dead, and the softer parts decayed. These, when magnified, often present beautiful and curious shapes. The use of them is not only to support the body, but also to prevent the sponge from being eaten by other animals.

There is found in the English canals and rivers a small, fresh-water sponge, usually greenish in colour. This is named Spongilla fluviatilis, the River-sponge, and affords an exception to the usual marine distribution of sponges. In the winter it dies gradually away, at the same time forming asexual buds, or "gemmules," in the interior of its substance, which are liberated in the spring, and become young sponges.

Some of the marine sponges are parasitic. Most people have doubtless found on the seashore now and then a dead oyster-shell, completely riddled with small round holes, very similar in appearance to those seen in "wormeaten" wood. These are the work of Clione, a parasitic sponge which is very fatal to the oyster. At first sight it seems a puzzle how the sponge made its way into the hard shell; it has no mouth to bite or suck its way into the solid 


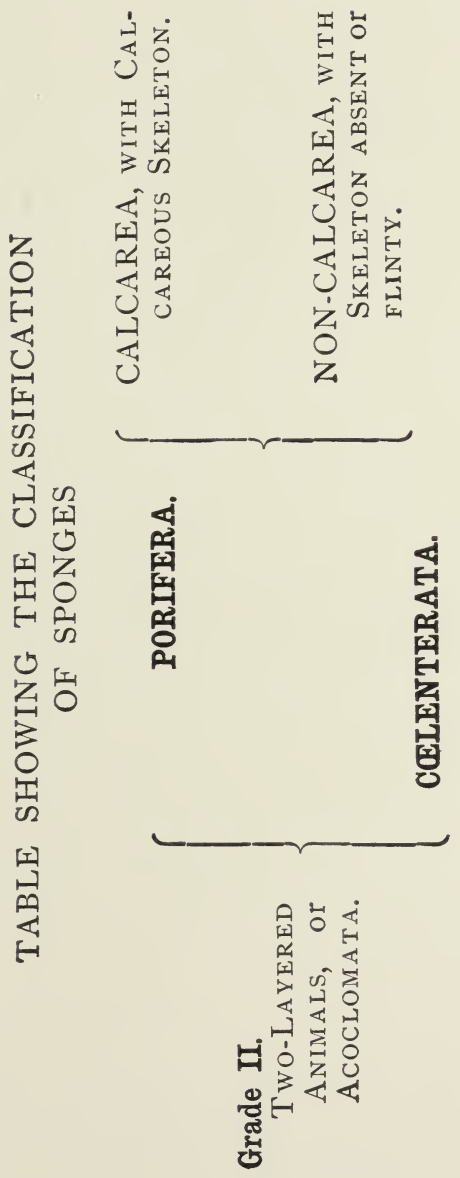


substance. The cells of the sponge, however, wear away the lime of the shell by means of some acid chemical action. Not only so, but they can attack stones as well, when these consist of limestone; and on some parts of the coast bits of sponge-eaten limestone washed up on the beach are quite common objects. They are pierced all through by holes, so that their appearance would suggest a sponge carved in stone, but for the fact that the holes are fairly uniform in size. Such stones, lying on the shore, often puzzle the finder, when they contain no apparent trace of the tenant that has worked its way through them.

The sponges have received the name of Porifera, on account of the structure above described. They are often classed with the Cœlenterata, because, among other reasons, they practically belong to the two-layered type of structure, and because they form a complex organism that may almost be called a colony. But some prefer to place them in a group by themselves, apart from the Cœlenterata. The chief reason of this is that the sponges, as compared with a primitive two-layered type indicated by their own larvæ, are turned upside down, the mouth being, as above stated, originally situated at the fixed end.

\section{CHAPTER VII}

WORMS

When the great naturalist, Linnæus, framed his classification of the animal kingdom, he in- 
cluded in the division Vermes or Worms, nearly everything except the vertebrates and insects.

This assemblage would have been more correctly styled if instead of "Vermes" it had been described as "animals unsorted." Subsequent zoologists have by degrees picked out and separated from the Vermes first one group of animals and then another. But the process is still going on, and several of the groups which are still classed under the name of "worms" might, with very great justification, be separated from each other; it is custom, rather than family resemblance, that accounts for their being retained under one heading.

Widely although the various "worms" may differ from one another, one thing may be stated regarding the most of them, and that is, that they "crawl"; that is to say, they move along by means of successive contractions of successive parts of the muscular wall of their elongated bodies. This "crawling" mode of progress is the chief thing involved in the popular idea of a worm; but the popular definition of a worm includes also the larvæ of insects, such as c. terpillars and beetle-grubs. The latter, it must be noted, crawl with the assistance of legs, while the true worms crawl without any such assistance. Any adornments that they may possess, whatever else they may be, are not legs.

The worms were formerly included along with the insects and lobsters, in a division called Annulosa, or Ring-bodied animals, but it has now long been recognised that the latter are worthy of a division to themselves. It will easily be seen, however, that the term Ring-bodied animals is very appropriate to all of them. If we look at 
either an earthworm or a lobster, we can but recognise that the body consists of a number of successive parts very similar to each other; and since the body of each is, in section, more or less round, these successive parts may very aptly be termed rings. Modern writers, however, prefer to call these parts not rings, but Metameres, i.e. successive parts. The symmetrical arrangement of the body in a series of such parts is called "Metamerism"; and the animals which possess it are said to be "Metameric" in structure. Sometimes also the successive parts are spoken of as "segments." Compare Fig. I 2 ; $A$ and $C$ show the successive body-rings of worms.

The earthworm, with its many rings, is one of the higher forms among the worms. Among the lowest forms there are worms in which the ring structure cannot be detected. Between the limits thus marked out, there lies, so to speak, the battleground of modern zoology. For the origin of metamerism, and the pedigree of vertebrates, are among the questions that are being discussed in connection with various groups of the worms.

Among the lowest forms of worms are the Planarian worms, already alluded to as examples of the third grade of animal existence. These belong to the class Turbellaria, which is represented by plenty of both fresh water and marine forms in our own country and on its coast. The Turbellaria are divided into groups called Acœla, Dendrocœla, and Rhabdocœla. These names allude to the intestine, which in the first group is wanting, in the second branched like a tree, and in the third straight. The Cestoda or tape-worms, which absorb nourishment through the skin, and therefore need no alimentary canal, and possess none; 
and the Trematodes, represented by the Liverfluke, which infests sheep, together make up the group of flat-worms (Platyhelminthes), of which mention has already been made (p. 44). In all of them the body is more or less flat, and the digestive cavity, like that of Cœlenterates, has but one opening, the mouth. The life-history of parasitic worms is described in a well-known volume by Leuckart, which forms the basis of our knowledge on the subject. Since its publication, discoveries regarding parasites have been constantly added by other observers.

The history of the Liver-fluke is a most complicated example of alternation of generations. The adult form infests the sheep's liver. There it produces eggs, which afterwards find their way into water. Here they die unless they find their way into a certain water-snail, which many of them do. Within this snail-Linncea truncatulathe egg develops into a sac-like body, called a sporocyst. This produces within itself numbers of a small creature which is called the Redia form. These in turn produce a tailed form, called a Cercaria, which gets out of the snail, swims in water, and finally settles down on some plant. Here it is eaten by an unfortunate sheep, within which it develops into the adult fluke.

The other great divisions of the Vermes are as follows: The Nematodes or thread-worms, a group of parasites which includes the dreaded Trichina; the Nemertines, a group mostly carnivorous, possessing a curious proboscis, and often an armed skin; the Leeches or Hirudinea, and finally, the Chætopods (Bristle-footed Worms), the highest group of all, containing the forms often spoken of as Annelides-i.e. Ring-shaped Worms. 
These last are again subdivided into the following: The Archiannelida or Primitive Annelids, some of which have a curious ciliated larva, already referred to (p. 42) as the typical Trochosphere or Wheel-ball; the Oligochæta (FewBristles), which include the familiar earthworms; and the Polychæta (Many-Bristles). Of the latter, some, the Tubicola, live in tubes which may or may not be fixed to some object; while others, the Errantia, or Wanderers, are free and very active. Nereis, the Rainbow Worm (p. I59) may be named as an example. Our illustration shows instances of each group. $A$ is the Sea-Mouse, a bristly creature so named by some very imaginative person. It has two kinds of bristles, long and short, the former being possessed of a peculiar lustre (see p. 73). $\quad C$ is Syllis, one of a very curious family of worms. In both $A$ and $C$ are seen a row of paired appendages; these are not "legs," but expansions called "parapodia" which serve the purpose of legs, besides which they frequently act as breathing organs, a special part being appropriated to this purpose. Each of these animals is active and carnivorous, and has a head. The Syllidæ are remarkable for the very peculiar way in which they divide, new individuals being formed and cast off from the end of the body. There is, however, a deep-sea form of Syllis which divides in a very odd manner, giving rise to new individuals placed transversely. The result is a most extraordinary looking creature, a network of worms with numerous heads, each branch being eventually provided with one of its own.

The tube-dwelling worms are represented in our picture by Terebella, Serpula and Spirorbis, ail very common forms on the English coasts. 
The Terebella glues around its body a number of grains of sand and bits of shell, thus forming a case; the projecting threads at the head end are

A

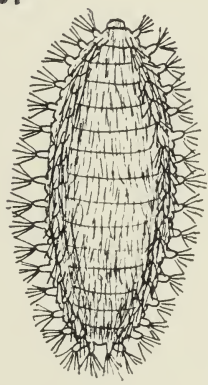

c

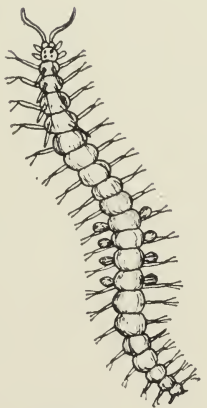

B

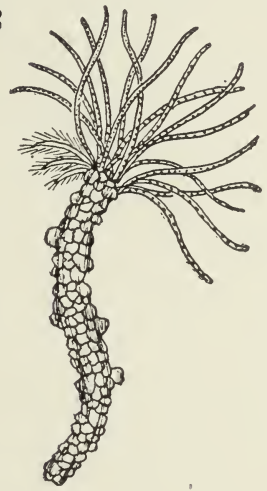

D

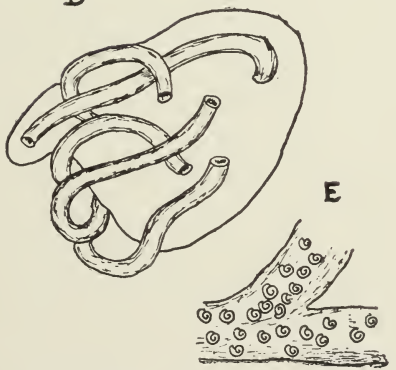

FIG. 12.-Worms. $A$, a Sea-Mouse, Aphrodite aculeata; $B$, Terebella littoralis; $C$, Syllis; $D$, Serpula vermicularis; $E$, Spirorbis nautiloides, on a piece of seaweed.

the gill-filaments, borne by the anterior segments of the body. These are plumed; the thread-like 
structures which are seen to lie in front of them are the tentacles or feelers. $D$, Serpula, is common on shells and stones. The animal has a plumy bunch of gill-filaments, brilliantly coloured, and a stopper with which it can close the mouth of its tube. This precaution is necessary to keep out its predatory cousins belonging to the Errantia, who poke in their heads and eat the tube-dwelling worms. $E$ is Spirorbis, a minute form with a coiled tube, which looks at first sight like a small univalve shell. It is common everywhere, on shells and stones, and encrusting Fuci and other seaweeds, which it sometimes. covers almost completely. Spirorbis also has. plume-like gills and a stopper. In the latter is a cavity where the creature's eggs are incubated for a time.

The reader will have no difficulty in finding and identifying both Serpula and Spirorbis. Terebelia is frequently washed up on a sandy shore. On the Lancashire coast one may feel sure of finding this and many other sand-dwelling animals, after an east wind. The east wind, driving back the water at low tide, kills these creatures. with cold, and presently they are washed up dead or dying by the high tide. Pectinaria, another worm with a tube of sand-grains, in which, however, the body lies loosely within the tube, may also be found in thousands under the same circumstances.

We must not forget to say something regarding the most commonly known member of the Vermes, the familiar earthworm. The worms are the first of the great group of animal life in which we find true land animals. There are terrestrial forms among the lowest worms, at least forms 


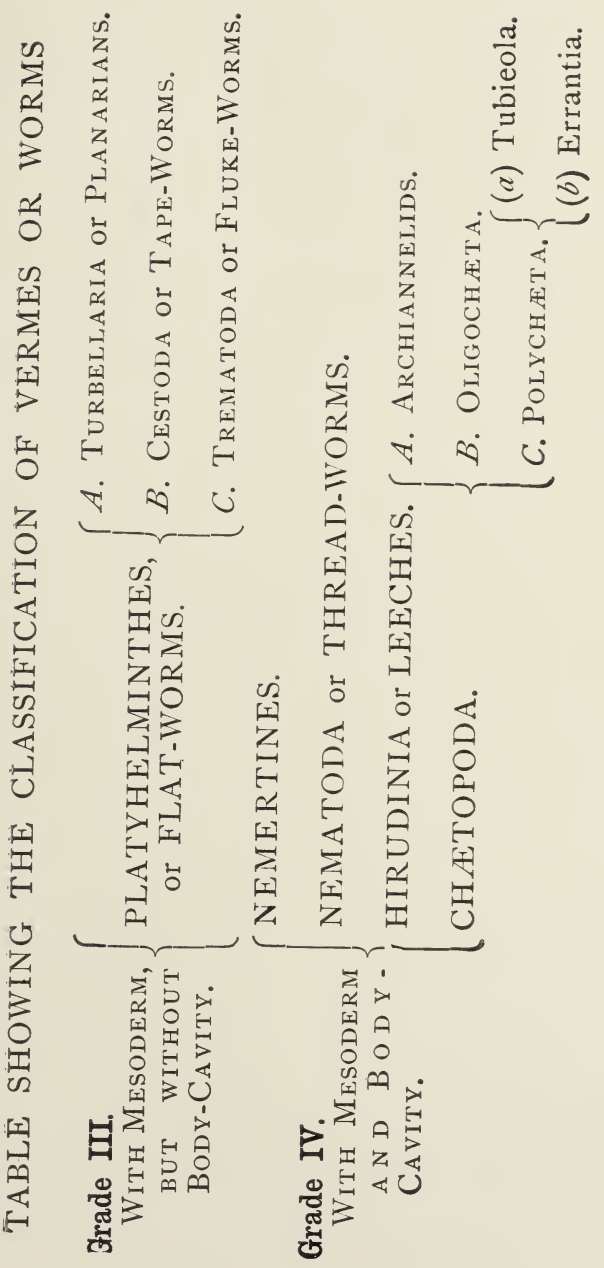


that live in earth that is damp; but the earthworm is in the strictest sense a terrestrial animal. Darwin showed that it not only dwells in the soil, but is in a sense the manufacturer of soil, since the fertility of the earth depends greatly upon the work of earthworms. They pass the soil through their bodies, digesting the organic particles they find in it, and thereby loosen the soil, reduce it to a state of fine division, and render it more fit to support the growth of plants. The "worm-casts" formed by the soil that the earthworm has passed through its body may not have been noticed by everybody. More obvious are the worm-casts in sand left by the sanddwelling marine annelids. 'These everyone must have seen who has walked on a sandy shore at low tide.

The worms include many puzzling forms, which have not been alluded to here. Among these must not be forgotten the Rotifers, or wheelbearing animals. These are of minute size, and when first discovered were therefore placed amongst the Infusoria. They are common in ponds.

\section{CHAPTER VIII}

ARTHROPODA, THE LOBSTERS, SPIDERS AND INSECTS

THE above is a very descriptive name for a division which includes the Crabs and Lobsters and the Insects. Formerly they were included, along with the worms, under the name Annulosa, the Ringed Animals. They resemble these as 
possessing what is termed metameric symmetry, but they are distinguished from them as the Leggy Animals, a fact which is explained in the name, Arthropoda, joint-footed. Worms, as we have seen, have no true legs, but the Arthropods, theoretically, have a pair of legs to every ring. In some of the lower members of the group this is literally the case, the Centipedes, or hundred-footed animals, for example (Fig. I3). In higher forms the number of legs is greatly reduced; several successive rings may become merged with one another, losing, along with their independence, their legs. The true Insects, thus, have only three pairs of legs and the Spiders four.

What are theoretically regarded

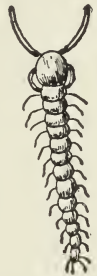

Fig. 13.-A Centipede, Lithobius elongatus, from Tunis, slightly reduced in size.

as legs, however, may practically be turned to many other uses, according to the position of the particular body-ring to which they are attached. 'Thus, in the case of a body-ring near the mouth, we find such things as " jaw-feet," maxillipedes-that is to say, legs used for jaws. It consequently results that zoologists are sometimes driven to speak of "walking legs," or, hiding the tautology under a Latin phrase, "ambulatory legs "; and absurd although this may seem, it is sometimes quite necessary for the sake of accuracy. It is therefore more convenient to speak of the "appendages" of a body-ring than of its legs. For this vague term can be applied equally to all the row, whatever their uses. Among the different forms taken by the "appendages" are those of "antennæ," long, hair-like feelers attached to the head; 
"chelæ," or claws, such as the large claws of the lobster; "cheliceræ," or "claw-horns," tearing appendages attached to the head; "mandibles," mouth appendages used for biting, etc., etc. The reader who wishes to attain a clear idea of the structure of a segmented animal, and of the ways in which its parts are modified, should consult Huxley's classical study of "The Crayfish" (International Science Series).

The Arthropoda include two main groupsthe Crustacea, or Jointed Animals of the water, which breathe by gills; the Insects, or Jointed Animals of the land, which breathe through tubes in their sides, called tracheæ.

The Crustacea include the familiar Crabs and Lobsters. These are among their highest forms as well as their largest, and if we begin at the beginning we must seek much smaller forms. The group called Entomostraca include the socalled Freshwater Flea, a very active little thing found in English ditches, and a great many other freshwater forms: also the little Cypris, which has a shield forming a sort of bivalve-shell, and is interesting from its wide occurrence as a fossil form. Most of the Entomostraca have a larval form called a Nauplius; but this larva refuses to tell us anything about the past history of the Arthropods. It is itself already a jointed animal with legs. So we see that the Arthropods, unlike the worms and the Chordata, have obliterated all record of their poor relations. The parasitic "fish-lice," so-called, are entomostracous Crustacea, often greatly degenerated in consequence of their habit of life. Some live in the gillchambers of a fish, some on, or even embedded in the skin. 
Among the most curiously modified forms of the Crustacea are the Barnacles or Cirripedia. These creatures, like the sponges, have a freeswimming larvæ, which eventually fixes itself by its anterior end, so that the adult animal passes its existence upside down. The young is an ordinary little creature with jointed legs, but the adult protects itself by a strange armour of shell. An intermediate stage exists in which the creature eats no food; it has therefore been compared with the chrysalis of insects. At the top of the adult shell two little valves open and shut, allowing the legs to dart out and seize upon prey. These legs, gathered into a bunch, and extended and retracted together, remind one of the fingers of a hand opening and closing. They are clothed with a fringe of "cirrhi"

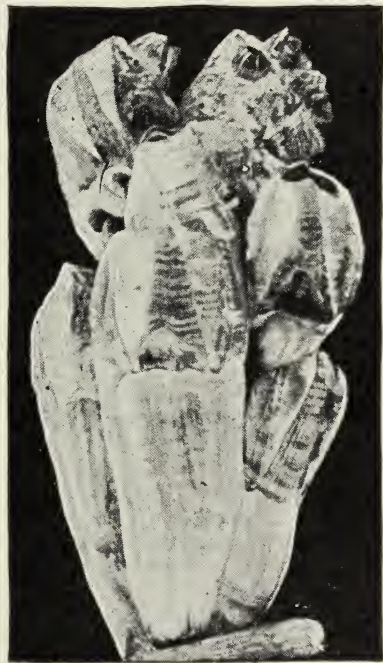

FIG. 14.-Shell of the Bell Barnacle, Balanus tintinnabulum, one-half the natural size. The figure shows several successive generations, perched one upon another.

or small processes; hence the name of the group. The Common Barnacle of our own shores, sometimes called the Acorn-Shell, is found on shells and stones, and often on those that are left uncovered 
between tides. In places where the rocks of the coast are very steep, a belt of white, several feet or yards deep, may often be seen above low-

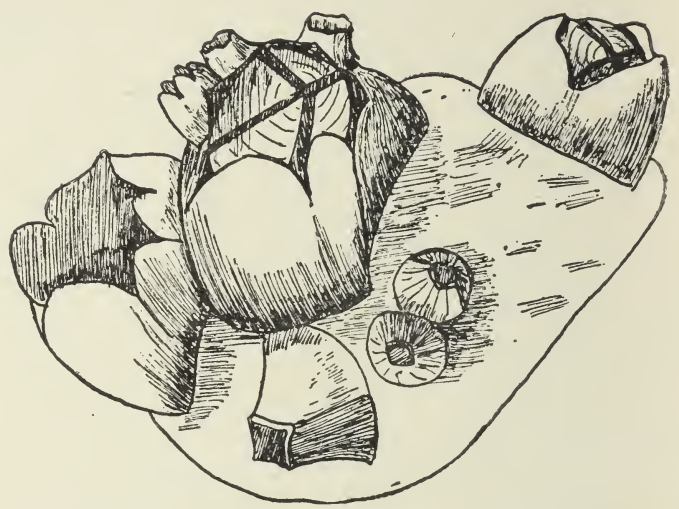

FIG. 15.-Shells of a Barnacle, Balanus hameri, found in European and North American Seas, natural size.

water mark. This white zone, when examined more nearly, is found to consist of barnacles, so crowded together that they obscure the natural colour of the rock. The Common Barnacle is one of the smaller species of the genus: in warmer seas barnacles attain to a much greater size (Figs. I 4 and I 5).

The higher Crustacea, Malacostraca, include the familiar Crabs and Lobsters, Decapoda. The lobsters receive the name of Macrura or Big-tails; associated with them are the Shrimps and the Hermit-Crabs (Fig. I6). The latter are therefore not crabs at all, but somewhat divergent lobsters. Their tails are soft, and they thus require pro- 
tection: they choose the dried shell of some univalve mollusc and live in it (Fig. 16). How far the case is that they need a house because their tails are soft, and how far the contrary is true that their tails are soft because they live in a house, it would be difficult to say. Readers of another volume in this series, Professor Hickson's "Story of Animal Life in the Sea," will remember that the hermit-crab often offers a curious instance of "commensalism" or partnership with other animals. The hermit-

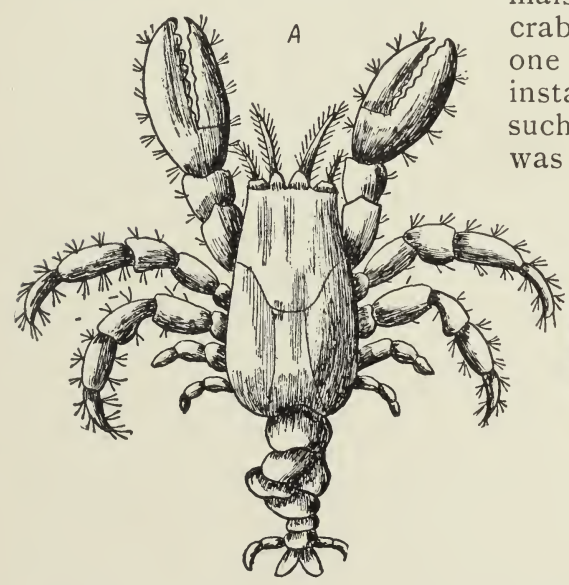
crab was, in fact, one of the earliest instances in which such a partnership was observed, the

FIG. 16.-Hermit Crabs. A, Aniculus typicus, from the IndoPacific Seas, one-half of the natural size. $B$, Caternus tibicen, from the Indo-Pacific Seas, slightly enlarged.

companion being in this case a sea-anemone perched on the shell in which the crab lives.

The true Crabs are called Brachyura, or Short-tails; for obvious reasons, the tail of a 
crab being very curiously modified and tucked in under the carapace or "shell." A form exceptional in the fact that frequents the land is the

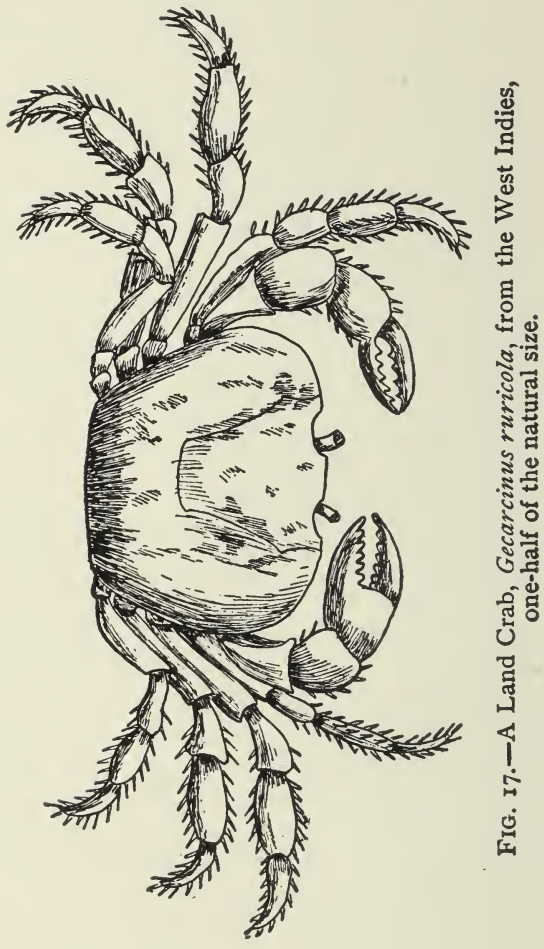

Land-Crab of the West Indies (Fig. I 7). Another land crustacean, Birgus latro, the Robber Crab, belongs to the previous group. 
In addition to the above the Malacostraca include the Arthrostraca, or crustaceans which have the front of the body jointed as well as the tail, so that there is no large shield formed by the fused armour of several segments (cephalo-thoracic shield, $c f$. Figs. 16 and 17 ), as in crabs and lobsters. The Amphipoda, or Sand-hoppers, sometimes called Sand-fleas, are familiar examples of these. There are several common kinds found on our English shores, and sometimes they appear in such numbers, hopping above sand or seaweed left by the tide, that they seem to form a sort of cloud, every unit of which, however, is but in the air an instant, falling and giving place to some other, while it prepares for a fresh hop. The socalled Freshwater Shrimp, Gammarus, is another common member of the Amphipoda. Fig. I 8

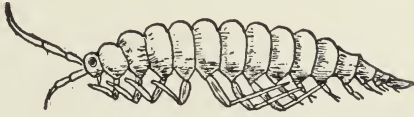

FIG. 18.-A Sand-hopper, Pallasea Cancellus, from Siberia, natural size. shows the general form of a Sand-hopper. Nearly allied are the Isopoda or Wood-lice, interesting because they are among the few terrestrial forms of the crustacea; they live, however, in damp places, and are but too well-known in gardens, where the gardener often mis-names them "insects."

The mention of terrestrial forms would naturally bring us to the discussion of the true Insects. In the Arthropoda we for the first time meet with terrestrial animals except in scattered instances, and the true Insects are the largest and most important group of these. There are, however, various creatures belonging to the 
Arthropoda which are neither Crustacea nor yet Insects. Among these is the familiar spider, an "insect" in popular language, but not so described by the zoologist. Among other differences, the true spiders have eight legs, whereas the true insects have only six. Fig. 19 shows a

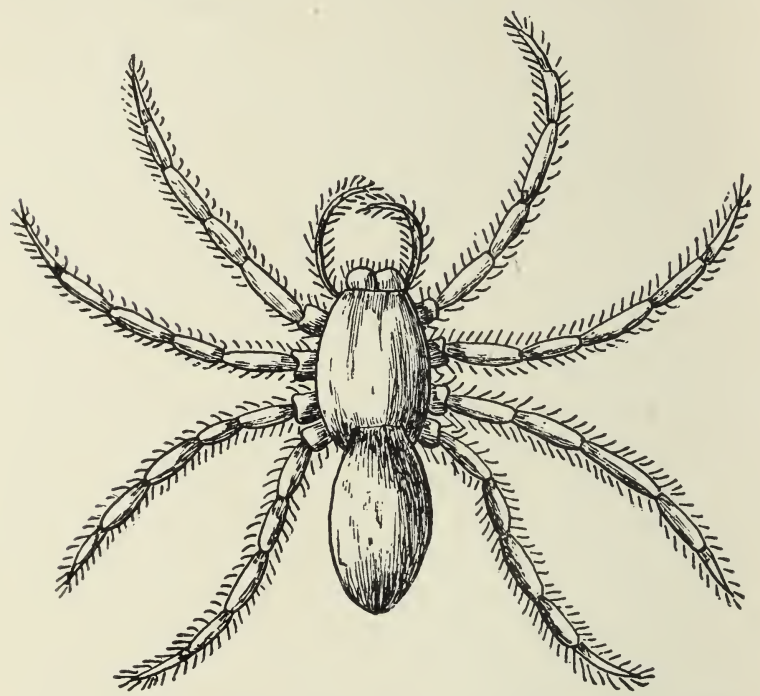

FIG. 19.-A South American Spider, Ctenus ferus, from the Amazon region, natural size.

typical spider; the eight jointed legs are attached to the thorax ("breastplate"); with the latter the head is united. The abdomen, as in insects, is formed by the fusion of several segments, and has no legs, but it has, however, out of sight, the spinning legs or "spinnerets," out of 
which the thread of the spider's web is spun. The venom of the spider is not a fable; spiders have poison-glands with ducts which open on the tops of the cheliceræ. They dispose of their prey by sucking it; they do not swallow solid food. The habits and webs of spiders are familiar to every one: their nests, as a rule, are only noticed by close observers. The nest is made of spun threads closely felted together to form a round hollow ball. This the house-spiders hang on a wall or among the rafters of a roof. There are, however, spiders which build their nests under ground; and in this case the nest may be conveniently furnished with a lid, which can be pushed up when the animal wishes to come out. Fig. 20 shows the nest of the Trap-door Spider, so called from the construction of its nest.

Fig. 2 I shows a spiderlike animal which, at first sight, seems to have five pairs of legs. In fact, how-

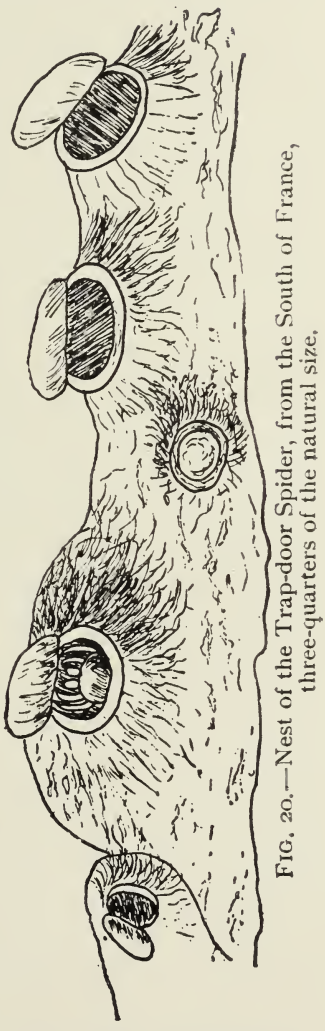
ever, it has only three pairs, thus approaching the insects in structure. These three pairs of legs 
are attached to the thorax, while the head, which is separate from the thorax, unlike that of the true spider, bears two pairs of leg-like appendages. This is the chief of a group which are sometimes placed in a class by themselves, on account of

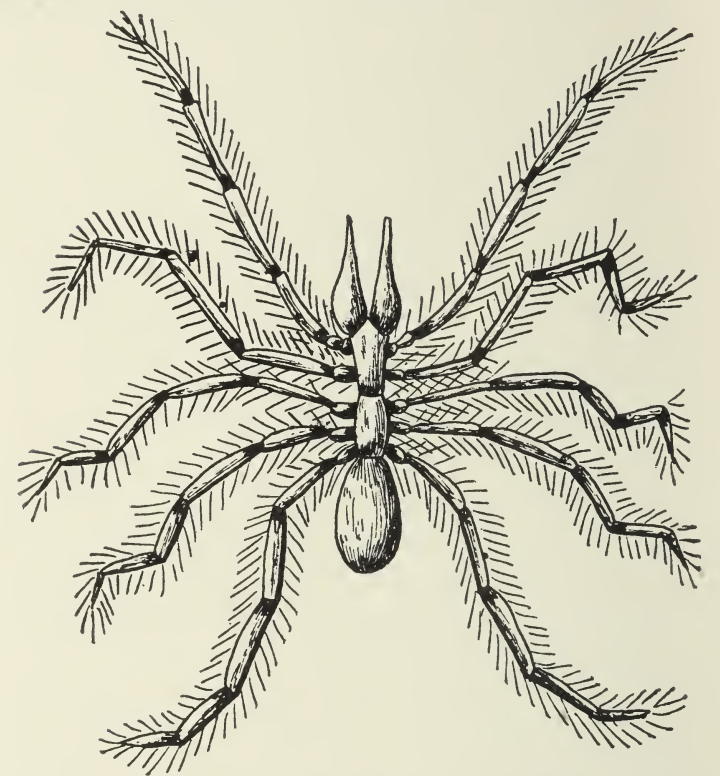

FIG. 21.-A venomous spider-like animal, Galeodes araneoides, from North Africa, natural size (Diagrammatic).

their great differences from real spiders. Their head is separated from the thorax; and the thorax is divided into three segments; these, however, do not come out clearly in the diagram. The head bears, posteriorly, a pair of appendages 
which are practically legs; in front of these a pair of long "pedipalps" or "foot-feelers"; and quite in front the comparatively short "cheliceræ." These creatures are very venomous; they move about by night to seek their prey.

Another kind of spider-like animal is familiar in English fields and waysides - the longlegged spiders, called Harvestmen or Phalangidæ, which spin no web, but jump upon their prey. Unlike the last group, the body differs from that of true spiders, in being more, not less, compact : for not only is the head joined to the thorax, but also the thorax is joined to the abdomen, the outline of the body being therefore almost globular. They receive the name Phalangidæ, Joint-Spiders, from the sharp joints in their long legs.

Allied also to the spiders are the Mites, Acarina, so destructive to cheese, flour, and other eatables; and the Ticks, which infest the skins of various animals. Fig. 22 shows a specimen of the latter.

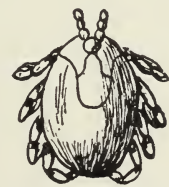

Fig. 22.-The Tick which infests the Hippopotamus, from South Africa, twice natural size. They are practically blood-sucking Mites. It is the female which attacks animals, while the males live among vegetation.

The Scorpions, also, are relatives of the Spiders. They are inhabitants of hot countries, and highly venomous. They possess a jointed tail, instead of an abdomen with fused segments, and a lobsterlike pair of appendages in front; these are the second pair of appendages, the "pedipalps," while the short "cheliceræ" lie in front. In the living animal the tail is often carried curled up 
over the back. The Mites, Ticks, and Scorpions all agree with the true spiders in possessing eight legs.

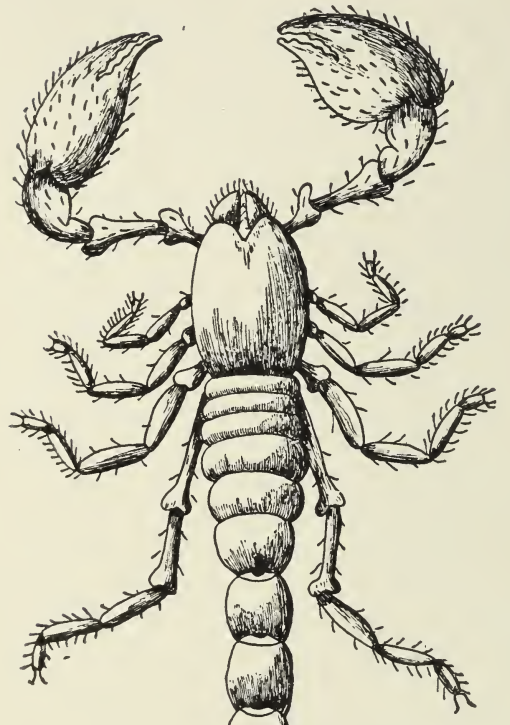

The King-Crab, Limulus, has not hitherto been named, because, though living in the sea, it is not a crab at all. It has been shown by Professor Ray Lankester to be related to the spiders. It is a large crab-likecreature, which may be seen in museums and aquaria, and is brought from the tropical seas.

Before passing to consider the true Insects, or Hexapoda, something must be said about the discovery of Peripatus, a creature which comes from Cape Colony. It has been called caterpillar-likein appearance, but its structure is in many respects

FIG. 23.

A Scorpion, Buthus Kochii, from India. and much resembling those of insects in appearance, are hollow, like the "parapodia" of worms. 
The Centipedes have been already referred to. These, with the Millipedes, form the group Myriapoda. In outward form, at any rate, these suggest an intermediate position between Peripatus and Insects.

The true Insects have a definite head, separated from the thorax, and a constriction between the thorax and the abdomen; this is why they are called insects, "cut in two." The thorax bears three pairs of legs, the mouth has typically three pairs of appendages, which may be altered and modified in many different ways, according to the nature of the animal's way of feeding. While the Crustacea are typically adapted for breathing in water by means of their gills, the Insects are adapted for breathing air. This they do by means of their air-tubes or tracheæ, the inlets of which open on their sides. These are divided into fine branches, which diffuse air through the body of the Insect. Two interesting points must be noticed about insects. The first is that they were the first group in which zoologists were able to study the nature of larval forms, long before the microscope had revealed the larval forms of marine animals. The changes undergone by insects are known as metamorphosis, or change of form; and are typically represented by the life-history of a caterpillar, which assumes during the winter a resting form called a Chrysalis or Pupa, and finally emerges as a Butterfly. Insects have sometimes been classified according to the greater or less completeness of the metamorphosis they undergo, which in some cases is comparatively slight. It has been mentioned elsewhere that larval forms usually exist where the young animal is placed 
under very different conditions from the adult. Fig. 24 shows two well-known instances of insect larvæ in which this is strikingly the case, the larval form being a water-dweller, and the adult a winged fly. Of these, one, the larvæ of the Dragon-fly, crawls about free; while the
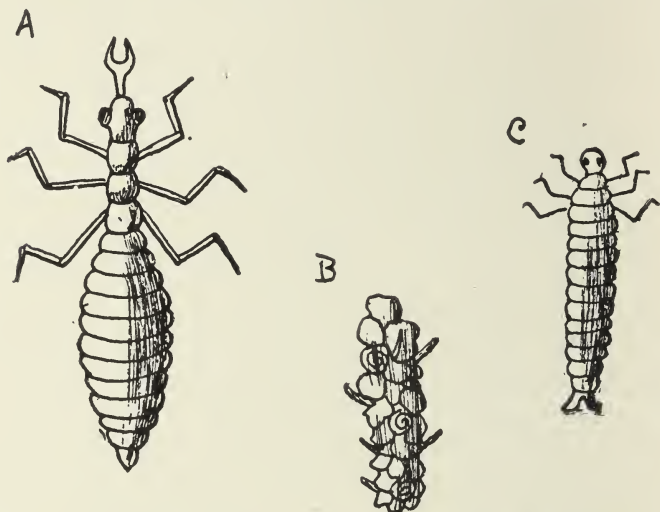

FIG. 24.-Larvæ of insects. $A$, of a Dragon-Fly, enlarged; $B$, House of the larva of the Caddis Fly, natural size; $C$, the Caddis Larva itself, enlarged.

other, the so-called caddis-"worm," builds itself a case of grains of stone and shell cemented together.

The second point of interest is the wonderful part which has been played by insects in modifying the world we live in. We owe the bright colours and the sweet honey of flowers to the selection exercised by insects; they carry the pollen of flowers from one plant to its neighbouring kindred, thus securing cross-fertilization for the advantage of the plant, and thereby perpetu- 
ating any quality, such as colour or sweetness, which has originally attracted the insect to the flower. While a few plants only are fertilised by means of the wind, a vast majority depend entirely upon insects for the cross-fertilisation which is so necessary for the production of healthy seeds. We have already alluded to the part played by the earthworm in preparing the soil. If the earthworm has been the ploughman the insect has been the more intelligent gardener, who has filled the world with bright flowers. The earlier forms of plant life had green and inconspicuous flowers (Cryptogamia); the Phanerogamia, or showy-flowered plants, including all those that bear what are popularly termed flowers, have been produced by the artificial selection exercised by insects long before man was here to admire the result, and to carry on the same work in his gardens. The insect owes its food to the plant world; the plant world owes health and beauty to the constant ministration of the insect; so marvellous is the inter-connexion of one form of life with another.

The number of different kinds of insect is enormous; the number of named species has been estimated at nearly a quarter of a million. It is therefore no wonder that entomology, the study of insects, has claimed the rank of a special science. We cannot here do more than refer in passing to a few of the more familiar types. First of all, by right of its work in fertilising flowers, let us take the Bee. Fig. 25 shows its honeycomb and its larvæ. The bee-grub differs from the caterpillar in its comparative helplessness. It is fed like a child by the worker bees, which are undeveloped females; and it does not 
leave the cell in which the egg is originally placed until it is ready to take on the adult form. The

A

B

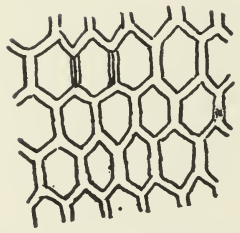
metamorphosis is complete; that is to say there is a grub stage and a pupa stage before the adult stage. There are three kinds of bees-the workers, which are sexless; the drones, which are males, and the queen, who is the sole female of the hive. The bee-grub may develop into a worker or a queen, according to the food it receives as a grub, the grubs that are intended to become queens being placed in a larger cell. The bee-grub differs from the

FIG. 25. $-A$, Larva of the Bee, Apis mellifica; $B$, Section of Honeycomb.

caterpillar in having no feet.

The ants are nearly allied to the bees, and also have a complete metamorphosis. Fig. 26 shows the English red ant, female and neuter. The wings of the female drop off after the pairing season, a
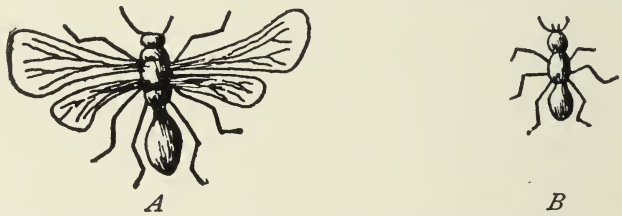

FIG. 26.-Ants, Formica rufa, English, enlarged. $A$, Female ; $B$, Neuter, or Worker.

fact which has given a name, Hymenoptera, to the whole group to which the ant belongs, al- 
though the name is often quite inapplicable. A recent discovery in entomology is the fact that ants have a voice. Dr. D. Sharp of Cambridge has described their "stridulating," i.e. noise-producing, organs. These consist of parallel ridges present on the sides of certain segments. By working the body up and down, the insect scrapes these ridges with the edge of the preceding segment, so that a musical note is produced, intelligible to other ants.

The question has also been investigated by French observers. The principle involved
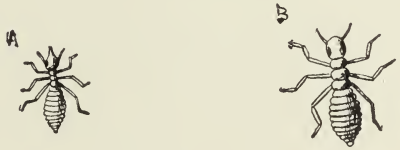
will readily be recognised by those who in childhood were guilty of trying to extract music from a comb.

The white ants, FIG. 27.- White Ants, Eutermes morio, so destructive in tropical climates, from Pernambuco, twice the natural size. $A$, Soldier; $B$, Worker ; $C$, Young male ; $D$, Female. are not true ants, but belong to a different order. These also live in colonies; like the bees, they have an egg-laying queen. She has a partner, the king. There are neuter soldiers and neuter workers, both wingless, while the male and female have wings, afterwards lost.

The Lepidoptera or butterflies and moths receive their name, Scaly-winged, from the beautiful microscopic scales with which their wings are covered. Fig. 28 shows the cocoons which the larvæ of some of the moths make for themselves 
in which to pass their pupa stage. Some are made wholly of silk, others of dried leaves woven

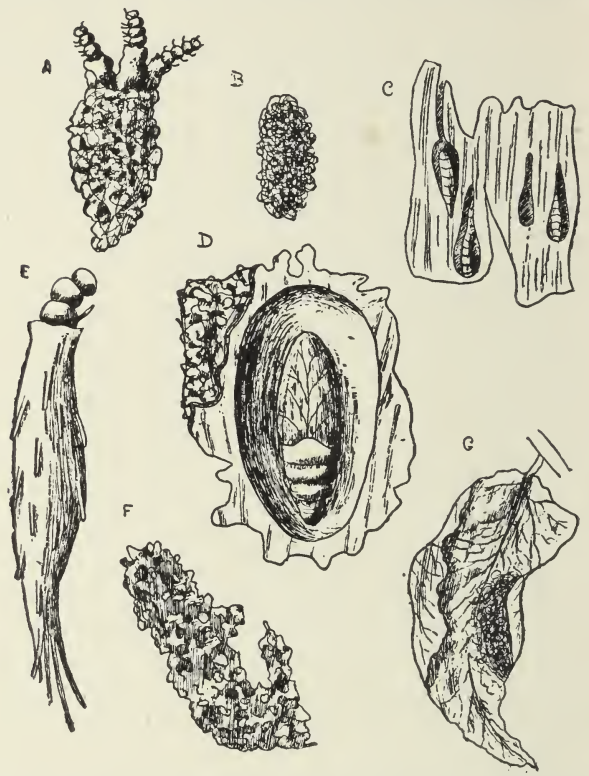

Fig. 28.-Cocoons of Moths. A, Compound Cocoon of Coenodomuc hockingi, from India, one-half natural size ; $B$, of a Silkworm, Bombyx Faponica, one-half natural size ; $C$, of Greenshaded Honey Moth ; $D$, of Death's Head Moth, one-quarter natural size; $E$, of Metura Savendersii, from New South Wales, natural size; $F$, of Castnia Endesmia, from Chili, one-sixth of the natural size ; G, of Attacus attas from Bombay, one-fourth of the natural size.

together. Fig. 29 shows a Moth with its caterpillar, cocoon, and chrysalis. The threads of which a caterpillar weaves its cocoon are famil- 
iarly exemplified in the silk of commerce. The caterpillar, in some cases, is gregarious, and builds a common nest (Fig. 30).

The beetles, Coleoptera, are, like the butterflies, endlessly numerous. They are characterised by the striking difference in their two pairs of wings, of which the anterior pair is strong and horny, and forms, when at rest, a sheath which
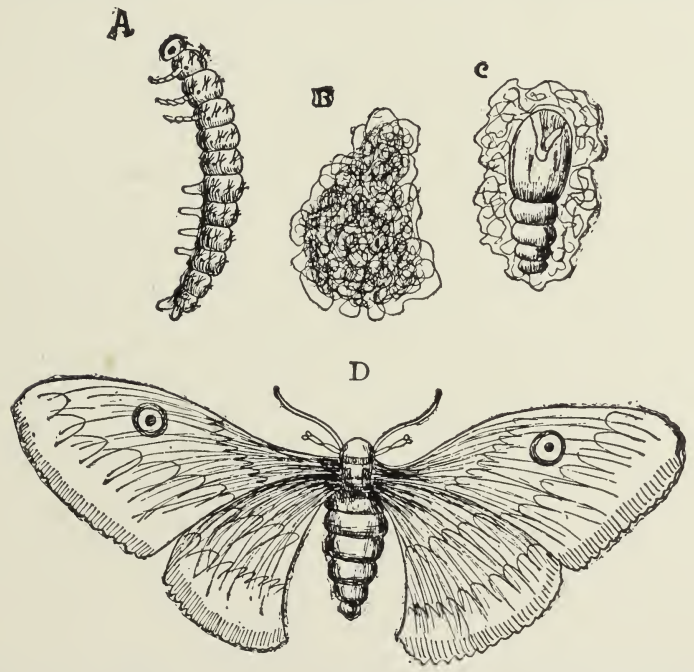

FIG. 29.-A Moth, Saturnia pyri (S. Europe), with its Caterpillar, $A$; its Cocoon, $B$; Cocoon cut open to show Chrysalis, $C$; Adult insect, $D$.

covers the thinner posterior pair of wings. The metamorphosis is complete in this group also. Fig. 3 I shows an example which is typical except in one respect-the adult form, namely, is one of 
the comparatively few instances of adult insects that live in water.

Much has been said above in praise of insects and their wonderful work in selecting flowers.

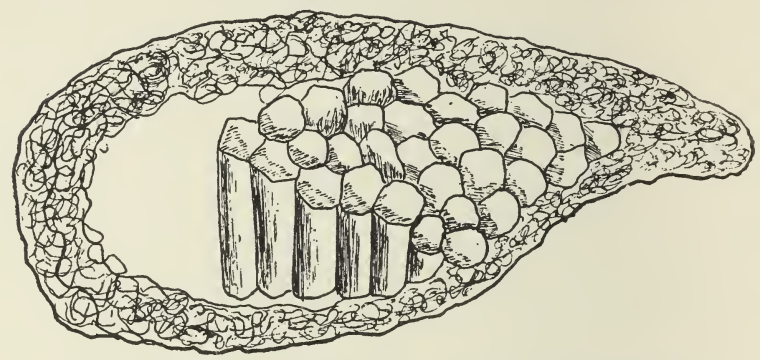

FIG. 30.-Nest of gregarious Caterpillar of a Moth, Hypsoides.

There is, however, another side to this, as the gardener and farmer know too well. While the winged honey seekers help the plants, their larvæ
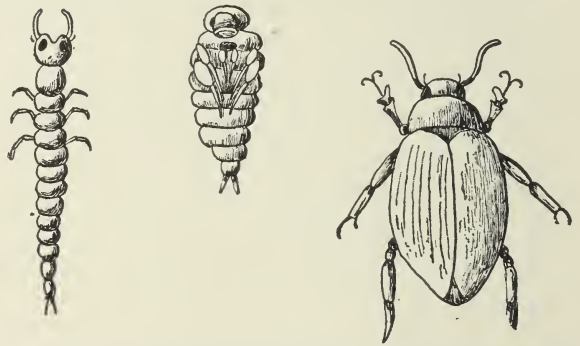

FIG. 31.-Development of an English Water-Beetle, Dytiscus. Grub; Pupa; Adult insect.

devour them, and so do many other forms of insect. Fig. $3^{2}$ gives us in miniature some of the 
most notorious insect pests. The work of the locust has been dreaded since the days of the Pharaohs and before: the Colorado beetle which infests the potato, is a plague as terrible, if more modern. The weevils and caterpillars that destroy trees, though not directly dangerous to our food supply, are sufficiently destructive. The terror of insect pests lies in their vast numbers, which may render an otherwise harmless creature dangerous. I read last year of a curious railway mishap in the United States. A train was brought to a standstill by the wheels sliding on something greasy that covered the track. It proved to be a flock of the so-called "Army worm," a variety of caterpillar which travels long distances in crowds, when its numbers have become too many for the supply of food, or when

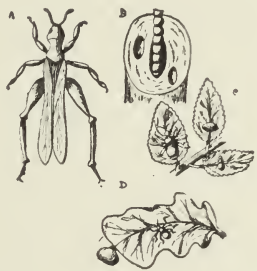

FIG. 32.-Insect pests. $A$, Locust, Acridium peregrinum, one-fourth natural size; $B$, Caternillar of Wood Leopard Moth, Zeutzera AEsculi, boring in wood, about onethirtieth of natural size ; $C$, Colorado Beetle, onefourth natural size; $D$, Leaf-rolling Weevil of the Oak.

it is about to enter into the pupa stage. These covered the railway track, and the whole country for a long distance; and the "greasiness" of the rails was produced by the crushed bodies of the unfortunate caterpillars. The train was delayed for hours, while a gang of men with brooms cleared the way in front of it. 


\section{CHAPTER IX}

MOLLUSCA, THE SHELL-FISH

THE shell-fish are called Mollusca, the softbodied animals. It will easily be seen that this name was intended to point out the distinction between them and the Arthropoda, as regards the way in which the skin is protected. In the latter, as we have seen, the skin itself is hardened. In the shell-fish, the skin secretes a covering which lies outside it. Just as our skins pass out superfluous moisture to the outside, in the form of perspiration, so the skin of the mollusc continually passes to the outside the solid substances which the body has taken in from the sea-water; and by the continual accumulation of these, the shell is formed. This, at least, is the view taken by modern authorities of the formation of the shell in most instances.

The juvenile shell-collector usually begins his knowledge of the classification of the Mollusca, by learning that shells are classified as Univalves and Bivalves. This distinction is useful as a beginning. Univalves, that is to say shells which consist of one piece, are those of the snail-like animals, Gasteropoda, or Gastropoda, as some prefer to spell it. Bivalves, or shells which consist of two flaps, are those of the Lamellibranchiata or animals with plate-like gills, such as the mussel or oyster.

Let us begin with the former. Everybody knows the snail. The snail proper bears a typical univalve shell: though in its relatives (the slugs), the shell is more or less suppressed. The name, 
Gasteropoda (stomach-footed animals), is supposed to be descriptive of the way in which a snail crawls. Half getting out of its shell, so to speak, it does its best to lay its body to the ground, and its so-called "foot" is an extensive muscular expansion underlying its body, not just a muscular organ thrust out of the shell, as in some other groups. The shell, the mode of crawling, and the "horns," tipped with eye-specks, and directed, intelligently and inquisitively, towards things of interest-these make up, for most people, the idea of Snail. But the most distinctive feature of the class is a less obvious feature, namely, the structure of the tongue. We may see, on any damp day or dewy evening, the snail working away with its tongue at some tender leaf. Its tongue is practically a file with which it files away the substance of the leaf, the resulting green mash being thus made ready in minute quantities for the snail to swallow. Thus are made the too familiar holes which disfigure the leaves of plants in our garden. When seen under the microscope, the file-like structure of the tongue is visible; indeed, in large tongues, it may, to some extent, be made out with the naked eye. Across the tongue, which is a flat ribbonlike structure, there runs a pattern of small teeth, bilaterally symmetrical, and this pattern is repeated over and over again throughout the whole length of the tongue. It might be thought that snails' tongues, being so much alike in their mode of use, would not need to be very various in pattern: but far from this, they vary in appearance as much as the shell. Not only is there a different pattern for every different order of the class, but a different pattern for every genus; nay, 
there are even distinctions between the tongues of different species in the same genus. Consequently some authorities on shell-fish prefer to classify them by their tongues, a classification which for the most part holds good. So characteristic is the tongue of the Gasteropod, that when new animals have turned up which were difficult to classify by means of the structure of the body, they have been finally recognised as Molluscs, somewhat related to the snails, by the tongue. This file-like tongue-ribbon of the snails is often called the Odontophore or Tooth-Carrier; sometimes the part which actually bears the teeth receives the name of the radula.

The snail and its relative, the slugs, belong to the Pulmonate (i.e. air-breathing) division of the Gasteropoda. The sea-slugs, in which, like the land slugs, the sheil is absent or reduced, are relatives of the land snails. Some of those found on our own shores are handsome creatures, brilliantly coloured. Both groups fall under the division Euthyneura, while the majority of the marine univalves belong to the division Streptoneura (i.e. Gasterop ods with twisted nerves). The Gasteropods, in the course of the evolution of their shell, have had the body thrown crooked by the burden of carrying it; the Streptoneura are the forms in which this crookedness is most pronounced; in the Euthyneura it is less so. There are degrees of crookedness even among the Streptoneura; and the limpet is less crooked than the periwinkle (see Table, p. 30).

The older classifications of the Gasteropoda were largely founded on the characters of the shell; but these, though in the main they hold good, have required some modifications in recent 
times. Conchology, the study of shells, was at one time the hobby of many collectors whose knowledge of the animals possessing the shells was not of a very extensive kind; and consequently the very name of conchology is often enough to ruffle the feelings of the zoologist of the present day. Yet many interesting problems of variation may be studied from shells alone, by those whose circumstances forbid them to study the living animal. Nor is there any branch of zoology which is more useful to the teacher who wishes to catch the eye and the attention of the beginner in the study of natural history, especially if the beginner is young, as beginners ought to be. Therefore we must by no means undervalue the past labours of conchologists, or the valuable collections which their industry has brought together and set in order for the benefit of the world.

For example of the most crooked, or Azygobranchiate division of the Streptoneura, turn now to Fig. 33, in which we see a typical Gasteropod shell, Murex ramosus, the Branchy Murex, aptly enough named from the many prickly branches which beset it. These rough points are probably assumed for protective purposes; any animal that might wish to dine upon the Murex ramosus would think twice before trying to swallow it - the morsel of shell-fish is so small, its shelly case so large and so prickly. If we look for its nearest English relative, that is Murex erinaceus, the Hedgehog Murex, or Stingwinkle. This, though a comparatively plain shell, has still enough rough ridges upon it to have secured it a comparison to the prickly hedgehog. Perhaps the most prickly member of the genus; 
however, is Murex tenuispina, sometimes called Venus' Comb, because the crowded parallel spines which decorate the elongated front of the shell somewhat resemble

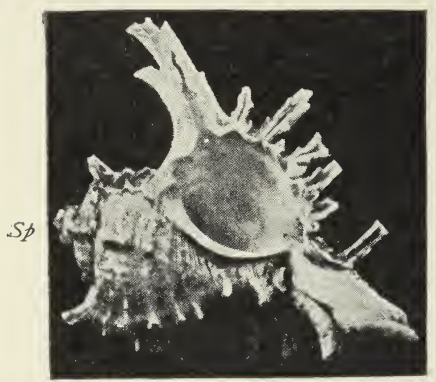

A

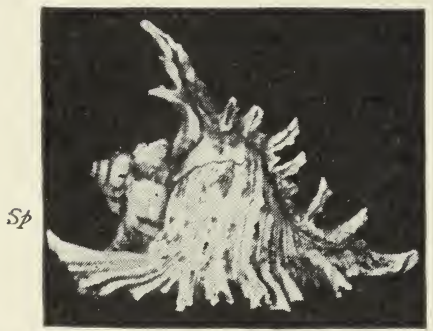

B

FIG. 33.-The Branchy Murex, $M$. ramosus, a typical specimen of the shell of the Carnivorous Gasteropods. $S p$., spire or posterior end of the shell; $S$, siphon or anterior end of the shell. Fig. A, shows the mouth of the shell ; Fig. B, the exterior only. Less than one-half the natural size. the parallel teeth of a comb.

How does the $M u$ rex get its living? Let us notice the shape of the shell, drawn out to a point, at the end opposite to the spire. According to the older classification of the Mollusca, now somewhat fallen out of use, this point marks the shell as belonging to one of the Siphonostomata (shellfish with a siphon at the mouth of the shell, i.e.). These shell-fish are, with few exceptions, carnivorous; not that the siphon shape of the shell has any direct connection with the animal's way of feeding. Just as the snail files among soft vegetable substances, so the Murex and many of its re- 
lations file away much harder things. A Stingwinkle, or a Dog-whelk, can sit down over a helpless bivalve shell-fish, and patiently file away, until it has worked a neat round hole in the protecting shell of the latter. You may find, among the dead shells on any sandy part of the English coast, any number of bivalve half-shells with a neat little round hole in them, indicating unmistakeably how the tenant came to its death. There is some controversy as to the spot chosen by the assailant for its attack. Some authorities have stated that the predatory mollusc is so wise that it knows where to find a weak spot, and makes a hole just over some vital organ of the bivalve, or else above its adductor muscles, so that, when these are cut, the half-shells cannot be drawn tightly together and kept shut. Recently this has been denied, and statistics of the attacks of Purpura, the common small whelk, a relation of the Murex, on Mytalus edulis, the Common Mussel, have shown that the perforation occurs in every part of the shell. It is possible, however, that the Mussel, from the peculiar shape of its shell, offers an exceptional case; and I am inclined to think that in the case of bivalves of a more flattened shape, the earlier statement holds true. At South Shields, England, perforated half-shells of the Common Vemus (Fig. 34) are so abundant that the children string them for necklaces; yet I have never been able, by the most industrious search, to find more than one or two specimens in which the hole is at all near the lip of the shell. It is possible that these exceptional instances were the work of a young and inexperienced univalve mollusc, or a stupid one. It is possible, also, that the mode of attack differs somewhat according to the species 
of the assailant. (It should perhaps be explained, for the benefit of those who have no experience in the ways of children or of shell necklaces, that the hole must be moderately near the beak of the shell, to enable the shell to "sit" properly on a string. Every unit in the necklace may therefore be counted as one in favour of the older theory.)

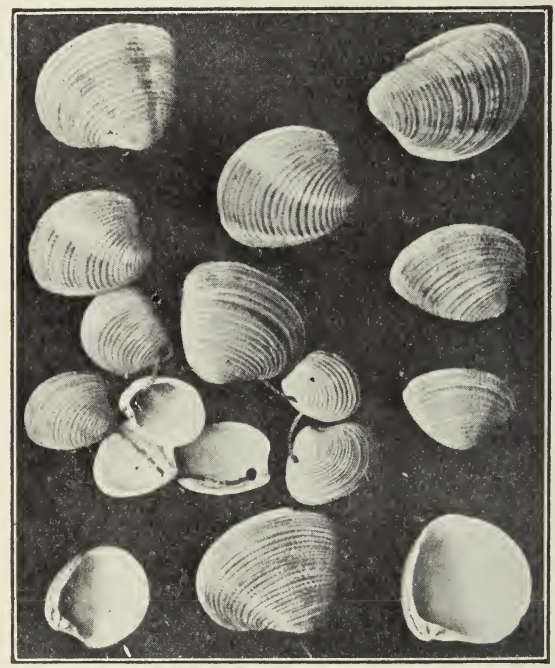

Fig. 34. - Half Shells of the Common Venus, several of them perforated by carnivorous molluscs. From Souch Shields, England.

Many of the Siphonostomatous molluscs are surprisingly active and strong, so that they are well fitted for a predatory existence. In fact, they not only eat bivalves, but occasionally attack the vegetable-feeding univalves when nothing better is to be got, so that occasionally the shells of 
these also may be found displaying the deadly little round hole we have described.

Let us contrast with the Murex one of the shells which are "holostomatous," i.e. possessing an unindented shell-mouth-that is to say, one without a "siphon." The common edible periwinkle, Littorina littorea, may be taken as an example. No shell is more familiar; even the town-dweller, who has never found it on the seashore, has seen it often on stalls in the slums. The mouth of the shell is quite round and unindented, and in this case the character holds good as the mark of a vegetable-feeder-a non-predatory sea-snail. It is hardly necessary to remind the reader that its name (the shore-shell) is given it because it lives where the tide leaves the rocks exposed during part of the day. Another common species of Littorina, which frequently lives a little lower down, where the large sea-weeds grow, has been described in Chapter II.; and another, $L$. rudis, lives a little higher up, so that it spends most of its time in a dry state, and is fast on its way to become a land-shell. At most of the familiar English seaside resorts one may see dozens of it baking in a hot July sun on rocks where only the highest tides can reach them: and yet under these conditions they continue to live and flourish. The periwinkles are remarkable for the great length of the tooth.ribbon, in comparison with the size of the animal. The number of separate teeth upon it has been estimated at 3500 .

A familiar feature of the common periwinkle is the lid or stopper (Operculum), with which the animal can close the mouth of the shell. This is developed and carried by the outside of the animal's foot. In the periwinkle and other Eng- 
lish molluscs it is comparatively soft and semitransparent, and reminds one of a thin slice of horn. In many tropical molluscs, however, it is hard and shelly. The large tropical sheils named Turbo have massive lids of considerable weight. These shells, which are nearly allied to the pearly Top-shells (Trochus) of the English shores, are sold as ornaments, the outer coat of the shell being partly scraped off to show the inner coat of pearl: it is rarely, however, that the purchaser obtains a lid, or even knows that the creature had one. The reverse is the case with some of the smaller kinds, the lids of which, being brightly coloured, are imported without the shell, and sometimes set as articles of jewellery. Some of these are of a bright green hue.

While the lids of the Holostomata are rounded in shape, those that belong to the Siphonostomatous shells are necessarily more or less modified so as to fit the mouth of the shell, and are consequently oval or even claw-like in shape. The Sting-winkle already spoken of, the common small whelk, Purpura lapillus, and the large whelk, Buccinum undatum, are common shell-fish in which the elongated lid may be studied. The lid is not, however, like the tongue-ribbon, an essential feature of the structure of every univalve mollusc.* Not only are there special instances in which it is greatly modified, but also there are whole groups of univalve molluscs in which it is absent.

A curious suggestion has been made with regard to the lids of univalve shell-fish; namely,

* There are one or two exceptional cases of gasteropod molluscs that have no tongue-ribbon. The majority of these are parasitic forms, which can get their food without the trouble of filing it down. 
that the snapping to of the lid is capable of producing a sound, which may perhaps be audible at a distance under the water. Various molluscs have been credited with producing sounds, either by muscular movements or by the grating of the shell as the animal walks. The common Tortoiseshell Snail, Helix aspersa, sometimes makes a most alarming noise when crawling over a window. It has been disputed whether the sounds thus made are produced.by the grating of the creature's tongue-ribbon on the glass, as it files off small particles of algae and vegetable moulds, which are invisible to our eyes: or whether they are sounds due to suction of the muscular surfaces, such as may be produced by drawing a wet finger across glass. The noise, however produced, is, as I can testify from experience, sufficiently loud and weird to be very startling, if heard in the dead of night.

'Turn now to the Bivalves or Lamellibranchiate molluscs, which include the familiar oyster, cockle, and mussel. These are also known as the Pelecypoda, and as the Aglossa, or molluscs without a tongue-ribbon. The name Lamellibranchiate refers to the shape of the gills - " plate-like," or flat; the name Pelecypoda to the shape of the foot, "hatchet-foot."

The animal usually chosen as a type of these, the fresh-water mussel, is rather a dull sort of creature, so we have chosen a prettier and more lively specimen as a representative of the class; namely, one of the Scallops, Pecten opercularis, sometimes called the Quin, the shell of which is shown in the frontispiece of the book. This is one of the most beautiful, perhaps the most beautiful, of the English shells. The generic name, 
Pecten, the Comb-shell, probably refers, not to the shape of the gills, which is somewhat peculiar, but to the marking of the shell, which presents raised ridges, side by side. Anyone familiar with shells will see at once that this is an unusual pattern. There are plenty of bivalve shells with concentric ridge markings, comparatively few with radiating ridges. We shall see presently that there is a good reason for this. The specific name "opercularis," lid-like, refers to the neat round shape of the shell. Each half of the shell has a pair of "ears," so-called. The person who first gave this name to these flaps of shell, three of which are three-cornered and the fourth nondescript, must have been familiar in his youth with books afflicted with the "dog's-ear" disfigurement; for certainly there is no other kind of ear which greatly resembles these. The notch beneath the irregularly shaped ear is called the "byssal notch": many Pectens spin a byssus or thread, like that spun by the common Sea-Mussel, and thus anchor themselves to fixed objects for a time; this notch is the place where threads of this kind leave the shell.

The two valves of the shell differ in depth, one being flatter than the other; and the "ears" of the two valves differ in shape. The inside of the shell shows muscular impressions, but these cannot be seen in a photograph. The picture, however, shows the strong hinge-ligament which joins the halves of the shell, and the difference in depth and shape of the two valves. The valve on which the animal usually lies is the lighter in colour of the two, and has one ear much longer than the other.

The creature swims by means of the "mantle," 
or muscular margin of the body. It contracts this suddenly, after first opening the shell and taking in as much water as possible. Thus the water is squeezed out again, and the effect of this is to propel the animal in an opposite direction.

Now we are in a position to understand a little more about the shape of the shell. These curious "ears" possessed by the two valves, together form a straight, strong edge, which cuts the water as the animal flies along. It reminds us of a ship's prow, and not without reason, for the use of each is the same. A boat's sharp prow, compared with the rounded front of a "tub," makes all the difference in the possibilities of straight steering, and favours the putting on of speed: the ears of the shell are not less useful to our Scallop. The following account of the swimming powers of this species of Scallop, quoted by. Woodward, was given by the Rev. D. Landsborough, who observed young specimens, about the size of the small ones in our picture, swimming about in a pool of sea-water, left by the ebbing tide. "Their motion was rapid and zigzag; they seemed, by the sudden opening and shutting of their valves, to have the power of darting like an arrow through the water. One jerk carried them some yards, and then by another sudden jerk they were off in a moment on a different tack." To the sharp prow, the Pecten owes this capability of arrow-like flight. Its eyes are situated on the fringe of its mantle, and consequently near the wide end of the shell; its peculiar mode of progression, therefore, enables it to back away instantly from any enemy it sees. 
Something must be said regarding the interior of the shell. The majority of bivalve shells have a complicated system of so-called "teeth," or interlocking projections, at the hinges of the shell: these exhibit great variety in different kinds of shell, and are therefore often a ready means of distinguishing one shell from another. The Scallop, however, is very deficient in this respect, as are also some of its near relations, for instance the oyster and its family group. The Fresh-water Mussel also gains its name, Anodon, or Anodonta, the Toothless One, from the same circumstance. The name often puzzles the beginner, who asks, bewildered, "But do Bivalves ever have any teeth?" True teeth, of course, they have none-it is the shell-hinge that has teeth, not the animal inside it. Not only have the bivalve shell-fish no teeth indeed, or tongueribbon, but furthermore they have no head. For this reason the group has not only received the name already mentioned, of Aglossa, the Tongueless Ones, but also that of Lipocephala, i.e. Molluscs in which the head is not developed. The reason of its absence is not far to seeka head would be no use inside such a shell. The snail-shell, so differently built, allows freedom for the head; the bivalve mollusc, squeezed in between its valves, has room only for a mouth.

We have referred above to the ridges on the outside of the shell. Now that we have learnt that the Pecten is a very active animal, and moves in the manner described, we see that these ridges run parallel to the direction in which it moves as it darts away ears foremost. Let us try to realise what is the effect of this.

Take a mat with parallel stripes and move it 
along the floor or table in the direction of the stripes; then try moving it in an opposite direction across the stripes. It is easy to perceive that in the former case one's eye does not detect the movement nearly so soon as in the latter case. To explain this would necessitate a lengthy digression on the subject of optical illusions: that the fact is so everyone may easily ascertain by experiment. The ridges, therefore, converging in the direction towards which the shell is going, are a protective decoration, enabling it to slip away more easily from under the eyes of its foes. The reader will readily recall a parallel instance in the common Cockle. This also is a very active creature; it takes leaps by means of a strong muscular foot; and the ridges on the shell, like those of the Scallop, converge towards the hinges, that is to say, in the direction in which the shell moves. Another instance of a very active shell-fish with similar markings is afforded by certain kinds of Lima, a near relative of the Scallops. It may be added that all Scallops are not equally active, nor all Limas; and various modifications of their form and colour might be pointed out which lead us to suspect that in the less active kinds the pattern of ridges is often somewhat obscured by means of these differences.

Now, take up a comb and draw it over your fingers, firstly along the teeth, and secondly across them, and you will be able to estimate the gain in speed and comfort to the comb-shell, Pecten, and to the common Cockle, from having its ridges set in the direction in which it is going. Were the ridges concentric, as is so often the case in bivalve shell-fish of a more sluggish dis- 
position, the friction caused by the ridges would seriously delay the progress of the shell.

Something must be added regarding the colouring of the shell, which is vivid, corresponding with that of the animal within. It is capable of great variety, though perhaps not so great as in some of the smaller Pectens. The predominant -shades are pink, crimson and yellow, either separately or mixed; that is to say, some shells are pure pink, some almost pure yellow, some almost pure crimson, while others present every imaginable shade of pinkish yellow, reddish brown and brownish crimson. Local variation of colour is so marked that we may suspect the variations in tint to be in some degree protective. The shell also varies considerably in size and strength according to the neighbourhood in which it has grown.

This scallop-shell is but one of many: a number of other species are found on our own shores, and many others again in foreign seas.

One shell of the English coast is very annoying to the juvenile shell-collector who gathers specimens on the shore. This is Pecten pusio, a very small and delicate kind, with a raised pattern of fine markings upon the ridges, which are very narrow. A good specimen of the deeper valve is common enough, but the shallow valve, if of any size, is distorted into all manner of shapes, as if it had been squeezed and crumpled. The disappointing character of these specimens, from an æsthetic point of view, is explained when we learn that it not only lies on its shallow valve, but becomes fixed in this position, instead of hopping about freely like the $P$.opercularis. It therefore has frequently to adapt its shape to the 
nature of the ground where it has happened to fix itself. Thus arises the disfigurement of the shell.

So far we hav ${ }^{-}$only considered two great groups of the Moliusca, two which are represented by common shells, familiar to evervbody. We must not leave the subject of the Mo!lusca without referring to their most aristocratic group, the Cephalopoda. These are represented in museums by the shells of the Pearly Nautilus, and of its not very near relative, the Paper Nautilus; and they are represented on English shores by the cuttle-fishes. All these agree with the Gasteropoda in the possession of a tongue-ribbon, and in classification are therefore treated with them under the name Glossophora.

With the Pteropods, transparent forms found swimming over the surface of the deep sea, the reader is not likely to have much to do. In classification they are now placed near the SeaSlugs.

The Placophora, or Polyplacophora, wholly different from our usual idea of a shell-fish, may be named as creatures which the reader is quite likely to meet with. Though not very common, they are widely distributed over our coasts, and may be found near low-tide mark clinging to stones. Imagine a wood-louse without any apparent head which has taken to clinging to the rock like a limpet, so that it cannot be removed without injury, and you have a rough idea of their general appearance. Chiton is the name of these animals, which have received the group name of Polyplacophora, carriers of many plates, because their external covering consists of an armour of successive shelly plates. These also. 
belong to the Glossophora or Tongue-ribbon Carriers, of which they present a comparatively primitive form.

Reference has already $\mathrm{bc}^{\wedge \sim}$ made to the labours of the earthworm and of the insects, and to their important effects upon the vegetable world. Although the Mollusca include but one terrestrial group, the Snails, they, too, have played an appreciable part in modifying plant life. If we owe our flowers to the insects, we have probably to thank the snail for our medicines. For the snail dislikes bitter-tasting leaves, and lets them alone, thus exercising an artificial selection in favour of the survival of medicinal plants. In the same way the snail has favoured the survival of hairy and thorny plants, upon which it cannot easily crawl.

The larval forms of the Mollusca differ considerably from the adult. That of Anodon, the fresh-water mussel, at first received, in consequence, a different name, that of Glochidium, by which it is still known, although it has now been long identified as a larval form. It is exceptional in the fact that it is parasitic on fish.

The usual Molluscan larva is a ciliated crea. ture which has been compared to a modified trochosphere. It is preceded by a gastrula stage, and it develops later on into what is called a "Veliger," or "veil-carrying" larva, so called because it has in front a broad two-lobed ciliated expansion, the velum. This larva is adapted for swimming, which is accomplished by means of the velum. In terrestrial molluscs, the development is necessarily much more direct. It is worthy of note that the periwinkle mentioned above, which lives high and dry ( $L$. rudis) has 
no larval form, while its relatives that live under water develop in the usual way.

The eggs of Mollusca are often enclosed in tough cases, calculated to resist waves and

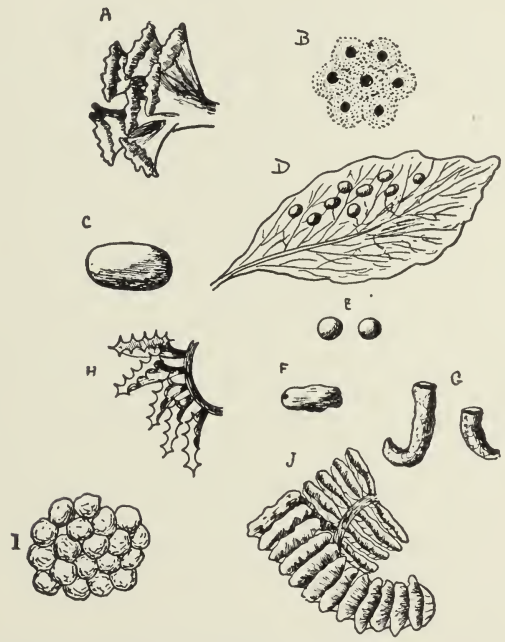

FIG. 35.-Eggs (reduced to half the natural size). $A$, Egg-Capsules of Murex. B, Frog's Eggs. $C$, Eggs of large Landsnail. $D$, Eggs of Snail placed on a leaf. $E$, Cockchafer's Eggs. $F$, Egg-case of Cockroach. $G$, Egg-cases of Locust. $H, I, \mathcal{F}$, Eggs of Gasteropod Molluscs. H, Sycotypus (Pyrula). $\mathcal{F}$, Fusus.

weather. Some of these are shown in miniature, in the group of eggs of various kinds, Fig. 35. 


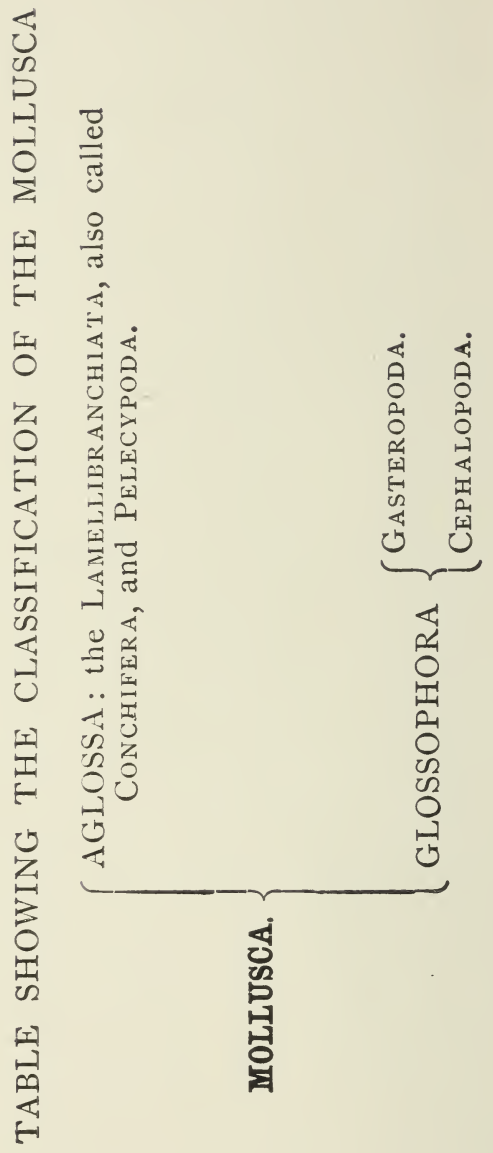




\section{CHAPTER X}

THE BRACHIOPODA OR LAMP-SHELLS

THESE were at one time included under the Mollusca, on account of their possession of a bivalve shell. This shell, however, is placed practically back and front of the animal, not to the right and left of it, as is the case with the shells of the bivalve Mollusca.

The name, arm-footed, was given them in reference to a pair of special structures called the arms, bearing a large number of tentacles; it is now more frequently spoken of as the lophophore (see p. I22), and regarded as comparable to the lophophore of the Polyzoa, spread out into two portions. With the latter group the Brachiopods were formerly united by Huxley, under the name of Molluscoidea. This name is now obsolete, because it is understood that all these creatures are widely different from Molluscs; but the theory of relationship of the Brachiopoda to the Polyzoa, implied in it, still holds good.

The chief importance of this group lies in its fossil forms, which are exceedingly numerous, particularly in the Mountain Limestone of the Carboniferous Period; it is crowded with their shells, especially a form named, from its elongated shape, Productus. The shells of Brachiopods are equal-sided; that is to say, the right and left valves match; but they are inequivalve, the ventral valve being much the biggest. It often contains a foramen, or hole, at the beak, for the passage of the pedicle, or stalk, by which the animal is attached to the ground (e.g. Tere- 

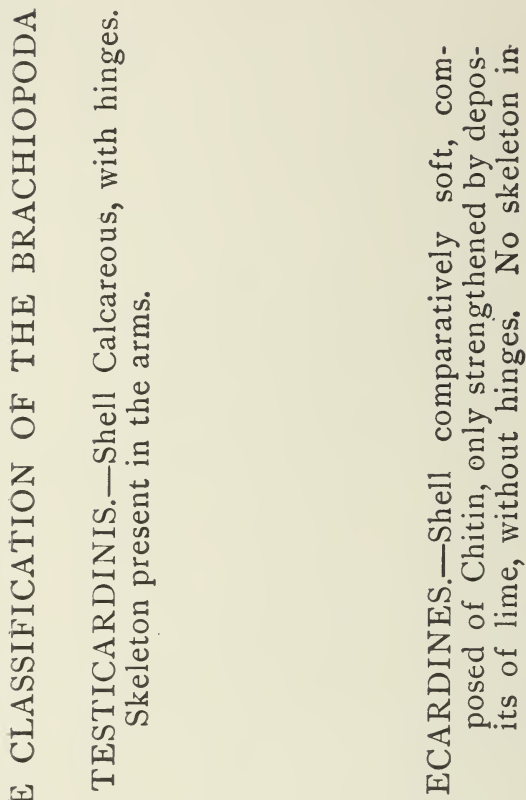

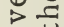

चै के

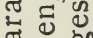

ชี

리을

ชำ

焉

记焉

|이

ขं घี

[I] 0 .

Z च

บ 0 ता

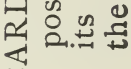

단

0

[I]

告

논

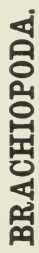


bratula, Rhynchonella). Sometimes, however, the pedicle passes out between the valves (Lingula, e.g.), in which case there is no foramen; or it may be arranged in other ways. Sometimes the shell is merely attached to the ground by its side, like an oyster. Some forms are enormously widened in a lateral direction, e.g. Spirifera, and the Productus above named. Lingula, among others, is remarkable as being a form that has survived from the earliest geological period to the present day.

The larva, in its best known forms, passes through the typical larval stages of the animal kingdom. It is first a one-layered larva, then a two-layered form, and then becomes a ciliated animal. In this three regions may be distinguished, representing respectively the head, body, and pedicle.

The shells of the Brachiopoda, including the kinds above named, may be seen by the reader in any geological museum.

\section{CHAPTER XI}

THE POLYZOA; MOSS-CORALS AND SEA-MATS

We have already described the creatures which are popularly known as Corallines. Modern zoologists have long separated off from the Corallines of the older writers, a group of animals known as the Sea-Mats, which also are colonies made up of unit individuals. The common SeaMat, Flustra foliacea, may be picked up on almost any part of the English coast, being often 
torn up "by the roots" and washed in by the tide. When fresh it has a pleasant scent, which has been compared to that of Lemon Verbena, and a pinkish colour, due to the presence of the little inhabitants in their cells. When dry it has no odour, the cells are empty, and the colour a pale drab like that of a dead Coralline. Its texture is, however, much more crisp and brittle, and less horny, than that of a dead Coralline: it grows in flat, forked expansions, much resembling in outline the fronds of several common seaweeds; and each side of these is covered with a diamond pattern of little cells. This crowded arrangement of the cells, with a tendency to assume a geometrical pattern, is the readiest feature by which the beginner may distinguish a Sea-Mat from a Coralline. The latter arrange their cells in a free-growing, tree-like or fernlike form, without any crowding of the units into a geometrical pattern. The division of the flat leaf-like colony by two, resulting in bifurcated branches, is another obvious feature of the Sea-Mat.

Covering-and to the botanist's eye disfiguring - the branches of many sea-weeds, and growing upon oyster-shells, tangle-roots, and other fixed objects, we may find many little incrustations which remind us of the lichens of the land: the diamond pattern of little cells shows us, however, that, these things are relations of the Sea-Mats. The name of Bryozoa, Moss-Corals, was formerly given to these growths, Many of them bear long hairlike processes at regular intervals; these, which are large enough to be plainly seen with the naked eye, afford a ready means of recognising these creatures.

The Polyzoa include freshwater as well as 


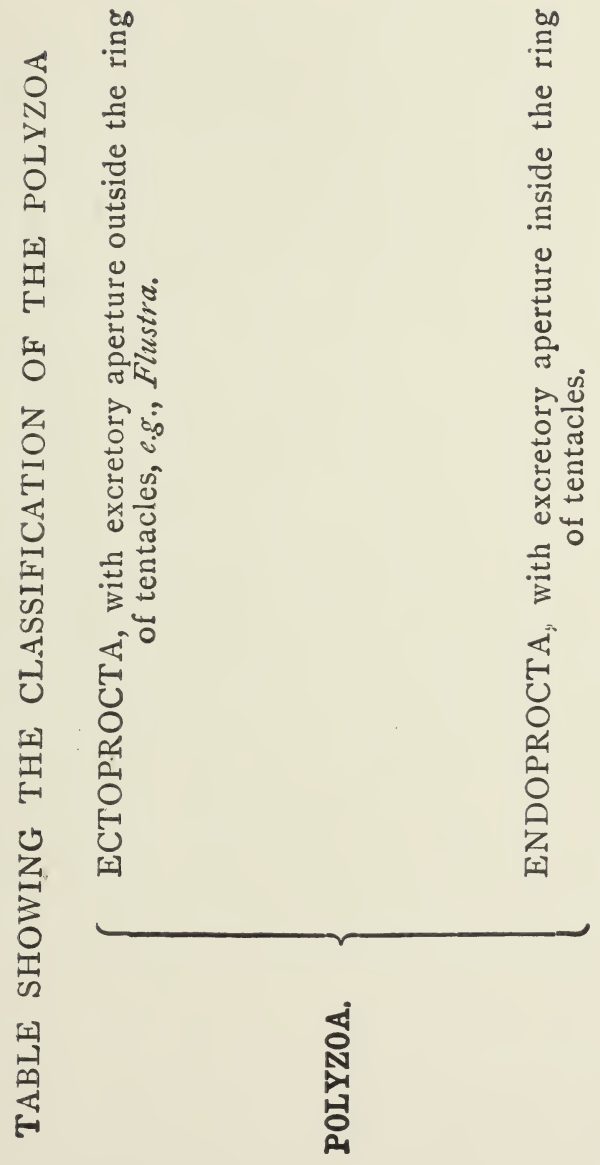


marine forms. They have a free-swimming larva, which becomes fixed after a time, and gives rise to the adult Colonial forms. The zooids of the latter have each an independent head with a crown of tentacles, called the Lophophore (Crest-carrier) ; but the fixed ends of their bodies communicate with one another. The hard covering of the colony, which retains its form after the animal is dead, is a kind of hardened skin: the apparent "cells" are the openings through which the individual zooids protrude themselves. Sometimes certain of the zooids undergo modification for special purposes: in this way are formed the "avicularia," snapping appendages, probably defensive in purpose, so called because they open and shut like a bird's beak. There are two divisions of the Polyzoa, the Ectoprocta and the Endoprocta. Among the latter there is found a form which is not colonial.

Phoronis, a curious worm-like animal, which has a larval form called Actinotrocha is sometimes placed in classification near the Polyzoa, which it resembles in possessing a crown of tentacles (Lophophore).

\section{CHAPTER XII}

THE ECHINODERMATA

Everybody knows the Star-fish and many people know the Sea-Urchin. An "urchin" is not a name for a naughty little boy, but the French (oursin) for a hedgehog. A Sea-Urchin is therefore a "Sea-Hedgehog," a name very appropriate 
for a creature armed with prickles. The Greek word echinos also means a hedgehog, so that the long name given to the group means simply hedgehog-skinned. The prickles attain their maximum in the Sea-Urchin, but they are well represented in the Star-fish, while in the Seacucumber the general tendency to "prickliness" is much reduced, and represented only by "spicules" (needles) of shelly stuff underneath the skin of the animal.

The largest and the most beautiful of the SeaUrchins of the English coast is known as the Purple-tipped Sea-Urchin, on account of the beautiful colour of the spines. It lives on rocky coasts, and during very low tides may be seen at home, although it usually takes care not to stray above the water-line. It is a shelly ball with a flat base; its surface is covered with long spines. Its mouth, which is in the centre of the base, shows five wicked-looking teeth peeping out. The shell is pierced by what look like hundreds of minute pin-holes, arranged in a complicated pattern; these are the holes through which it pokes its feet, which greatly resemble those of a Star-fish, being white suckers with a disc at the end. When thrown out to their full length they are, however, much longer than those of the Starfish, for they are naturally obliged to be thrown out to a distance longer than the length of the animal's own prickles. When moored by all its feet, extended from all sides of the shelly ball, the animal presents a curious and pretty sight. Large specimens are almost as big as a child's head, but smaller ones are more common. There is a considerable range of variation in colour; not only are various shades of purple found, but 
also purplish-red and red. The spines are mounted on something resembling a ball and socket joint, with a ring-shaped pad, so that they have a wide range of movement; if any of the spines are touched they are immediately set back over a considerable part of the neighbouring surface.

Other kinds may be found upon a more sandy shore. These are heart-shaped and much lighter in colour. The shell is thinner and of less weight. These adaptations for lessening the animal's weight enable it to move over sand: the species above described has no occasion for such precautions. When it crawls over rocks ard the strong seaweeds that grow on them, there is no fear of its sinking in. The sand-dweller, on the contrary, must take care that it is not swallowed up.

There are Sea-Urchins that carry their precautions against sinking to an extreme degree. These are the Shield-Urchins or Clypeastridæ, so-called from their flat shape; they include the American forms popularly known as "sandcakes." The diagram (Fig. 36) shows one of the most curious of these flattened forms adapted for moving over fine sand and ooze, and literally "as flat as a pancake." The mouth is approximately in the centre of the lower surface, $B$; the upper surface, $A$, shows a rosette pattern on the top of the shell. This is formed by the rows of holes for the very minute tube feet. In the English Sea-Urchin above described, which is one of the group called (for that reason) Regulares, the rows of holes are uniformly continued all along the rounded sides of the body down to the neighbourhood of the mouth. Here they are much re- 
stricted, forming merely a rosette at the top of the shell: hence they are described as circimscript or "petaloid." The excretory aperture is shown in the photograph as a smaller dot on one side of the mouth, while in the Echinus, on the contrary, it is at the top of the shell. The five odd-looking, elongated holes are a curious indi-

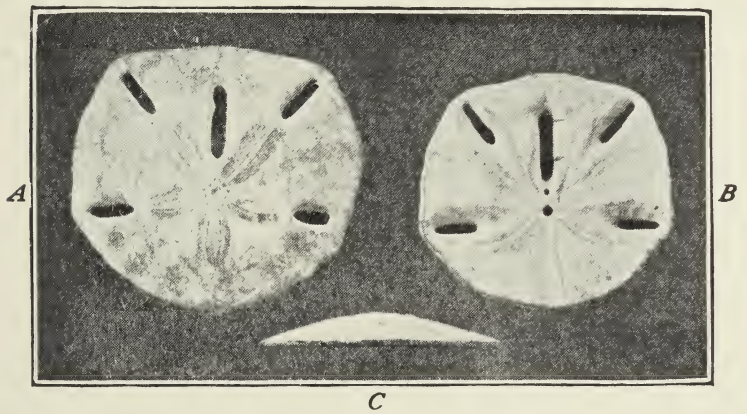

FIG. 36.-The Five-holed Sand Cake, Mellita pentapora, a flat sea-urchin from the east coast of tropical North America. $A$, upper surface; $B$, lower surface; $C$, side view.

vidual peculiarity of this Sea-Urchin. It has already been explained that the Shield-Urchins are flattened in order to distribute their weight; these holes are a contrivance for still further reducing the weight in comparison with the area. This is when the animal is lying quiet at the bottom of the water, but when it moves about what effect will the presence of the holes produce? Flattened animals are usually supposed to derive an advantage from the fact that they sink more slowly through depths of water; as in lying upon the ground, their weight is distributed, and they 
float, as it were, in the same stratum of water without sinking further down. 'This creature, on the contrary, has apparently feared lest it should move too slowly when it moves in a vertical direction, and it presents us with an arrangement by means of which its sinking through water is facilitated. Water will pass readily through the five holes as the animal goes either up or down, and the resistance of the whole flat area to the water is thus reduced and vertical movement rendered more easy. Thus, by one and the same contrivance, the animal has lessened its weight when lying quiet, and diminished the resistance it meets with when it moves. The distribution of the holes, moreover, is such as to regulate the animal's position in sinking, and to prevent it from falling "headlong." For although the creature has, strictly speaking, no "head," yet the end nearest the mouth is the thickest and heaviest part of the "cake," and would naturally tend downwards. This tendency is counteracted by the fact that the thicker end is unperforated, while the thinner and lighter end has a large central hole to diminish its resistance and enable it to $\sin \mathrm{k}$ more rapidly.

Adapted for living in sand rather than on rocks, but not so extreme in the peculiarity of their form as the Shield-Urchins, are the HeartUrchins, already referred to, shaggy-looking creatures whose fine yellowish-white spines give them almost the appearance of being clothed with fur. The excretory aperture is at the narrow end of the "heart," and the mouth at one side of the lower surface towards the wide end. The complicated apparatus of teeth found in other Sea-Urchins is absent in these. They are 
abundant on sandy shores. During the severe winter of $1894-5$, when the Mersey at Liverpool was frozen nearly for one memorable day, and filled with floating ice for many more, I saw the shore beyond New Brighton heaped all along with a bank, often two feet across, of the common Heart-Urchin. These, which afforded a fine feast for the hungry sea-gulls, had been killed by the intense cold, and afterwards washed ashore by the tide. The vast numbers of this creature which exist on that coast were thus unexpectedly brought to light.

These animals are sometimes described as "burrowing" creatures, because they live covered in sand. The term is rather misleading. Far from wishing to burrow, they spend their lives in a constant struggle with sand that closes over them only too readily; and their whole structure is adapted to prevent their sinking in a quicksand.

We began our chapter with the Sea-Urchins, because they are the most important members of the group to which they give their name; but there are forms belonging to the Echinodermata that are more familiar to the ordinary observerthe Starfishes. Those who take an interest in the cultivation of the oyster find them far too familiar -for the starfish is the oyster's deadliest foe, not even excepting man.

The common Starfish, Asterias rubens, may constantly be found among stones, about lowtide mark. Its manner of walking is peculiar and characteristic. On the under surface of each ray are rows of white sucker-like tube-feet, which can either be drawn in or pushed out. By doing each alternately the animal walks. First the feet are extended to their full length; then the terminal 
sucking disc of each catches hold of the ground. Then the feet are again retracted, while their discs still cling; the effect of this is, naturally, to pull the ray onwards. This process is repeated again and again, until some appreciable degree of movement is effected. The tube-feet are in connection with a system of vessels filled with fluid, known as the Water-vascular System of the Starfish. The fluid is driven on by muscular contractions until the feet are fully extended, and again driven back when the feet are retracted. The Water-vascular System is a structure common to all Echinoderms; and vessels of a comparable character are found in some worms.

How does the Starfish know where it is going? Underneath each ray, near the tip, is a little feeler (or tentacle) and a little eye spot. By means of these it gets an idea where each ray is going to; and, since it often moves but one ray at a time, this is sufficient for it. When necessary, however, the several rays can act in concert with one another.

The rayed form of the Starfishes led to their being at first included in the group of Radiate Animals, along with the tentacle-bearing Cœlenterata; but it has long been recognised that they are animals of much higher structure. Their very larvæ can barely be brought into comparison with animals so simple as the true "radiates."

The Snake-Stars, or Ophiuroidea, are closely allied to the Starfishes. In these the arms are thin and sharply defined from the little central disc, instead of sloping gently out of it, as in the Starfishes. The rapid wriggling movements of the arms have gained for them their very appropriate name. They are also called Brittle Stars, 
because the arms break off easily, sometimes at the will of the animal. Several kinds of them are common on our shores, although they are not so common as the ordinary Starfishes. Fig. 37 shows the general form of a Brittle Star.

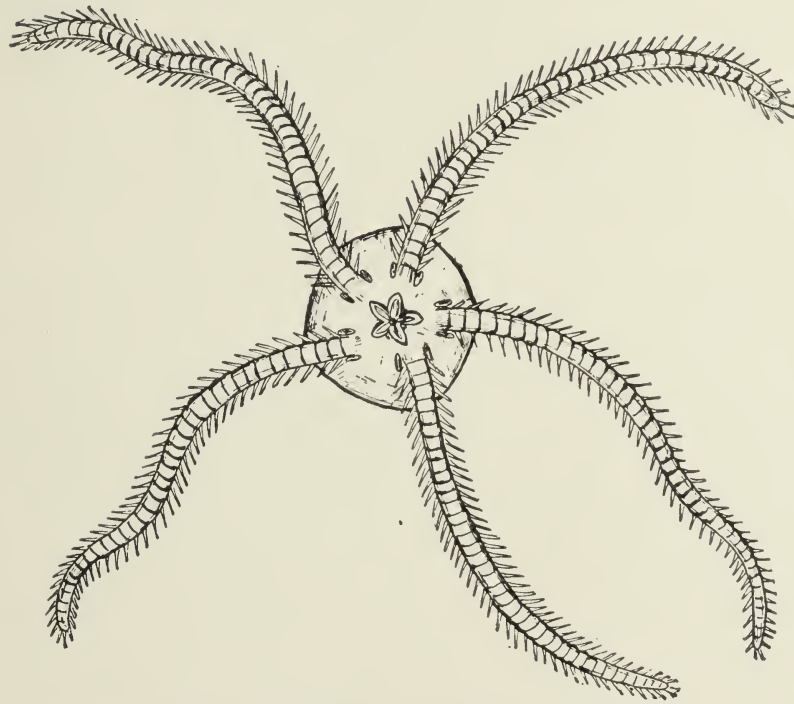

FIG. 37.-A Brittle-Star, Ophiopteris antipodum.

The Sea-Cucumbers, Holothuroidea, are another group of Echinodermata that are represented on our own coasts; by small specimens, however, while the Pacific Ocean furnishes instances of larger size-the Trepangs-which are used by the Chinese as articles of food. The name Sea-Cucumber is given in fanciful compari- 


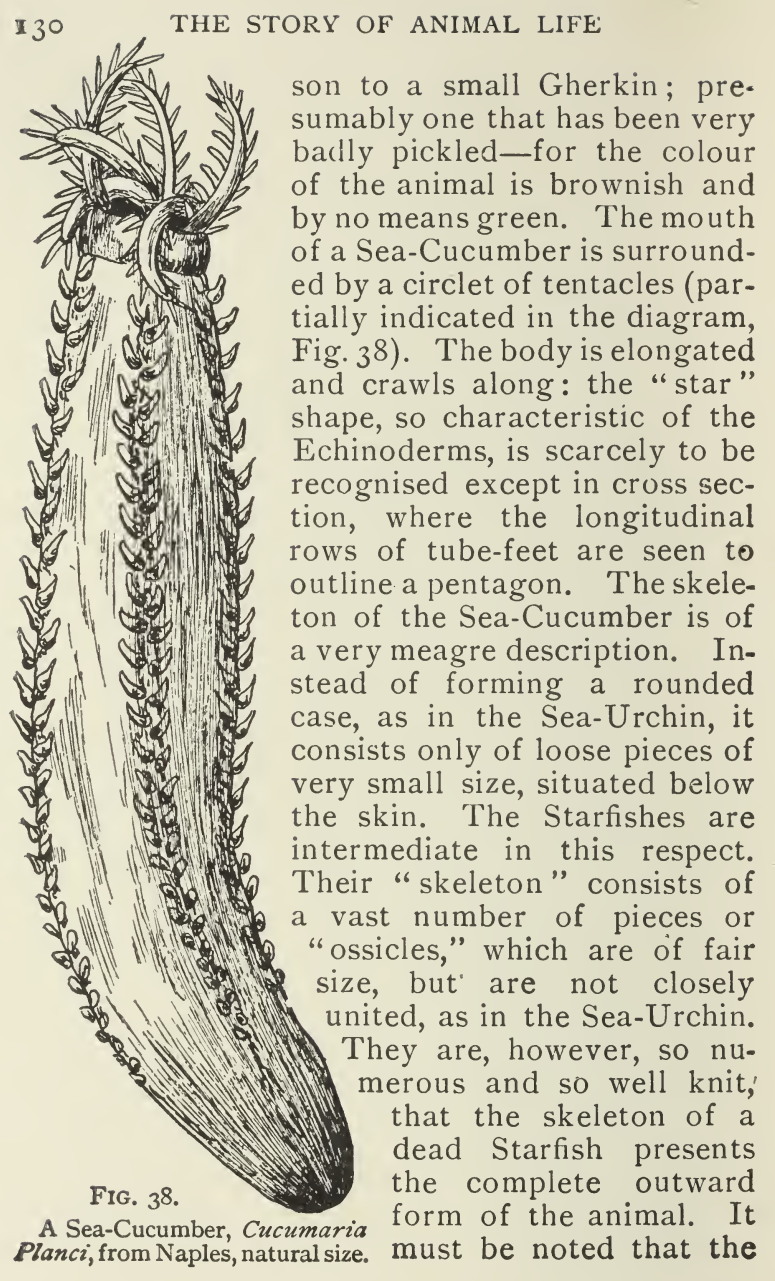


ordinary skeleton of the Sea-Urchin is only apparently exterior. As is the case with the ossicles of the Starfish and Sea-Cucumber, the skin lies out. side, and the hard particles belong to the middle layer, or mesoderm. In this the skeleton of Echinoderms differs from the "shell" of a crab or lobster, which is formed by a hardening of the skin itself.

The Crinoidea, Encrinites or Stone-Lilies, form another group of the Echinodermata. Though still represented by living forms, they attained

A

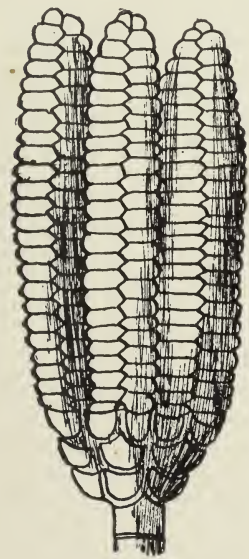

B

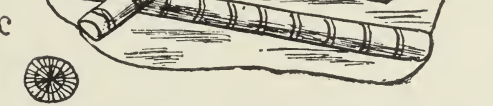

Fig. 39.- $A$, Head of a Stone Lily or Encrinite, Encrinus liliformis, a fossil from the Muschelkalk of Brunswick, natural size. $B$, Rock with stalks of encrinites. $C$, Section of a stalk.

their maximum development in past ages. The English "Mountain Limestone" of the Carboniferous period is full of their fossilized remains, which form a marble often used for ornamental purposes. The so-called "Stone Lily" consists of a "head" comparable with the body of a Star- 
fish or other Echinoderm, which is borne at the end of a long fixed stalk. 'The marble above named owes its ornamental appearance to the presence of these stalks, often very long, and cut through at every possible angle. The Crinoids have their living representative in English Seas,

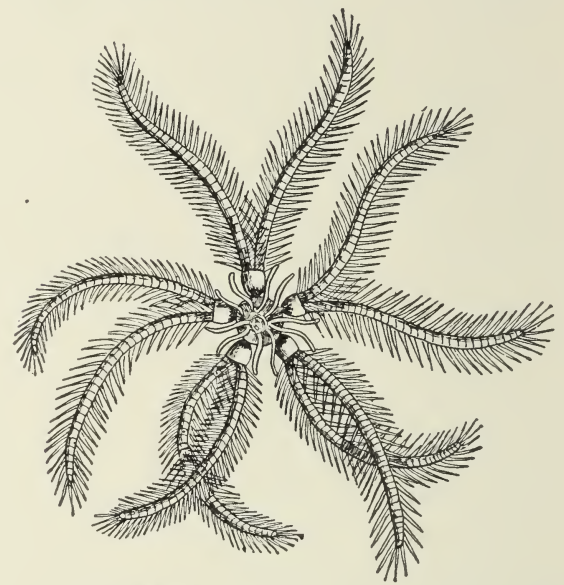

FIG. 40.-A Feather-Star, Antedon bifida, British Seas, threequarters of the natural size. The short threads in the middle are the cirrhi.

Antedon, the Feather-Star (Fig. 40). On the side opposite the mouth, where, in the Encrinite, the stalk would be, there are a group of elongated processes called cirrhi, by means of which the animal can attach itself to stones or seaweeds. When not thus fixed, it swims about, by moving its fringed arms, each of which is forked. It will be seen that when the animal is fixed by its cirrhi, it stands mouth upwards, so that its position com- 
pared with thaf of the Starfish or Sea-Urchin is upside down. The young of the Feather-Stars have stalks by which they are fixed, like the Encrinites; but afterwards the stalk is lost.

Among fossil Echinoderms there are two groups of stalked forms which have no living representatives. These are the Cystoidea and the Blastoidea. In both of these the stalk bears, as in Encrinites, a calyx or head, which is comparable, with the body of the free Echinoderms.

The Sea-Urchins possess a swimming larval stage, which goes through remarkable changes after passing out of the two-layered (Gastrula) form. It becomes provided with cilia, which are arranged in bands, and outgrowths of peculiar form are established in the case of the Sea-Urchins, while the larvæ of the other groups also present characteristic shapes. Within the larva the adult form develops, the outside of the larva being finally thrown off.

In the young Feather-Star, a subsequent stage of the young animal has a stalk, by which, like the Encrinite, it is fixed. This animal therefore is at first free-swimming, afterwards fix ed, and again free in its final stage-a remarkable series of changes.

These queer-shaped things, the Sea-Urchins and their allies, are perhaps the last creatures amongst which we should think of looking for relations of the Worms. Yet the eariest stages of the larva are considered to present a certain amount of resemblance to the Wheel-ball larva, which has been referred to elsewhere (pp. 42 and 72). Still more startling fact, these larvæ have been compared to that of Balanoglossus, the lowest member of the Chordata, and a relation of the Vertebrates themselves (see p. I43). 


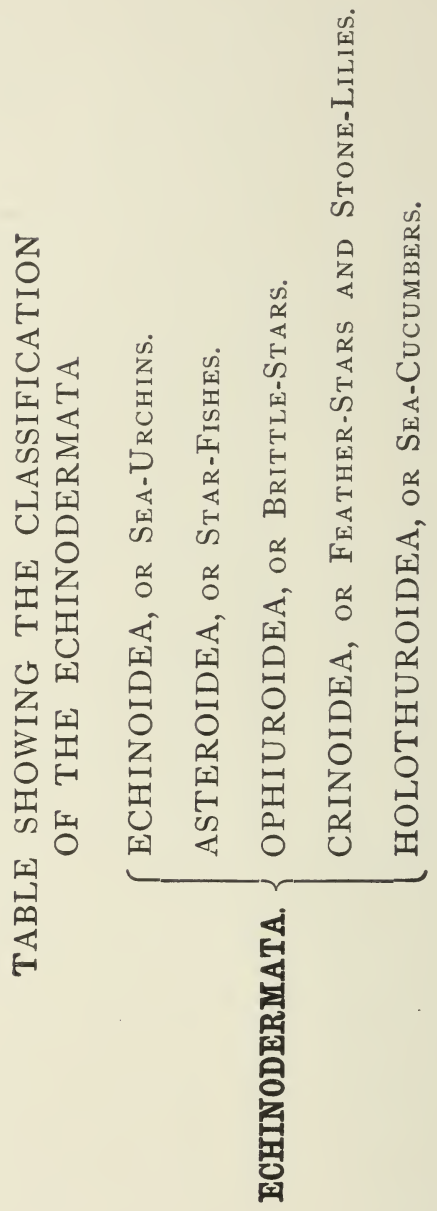




\section{CHAPTER XIII}

THE CHORDATA

THE older zoologists used to speak of Vertebrata and Invertebrata as animals with a backbone and animals without one, and everyone thought it a very natural way of dividing up the animal kingdom. It never occurred to anyone that it was possible to bridge the interval between them and find a link between the two. But now the Vertebrata have been compelled to give up their aristocratic pretensions, and own that they have risen from the ranks of the common people of the animal world; in other words, that they are descended from the Invertebrates. Their family secrets have been published to the world, and now everybody knows that they have poor relations. But how many, and how nearly related? This we do not accurately know; consequently the whole zoological world for many years has concentrated all its energies on attempts to find out the truth about the matter.

A great sensation was caused by the first discovery of a poor relation of the vertebrates among the Ascidians, or Leather-bottle animals. These are named from their shape and texture, for they have a leathery skin. Now some of these Ascidians have larvæ with a tail; and in the tail there is a long cord-like structure, which in many essential particulars resembles the cord which precedes the back-bone in the vertebrate embryo. This structure is called the Notochord (a string down the back). The credit of this 
great discovery belongs to Russia; for the presence of the Notochord in the Ascidian larva was discovered by A. Kowalevsky, in I 866 .

To the present generation of zoological students, the Chordate affinities of Ascidians are part of the A B C of knowledge; and it is hardly possible for them to realise that it is only thirty years ago since the idea was so new that Huxley, in his "Text-book of the Vertebrata," only alluded to it in a footnote. Would-be zoological critics, at a somewhat later period, met the theory with ridicule, for want of better argument. For critics include not only "those who have failed in literature and art," but also those who have failed in science.

The majority of the Ascidians are sessile animals, which fix themselves, like Sea-Anemones, to some object when they have passed their earliest stages of growth; and although there are many forms that swim freely, most authorities are inclined to believe that these have arisen by adaptation, and that the kinds that are fixed when adult are the original type of the group.

Anything more unlike what we should expect to find as a relative of the vertebrates could not possibly be imagined. What has been written about these little animals by various observers would make a whole series of volumes of the size of this one, so many are the puzzles afforded by their internal structure. The arrangement of their organs is in many respects very unsymmetrical. Their most striking peculiarity, perhaps, is the nature of the gills. These form a kind of basket-work, consisting of minute holes with intermediate supports; and they are associated with a special cavity outside them called 
the Atrial chamber. Into this the gills pass the sea-water which they have breathed.

The group, as a whole, is sometimes considered to present evidence of having degenerated from a higher type; but whatever else may be doubtful or obscure in its history, the nature of the larval notochord is quite clear and certain; zoologists have never had any doubt about its nature since the first few years after its discovery.

Ascidians are not at all uncommon animals on the English coast. Some of them may be met with on stones near low-water mark, and I have often seen them on the shells of oysters sold in the shops-for there the town-dwelling naturalist may often find a good many interesting things without much trouble. They are like little lumps of tough jelly; of various colours, according to the kind, red being the most common, and of very indefinite shape. You may see some of the colonial kinds forming pretty star-shaped patterns, attached to various objects, such as stones and the larger seaweeds.

The place of Ascidians in classification was a puzzle, until their relationship with Vertebrates was discovered. At one time they were placed with the Mollusca. Now they are grouped, together with the Vertebrata and some other creatures that remain to be spoken of, under the name of Chordata, or animals possessing a Notochord.

Some of the Ascidians present what has been already described in other types (p. 57) as "alternation of generations." The discovery of this fact was made by the poet Adelbert von Chamisso. Some of his verses are known to English readers, for whom they were translated by Mary Howitt, 
a poetess whose writings were popular with our grandmothers, and deserved to be so. This is not the only case in which a poet has been also a zoologist: Goethe studied the science, and framed a theory regarding the vertebrate skull, which he regarded as consisting of a series of vertebræ. In this he was less fortunate than the Italian poet ; for while Chamisso's observations were correct, and were confirmed by subsequent writers, Goethe's theory of the skull is anything but correct. It was made worse, too, by the speculations of subsequent writers, who attempted to follow it into detail, with the result of demonstrating its absurdity.

\section{CHAPTER XIV}

T H E VER T E B R A T A

WE have spoken of the Notochord as a structure which precedes the formation of the spinal column in Vertebrates. This needs a little more definite explanation. We all know that the spinal column of vertebrates is formed to protect the spinal cord. This protection is, however, an afterthought, so to speak, of the vertebrate structure; the lowest of all vertebrates is quite without it; and in the lower groups of fishes we may trace various steps of its formation. But in these cases where the spinal column is absent or incomplete, there is a large and well-developed notochord; and in the embryo of higher vertebrates, when the spinal column has not yet begun to be formed, the notochord is equally a conspicuous feature. 
It runs from the region known as the mid-brain, to the end of the tail, and lies throughout just

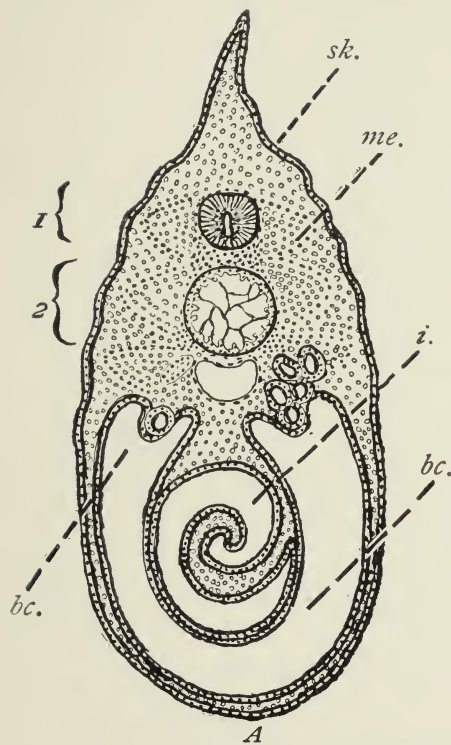
beneath the spinal cord. Whatever its original use in the

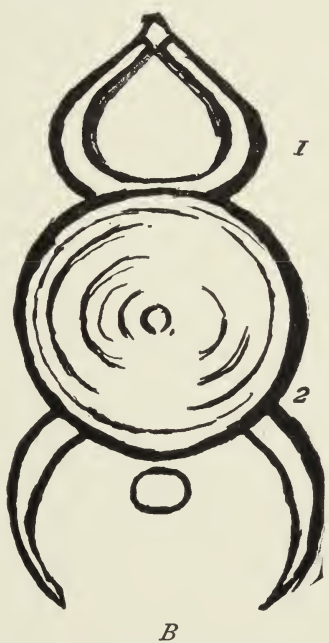

FIG. 4I.- $A$, The Notochord of Vertebrates. Section, considerably magnified, through the middle of an embryo one inch long, of Acanthias, one of the Spiny Dog-fishes allied to the sharks. I, Section through Spinal Cord; 2, Section through Notochord; below it lies a bean-shaped space, which is a section through a large blood-vessel ; $s k$, epiblast or skin ; me, mesoblast or middle layer of the body ; the dots represent the nuclei of its transparent cells. The intestine, $i$, lined with hypoblast, is traversed by a spiral valve, and surrounded by the horse-shoe shaped body-cavity. $B$, Diagram indicating the position of the Notochord in the vertebra of an adult Common Dog-fish (Scyllium canicula). I, "Neural arch" of the vertebra, consisting of processes of bone enclosing the central nervous system, or spinal cord ; 2 , bony centrum of the vertebra. hollowed out into a cup, in which lies a soft pad, the remains of the notochord. 
animal body may have been, it undoubtedly acts now as a support to the spinal cord, and indeed to the whole body. Bones, we must explain, do not exist either in the lower vertebrate, or in the early embryo. In the latter they are formed by degrees. The spinal cord and the notochord each begin to be surrounded by rings of cartilage or gristle, which by degrees is changed into bone. The rings surrounding the notochord, however, gradually encroach upon it and obliterate it. The place where it has been becomes the Centrum, or most solid part of each vertebra. The notochord at first is continuous, and has no division into successive parts; but when the bony spinal column is developed, it consists of a series of successive vertebræ. Each of them is made up of several parts, which by degrees become consolidated into the vertebræ.

The lowest member of the vertebrate group, separated in fact from the true vertebrates and placed in a lower division all by itself, is the little animal called the Lancelet or Amphioxus. It is often spoken of as a "fish"; but it is only by a stretch of our courtesy that it can receive that name, being an animal of a much lower form than the fishes. It was discovered in 1834 , in the Mediterranean, and described as a fish; but it had previously been discovered in 1778 , by a German naturalist who described it as a slug. The latter was misled by its external shape. He had not the advantage of the modern methods of preparing animals for examination under the microscope; in these days, Amphioxus is cut into successive slices along its whole length, and each of these carefully magnified, so that no detail of structure is lost. The Amphioxus burrows in the 
sea-sand; it lies buried in it, with its mouth just uncovered. Its food consists of microscopic vegetable organisms. Its distribution is very wide; it is found in both the Atlantic and $\mathrm{Pa}$ cific waters. It occurs most abundantly in the salt-water lakes of Sicily, and in the Gulf of Naples. The specimen first seen, in $\mathbf{I}^{\prime} 778$, came from the coast of Cornwall. There are eight species; the one which is found in the English Channel is the Amphioxus lanceolatum, also found in the Mediterranean and on the shores of North America.

The classes of the Vertebrata are Fishes, Amphibia, Reptiles, Birds and Mammals. We used to learn that of these, fishes had gills, and Amphibia gills for a time; but, to be strictly accurate, we must say that fishes have gills, and all the rest of the Vertebrata have gills for a time. There is no exception to this rule, not even among the highest vertebrates of all. But in those vertebrates which stand higher in the scale of life than Amphibia, viz., Reptiles, Birds, and Mammals, these gills are never brought into use. They only exist in the early embryo, and afterwards disappear, giving rise by their modification to other structures.

Strange to say, one of these structures is the ear. This takes its origin from one of the gill"clefts" or spaces. The Eustachian tube, which communicates between the ear and the nose, is part of this cleft; and the little bones which are inside the ear represent the bones of that gill. cleft. For, in fishes, bones support each gill, and are connected together to form a complex arrangement. In the higher vertebrates, which possess gills only in the embryo, this gill-skeleton 
is much modified, and persists as a bone, the hyoid bone supporting the tongue.

The gills of vertebrates, arranged in successive pairs along the throat, are "perforating gills"; that is to say, they consist essentially of holes or spaces which pass right through the wall of the throat.

If we were to seek for a general character of the vertebrates, besides those mentioned above, that they all possess a notochord and gills, we might also find it in the character of the skin. Fishes, Reptiles, Birds and Mammals, all agree in this, that they have a special clothing of the skin-scales, feathers and fur, respectively. These three kinds of structure, although so widely differing in appearance, are practically formed all in the same way, viz., by alternate ingrowths and outgrowths of the skin; the ingrowth forming the root of the scale, hair or feather, and the outgrowth its projecting part. If these infoldings and outgrowths of the skin could be straightened out into a plane surface, the skin of a small vertebrate would cover an enormous area. The above list excludes the Amphibia: in this class, it should be mentioned, the scales have been lost, and are only found in one group.

The scales of Fishes were at one time proposed as a basis of classification: large groups being characterized respectively by the possession of plain rounded scales (cycloids), scales fringed at the posterior end (ctenoid, or comb-like); placoid scales, consisting of bony plates, and ganoid scales, large plates covered with shiny enamel. These distinctions, however, were not found useful as a guide in classification. The diagram shows the elaborate scales of the common sole. 
Let us now consider some other creatures that resemble vertebrates in some ways, and help to form the group of Chordata. Balanoglossus is one of them, the Acorn-tongue Animal. This odd name is given to it on account of a

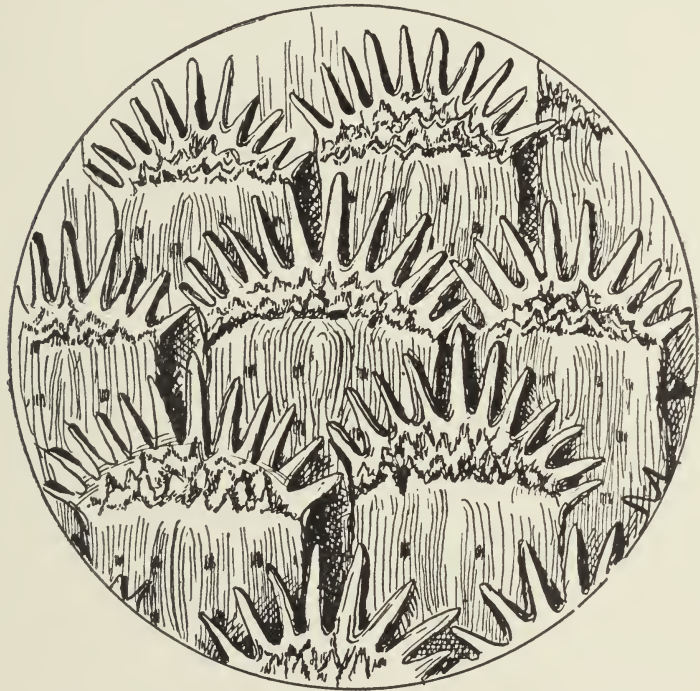

FIG. 42.-Scales of the Common Sole, highly magnified.

structure which is called (like the elephant's trunk) a Proboscis; this may be compared with a tongue, so far as its use goes, for it is thrust out to catch prey and again drawn in. It is oval in shape, and therefore fancifully compared to an acorn. It is highly sensitive, being richly supplied with nerves. The creature is to all intents 
and purposes a kind of worm; and, like many of the higher worms, it has a larva with bands of cilia. This larva, which is better represented in some species than in others, was originally described under the name of Tornaeria. It is considered to resemble, in some degree, the larva of Echinoderms; on this hint, some zoologists have sought to establish a connection between Vertebrates and Echinoderms, and have been able to find other points of comparison besides the one named. It remains to be seen whether this suggestion will lead to further results. It may be added that the larva of Balanoglossus has also been compared with that of Phoronis (p. I 22), thus assuming a relationship with the Polyzoa, and through them with the Brachiopoda. It appears, therefore, that the subject of the possible relationships of the Vertebrata is one of the greatest complexity. The last named theory, however, has been adversely criticised by very high authority.

We have not, however, explained yet what is the claim of Balanoglossus to be grouped with the Chordata. This consists in the fact that a certain part associated with the interior of the proboscis has been identified, from its structure, mode of origin, and relations with the nerves, as a notochord. Balanoglossus also agrees with the true vertebrates in possessing successive pairs of perforating gills (see p. I42), which are especially noticeable in the young animal. The presence of this feature is important, in view of the fact that some authorities have sought to throw doubt on the genuineness of the notochord of Balanoglossus.

Balanoglossus is not without relations, some 
of which have been recently discovered, while others have been known for some time, although their affinities were not at first recognised. Among these the most remarkable are sessile forms which have received the names respectively of Cephalodiscus and Rhabdopleura. Both produce buds and form a colony, and in both a notochord has been distinguished. The former was procured from the Straits of Magellan, while the latter makes its dwelling-place in a nearer region, having been found off the Shetland Islands, and off the Lofoden Islands. Cephalodiscus, which is a very curious creature, receives its name from a disc placed at the head end. The use of this structure is believed to be as follows. The units of the colony live inside a common system of tubes, which they secrete; each unit, when adult, is independent, and can move about inside the tubes; the disc is used as a means of attachment to successive spots of the tube-wall, as the animal wanders from place to place. Above the disc are twelve plume-like tentacles covered with cilia, which create a current in the water surrounding the head, and wash food particles into the mouth.

That these creatures are but distant relations. of the true vertebrates is a fact expressed by the names under which they are grouped in classification. Those forms which we have just described have received the name of Hemichordata - that is to say, Chordata which have but half a notochord, since the notochord is very restricted in extent; while the Ascidians are grouped under the name of Urochordata, or Chordata which only possess a notochord in the tail. The name of Adelochorda, "with an obscure chord," is, sometimes applied to the Hemichordata. 


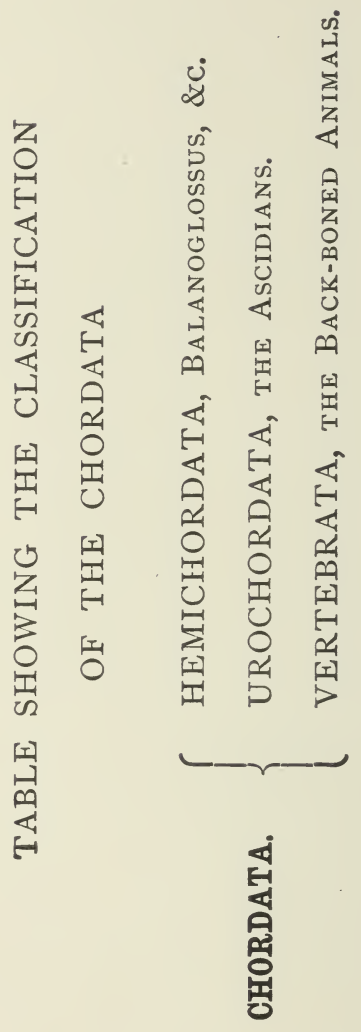


Let us return now to the Vertebrate. A character common to all the groups of the Vertebrata is the possession of teeth. Readers of the previous volumes of this series will recollect that, even among birds, instances of the possession of teeth may be found among fossil forms, although they are absent in the birds of the present day. In all the other divisions of the Vertebrata, the presence of teeth is the rule, their absence an exception so rare that we may easily note the chief instances of it. Among Amphibia, there are Toads that have no teeth; among Reptiles, the Tortoises and Turtles have none; among Mammals, teeth are wanting in Echidna, the Spiny Ant-eater; and in the Ant-eaters and the Whalebone Whales they are absent in the adult, although present in early embryonic life.

The majority of people, if asked to give a definition of the meaning of teeth, would reply that they are hard structures that grow in the jaw. But this is an idea that requires very considerable modification from a scientific point of view. In the first place, they are found in other places besides the jaws; and in the second place, they are by rights structures originally belonging to the skin. Both these important facts must be illustrated by reference to the Fishes, which exhibit the primitive types of teeth.

In fishes, not only are teeth found on the jawbone, but sometimes also on other bones which border upon the cavity of the mouth; they are found on the palatine bone, or roof-plate of the mouth, and, still more strange, upon bones which belong to the "hyoid apparatus," or skeleton of the gills (see above). The latter may form a set of throat-teeth, which are used for grinders, while 
the jaw-teeth are used for biting. Among the Carps, the jaw-teeth are reduced, and the fish depends upon its throat-teeth only. In the Wrasses, one pair of the bones that bear throat-teeth (the inferior pharyngeal bones) are fused, so as to form a stronger apparatus: and from this circumstance, the group of Fishes to which they belong has been given the name of Pharyngognathi, fishes possessing throat-jaws. They have, however, biting teeth as well, in the true jaws. The grinding teeth are apparently used for consuming the food in a leisurely manner when once it has been taken into the mouth.

A curious circumstance in connection with these "throat-jaws" is, that they produce musical sounds. Fishes have other means, however, of producing a voice-usually by means of the swimming-bladder and muscles in connection with it. Probably they are able, to some extent, to effect communication with each other in this way.

It has already been stated that teeth, in their primitive form, are to be regarded as skin-structures. Certain fish, which are looked upon as ancestral types, have, dispersed throughout the skin, a number of bony plates, or granules (placoid scales), more or less formidable, and tipped with a hard enamel-like substance. Teeth are regarded as but a special form of these. But if they are skin-structures, how come they in the mouth and throat? Because the mouth and throat are lined by an ingrowth from the external skin; the origin and growth of this is seen in the embryo.

In the Mammalia the teeth, though restricted in number, attain the greatest possible variety of form, so that the jaws of different but allied species may be distinguished by their teeth. 
Let us now return to the lowest vertebrate of all, which has a large notochord and no bones. This is the Amphioxus, the Lancelet. Amphioxus has no bones whatever, and no head, in the sense in which we usually employ that term; that is to say, most of the structures which we see in the vertebrate head are undeveloped. The peculiarities of the structure of Amphioxus are many. Among them may be named the curious gills: these form a sort of basket-work along the sides. of the throat, which at first sight bears little resemblance to the gills of fishes, and reminds us of those of Ascidians. The gills lead also, as in Ascidians, to another cavity, the Atrial chamber. This basket-work is formed, however, by the subdivision of the primary pairs of gills. These are very numerous, ninety pairs being sometimes. named as the number. They cut up the wall of the throat to such an extent, that additional supporting bars are needed to strengthen it; and, by the formation of these, both in parallel and in transverse directions to the primary partitions, the "basket-work" is produced, as the growth of the animal proceeds.

The primitive nature of the notochord is, however, perhaps the most striking feature of Amphioxus. The chord passes to the front of the animal's snout-head it can hardly be calledinstead of ending in the middle of the brain, as in true vertebrates, for there is, indeed, no "brain " of any extent to lie in front of it ; and the notochord, together with the spinal cord itself, have no other protection than a fibrous sheath. The spinal column is thus entirely absent, except so far as it may be regarded as represented by this. thin sheath. 
The Lancelet also differs from the true vertebrates, in that it has no limbs. There is a fringing fin along the body, but it is not comparable with the fins of fishes. It differs also in possessing no teeth.

In one respect, however, the Lancelet reminds us of a fish: and that is in the arrangement of its muscles; these form a successive series of overlapping masses on each side of the body, as in a fish.

The development of the Lancelet presents us with an instance of the two-layered larva, or Gastrula. This shows that Amphioxus is a comparatively primitive type. But it has been suspected that it is less primitive than it looks, and that it has degenerated from some higher form, owing to its preferring a dull mode of existence, half-buried in sand or mud.

There is a huge gap between the Lancelet and the true vertebrates. The lowest form of the latter is Ammocates, the larva of the Lamprey (Petromyzon). The latter, even in the adult form, has no true limbs, though there are fringing fins. The notochord sheath is supplemented, however, by cartilage bars which are equivalent to the beginnings of the vertebræ of the back-bone. The gills are very different from those of other true vertebrates, and it has no jaws. Teeth it has, however, on the tongue and the lining of the mouth. Probably this creature is greatly altered by adaptation to its peculiar mode of life, so that no certain conclusions can be drawn from it regarding the structure of primitive fishes. It has a sucking mouth, by means of which it hangs on to fishes, while it rasps away their flesh with its rough tongue. When not thus engaged, it hangs on to 
a stone by means of its suctional mouth, thus fixing itself at rest. The Hag-fish, Myxine, in many respects similar, devours dead fishes chiefly. The Hag-fish is found on English coasts: so is the Marine Lamprey; while two freshwater forms are found in streams.

Leaving the Cyclostomata, as the above fishes are called, we reach the true fishes, which have limbs and scales. Something has already been said regarding their teeth and gills. The Cartilaginous fishes, in which most part of the skeleton remains gristle and does not become transformed into bone, include the Sharks, Rays, and Dog-fishes, all savage animals with strong teeth. The common spotted Dog-fish of our own shores is familiar to everybody: fishermen regard it with disgust, as it is not eatable. The Rays are flattened fishes, which live at the bottom of rather deep water, and attain enormous size even on our own coasts. The Thornback Skate is covered with prickles (placoid scales). All these fishes are grouped under the name of Elasmobranchii, the Strap-gilled, so called from the structure of the gill-arches.

The majority of familiar fishes, such as the herring, mackerel, cod and sole, belong to the group of Teleostei, or Bony Fishes, in which, by contradistinction from the last group, as much of the skeleton as possible becomes bone. Nevertheless, traces of the notochord persist in the back-bone of these fishes. Break the back-bone across, of a cod or a sole, and you will find between adjacent sides of the centra, or middle parts of the vertebræ, a pad of gristly substance. This is the remaining substance of the notochord, which finds room between the cup-shaped sides of 
the centra. When the centrum, instead of being biconcave, is solid, as in the higher Vertebrata, the notochord is obliterated by its encroachment.

The Amphibia, familiarly represented by Frogs and Toads, receive their name, "adapted for both lives," from the fact that they usually divide their lives between land and water. They are, from one point of view, the most interesting of the classes of the Vertebrata, for they form a dividing line between the lower and upper Chordata. Below we have Hemichordata, Ascidians, Amphioxus, Fishes; all water-dwellers, breathing by gills. Above, we have Reptiles, Birds, Mammals, air-breathers, never possessing gills, except for a short time, as rudiments in the embryo, not brought into use. They are linked by the Amphibia, in which we see the larva a water-dweller, breathing by gills; the adult, an air-breather, adapted for life on land, and obliged to come to the surface to breathe, even when it passes its time in the water. The individual Amphibian tells us the past history of the higher groups; once they had gills-but growing older, they lost them.

Fig. 43 shows us an outline sketch of Amphibian larvæ; we should require an enlarged diagram of an earlier stage, to show the gills, which are external and projecting at first, but afterwards are overgrown by the skin with the exception of an orifice on each side. The dia. gram shows the gradual change of form. The tails in these tadpoles will presently be lost, for they belong to the Anura, or tail-less order of Amphibia (Frogs and Toads). The tailed Amphibians, Urodela, are represented in Great Britain by the Newts, Triton, popularly called 
Efts. Belonging to the Tailed Amphibians also, is the Axolotl, a creature found in the lakes of Mexico, and in those of the Rocky Mountains.
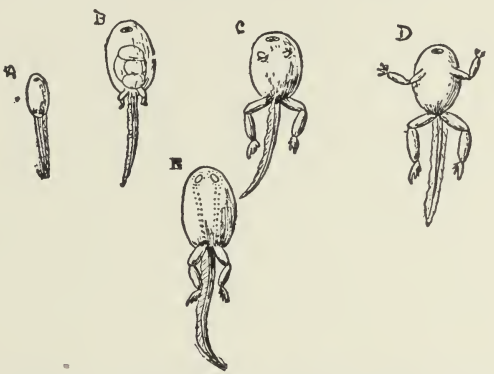

Fig. 43.-Tadpoles, three-quarters of their natural size. $A$ to $D$, different stages of the Tadpole of the Common Toad, from Epping Forest, England. E, Tadpole of Pelodytes punctatus, dorsal view.

It may or may not retain its gills; and forms with gills, and forms without, may be found in the same lake, each capable of laying eggs. The two forms were at first described under two different generic names: but when specimens of the gill-bearing Siredon, kept in confinement, lost their gills, it was seen that they became Amblystoma. There are other cases of larval forms that produce young, and this curious occurrence is known as "pædogenesis."

The Amphibia include the curious creatures called Cæciliæ (blind animals), or Gymnophiona. They are snake-like in form, and are without limbs; they burrow underground. Their real place in classification was not found out at first, but they were classed, by a wrong shot, with the Reptiles. They are interesting as being the only 
Amphibians that have scales. These are very minute, embedded in the skin, and arranged in transverse rings. The name Gymnophiona, naked serpents, is therefore doubly inapplicable: for they are not serpents, and not scaleless.

The Reptiles and Birds at first sight seem to be widely different. The latter are the warmest blooded of all vertebrates, the former are coldblooded. The one wear feathers, the other scales. Nevertheless, there is an intimate connection between them; the reader has doubtless already learned from other sources the facts about their relationship, so we will not here do more than recall a few of these facts. One is, that the birds of earlier times had teeth in their beaks, and possessed jointed tails. Another, that the Reptiles of earlier times included forms that were able to fly. A third notable fact is the presence of claws on the wings of some birds, showing that the wing of the bird was not always wholly specialised for use in flight.

We owe to Professor Huxley, the recognition of the close relationship of Birds and Reptiles, and the name Sauropsida (Reptile-like animals), under which both are included. They agree in being air-breathers and never having gills, except the rudiments present in the early embryo: this distinguishes them from Amphibia. They agree in having the skull set on to the back-bone by a single articulating surface or condyle; and thus differ alike from Amphibia and from Vertebrata. They agree in having the red corpuscles of the blood nucleated; and in this differ from the Mammalia, in which the red corpuscles are nonnucleated discs. From a popular point of view, we may say that the striking distinction between 
birds and reptiles lies in beauty and ugliness. Even in their eggs, the reptiles display no love for adornment, no colouring or pattern. Fig. 44 . shows the eggs of some reptiles.
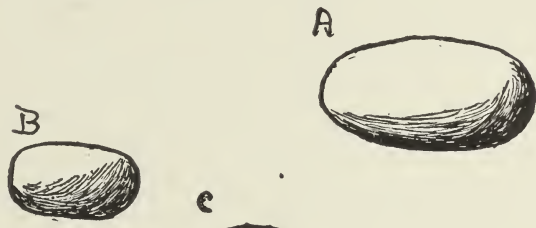

$\epsilon$
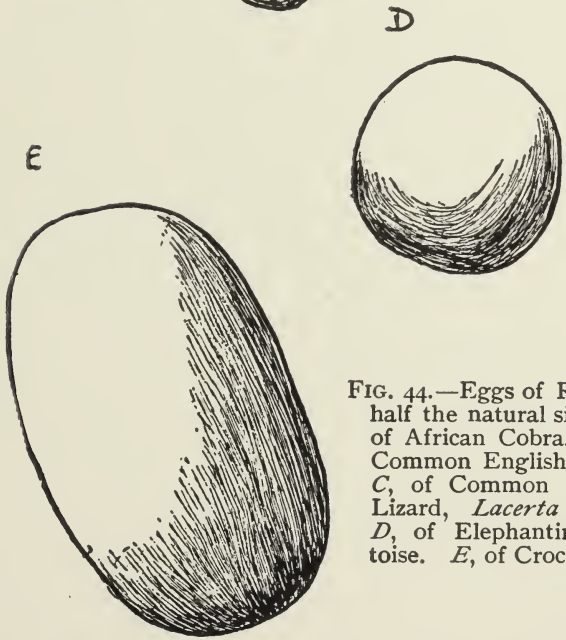

FIG. 44--Eggs of Reptiles, half the natural size. $A$, of African Cobra. $B$, of Common English Snake. $C$, of Common English Lizard, Lacerta agilis. $D$, of Elephantine Tortoise. $E$, of Crocodile.

The five chief groups of existing reptiles are the Chelonia (Tortoises and Turtles); the Rhyncocephala, represented only by Hatteria, a lizard 
found in New Zealand; the Lacertilia or Lizards; the Ophidia, or Snakes and Serpents; and the Crocodilia.

Perhaps the most interesting point regarding the reptiles that can be mentioned in brief space, is the fact that they present traces of a median third eye, which have been described by Baldwin Spencer, in the New Zealand Hatteria, and in other reptiles. It is situated on the roof of the brain. While the structure in Hatteria shows it to be an eye, its position corresponds with that of the pineal gland of vertebrates generally; so that we find, in fact, the trace of a third eye in all vertebrates, including ourselves. It is, however, a trace only. In the Lamprey fishes as well as in Hatteria, it reaches a further degree of development. This pineal eye has been compared in structure to the eye of Ascidians.

The Birds, excluding the extinct form with teeth and a jointed tail, to which the group name of Archæornithes is given, fall into two groups. These are the Ratitæ, or Birds with Raft-like, i.e. flat, breast-bones, and the Carinatæ, or Birds with keeled breast-bones. The former include the African Ostrich (Struthio), the American Ostrich (Rhea), the Australian Emu, the Cassowary of New Guinea, and the Kiwi, or Apteryx of New Zealand; all of them birds that cannot fly. The vast majority of birds belong to the Carinatæ, characterised by the projecting keel (Carina) in the middle of the breast-bone. The presence of this, which affords a safe attachment for strong muscles, is associated with the power of flight. It is impossible to treat the birds more fully in the space allotted to this little 
story, but a few words about feathers, however, may find a place here.

The colour of feathers is a subject of much interest. Everyone is far. liar with the brilliant tints often presented by the feathers of birds, and everyone who is a close observer of natural objects knows that there are some feathers which are iridescent, changing colour according to the direction in which light falls on them. It has been shown by Dr. Gadow that this variation of the colour of a feather is due to its structure; this may be described as prismatic, for the small divisions of the feather present acute angular edges, which reflect the light like the edges of a prism. These are symmetrically repeated all along the feathers, so as to reflect the same colour throughout. Thus in the plumage of the common red and green parrot, we see feathers that are red when held in one position, and yellow when shifted to another position; while there are also feathers that are blue when seen in one position, and green when seen in another; the alternative colour being the one next in order in the rainbow.

Another point regarding the colours of feathers has no doubt puzzled many of our readers; and that is, the metallic quality of the colouring in some exceptional feathers, and in these only. The feathers of the parrot just referred to, are, for instance, simply red and yellow, or blue and green; but the feathers of the peacock, though displaying the same colours, show a metallic lustre which is wanting in the other case. The feathers of the starling, the blackbird, and the black hen of the farmyard, though not so brilliant as those of the peacock, are the same 
as regards the quality of the light they reflect. The secret of the difference lies in the greater opacity of the feathers named; they are black feathers, while those of the parrot are lightcoloured. Now after the metals themselves, there are few objects in nature so opaque as the black pigment of a black feather. If a thin section through the roots of young black feathers is cut for examination under the microscope, the pigmented parts, although cut so very thin, appear completely opaque. And just as a glass gives a better reflection when backed by something opaque, so does the reflecting surface of the feather. Hence it is that the quality of the colours reflected by these feathers is what we call "metallic." If we ask for a definition of this metallic brightness, other than the accepted fact that it resembles the light reflected from metals, the artist will reply that it consists in two things -(I) the greater brilliancy of the light reflected, that is to say the greater completeness of the reflection; and (2) the entire absence of those gradations of light which are afforded by the reflections from any object, however dark, that possesses a surface translucent, even in the smallest degree. "Metallic" reflections, in fact, may be defined as those in which the greatest amount of light is reflected, and the reflected sunlight receives from the reflecting surface the least possible degree of modification. While-the actual tint of the colour reflected by a black feather, then, is determined by the form and position of its angular ridges, the quality of the reflection is determined by the opacity of the substance itself. It is interesting to note that the opacity necessary for reflecting a "me- 
tallic" lustre, may be produced by means of pigment, in the vegetable as well as in the animal organism; for instance, in the dark centres of Coreopsis (the Beetle Flower), and several other fashionable garden plants belonging to the Compositæ or Daisy family. Within the animal kingdom, we may note that the metallic lustre is almost entirely confined to land animals; their dry skins have more chance to develop opaque parts, than the moist tissues of creatures that live in the water. The most familiar exception to this rule is the SeaMouse, an Annelid worm found on English coasts (p. 73), which receives its odd name because it is a fat oval creature, covered with bristles, thus greatly differing in appearance from most worms. The larger bristles, which are of a dark purplishblack colour, have a bronze or golden metallic lustre. Various other annelids exhibit brilliant rainbow colours; for example, Nereis, the Rainbow Worm, also found on English shores; but without the underlying black opaque pigment, the reflections from the surface fall short of absolutely metallic brightness. On land, we see among the insects innumerable forms which present a metallic lustre, the beetles being the most notable in this respect. To return to the vertebrates, from which we started, everybody must have noticed that the fur of a clean well-kept black cat, when lit up by the bright sunlight in which the animal loves to bask, shows little rainbow reflections of red and green. These are due to the presence of little grooves and irregularities on the surface of the hairs, which play the same part in breaking up the light which they reflect, as do the sharp angles of 
iridescent feathers. Like the iridescence of the Rainbow Worm, they fall short of absolutely metallic brightness; the fault in this case being due not to the nature of the underlying stratum, so much as to the incomplete development of the light-reflecting grooves. Yet this instance serves to show the part taken by the dark pigment; for while the play of colours is perfectly obvious in the fur of a black cat, it is almost impossible to distinguish it in the case of cats with fur of lighter shades.

The Mammalia, or animals that suckle their young and produce them by birth, were formerly considered to be sharply defined from animals that lay eggs, such as the birds and reptiles. But in I884 Mr. Caldwell confirmed the statement which had been made previously, yet hardly credited by the scientific world, to the effect.that the lowest form of mammals lays eggs. This, the Dick-Mole or Ornithorhyncus anatinus (Birdbilled animal much like a goose), is a native of Australia and Tasmania. It lives on the banks of rivers, and burrows in the bank. It has webbed feet, and therefore sometimes receives the name of Platypus (flat-foot). It lays eggs two at a time, in its burrow; and these eggs, like those of other egg-laying vertebrates, have a yolk.

A kindred form, Echidna hystrix or Spiny Ant-eater, is found in Australia, Tasmania, and New Guinea. The Echidna hatches its young in a temporary pocket, which appears in the neighbourhood of the breasts, and disappears after the young are old enough to take care of themselves. The Ornithorhyncus has fur, the Echidna has spines, with hairs between them. Neither bears the slight- 
est resemblance to a bird; the comparison suggested in the name of Ornithorhyncus is fanciful, and depends chiefly on the flat beak-like mouth; these egg-laying quadrupeds may, however, be reasonably brought into comparison with Reptiles. Neither of them has any teeth; the Echidna has no teeth at all; the Ornithorhyncus loses them at an early stage of growth, and develops instead hard horny patches in each jaw. With these it crushes its food, which consists of small insects, worms, etc. The Echidna, on the contrary, lives in rocky places, and feeds on ants, which it searches for with its long-pointed snout. These two genera are grouped under the name of Prototheria or Primitive Mammals.

The pocket in which Echidna hatches its young, suggests a relationship with the next group, the Metatheria or Marsupialia, which are the characteristic mammals of Australasia. These are dis. tinguished by the possession of a permanent nursery-pocket, the "marsupium." In this they put their young, which are born, like those of other mammals, not hatched from eggs like those of the last group. They are, however, born in a very backward condition, and therefore require to go through a further period of incubation, so to speak, in the marsupium. Here each one attaches itself to a teat, to which it remains fixed. But it cannot suck as a new-born kitten or puppy does; and the milk is forced down its throat by the muscles of the teat.

The Marsupialia are not entirely confined to Australasia; a few occur in South America, and in North America they are represented by the "'possum," i.e. Opossum, of American stories. The Marsupials seem almost to mimic the forms 
of ordinary quadrupeds. Thus Notoryctes, a form discovered a few years ago, mimics a mole. The fact is that, just as among the Eutheria, or higher
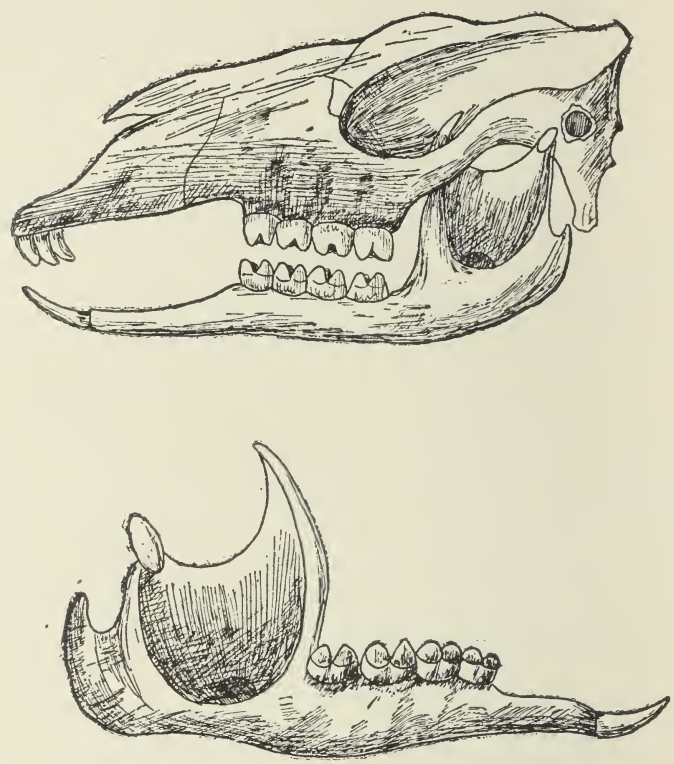

FIG. 45.-Skull and Lower Jaw of Great Kangaroo, Macropus giganteus, much reduced.

mammals, special types have become established, possessed of certain habits, and especially of certain habits with regard to food, and modified in accordance with those habits. Thus there are among them savage carnivora, harmless herbivora, and rodents; and these respectively share 
certain characteristics in common with the carnivora, herbivora, and rodents, belonging to the Eutheria. One of the herbivorous marsupials is the Great Kangaroo, Macropus. It gets its name, Large-foot, from the size of its hind-paws; on these it stands, and by their aid it takes remarkably long leaps. Its skull is shown in Fig. 45; this, however, has not the full set of teeth, some of which are soon shed. It crops the herbage with its front teeth, and grinds it with its back teeth, like other herbivora.

The study of the teeth is of great help in the classification of the Mammalia. Of the eight orders of the Eutheria, two alone, the Sloth order and the Whale order, show a tendency to the suppression of the teeth. Those of the herbivora and carnivora may easily be compared by anyone, in the sheep and the dog respectively. Fig. 46 shows the skull

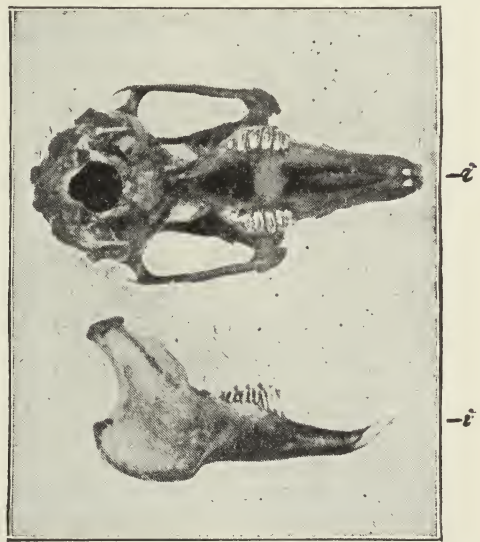

FIG. 46.-Skull and lower jaw of Rodent ; $i, i$, incisor teeth, separated by a long interval from the molars. About one-half the natural size.

of a Rodent, with elongated front teeth, adapted for that persistent gnawing which makes the animals of the order, such as the Rat and Rabbit, so terribly destructive. 


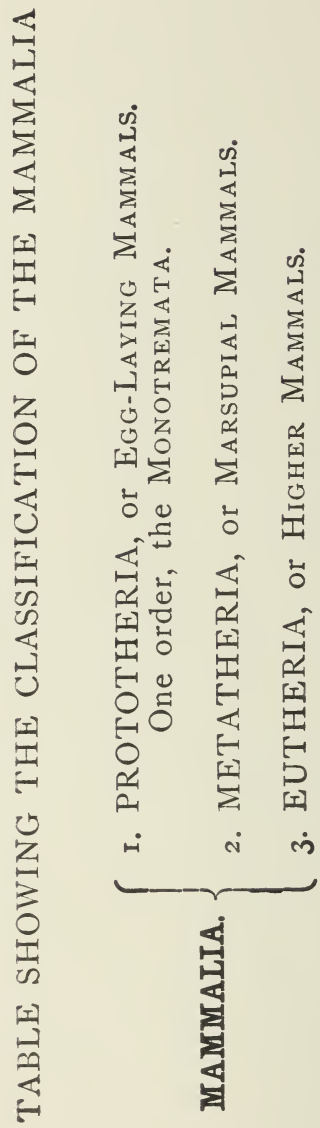


The Mammalia are a terrestrial group. Exceptions are the Cetacea (Whales), Sirenia (Dugongs), and Seals or Sea-Carnivora, but all of these are air-breathers; even the Whale can only stay under water for a limited period of time. Hence we see that none of them are really animals belonging to the water; they are land animals adapted for life in the water.

This brings us very near to the last chapter in the Story of Animal Life. We have seen that our story began with the One-celled Animals, and went on with the tale of the Two-layered Animals, in which each layer was built up by cells in partnership. From Two-layered Animals we passed to Three-layered Animals, and from them to Three-layered Animals with a "body-cavity." When we reached the latter, we found amongst them traces of the ancestry of the vertebrates. From the lowest of the Vertebrata, the Lancelet, we passed on to the Lamprey, and from that to the true fishes. In the latter we found the parent type of all the other Vertebrata, possessing gills in the adult, while the latter only possess them, or traces of them, in early stages of growth. The Amphibia formed a group to themselves, in which we traced the loss of gills in the adult. In the Reptiles, four-legged egg-laying animals, we found not only a close relationship with birds, but also, through the four-legged egg-laying Ornithorhyncus, a relationship with the Mammalia. The last group comprises all the furry animals, and culminates in the order Primates, in which the great Cuvier included Man.

Another volume of this series, "The Story of the Earth," has already dealt with the distribution of animal life in time; while "The Story of Ani- 
TaOdoyHuY

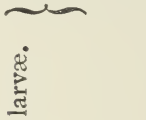

(I)

a

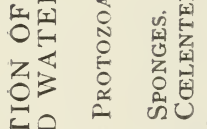

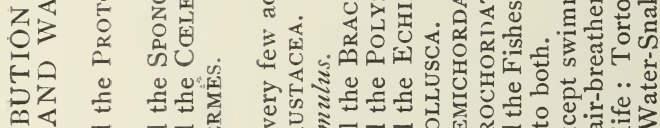

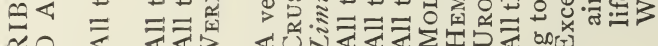

뜰 \& सं

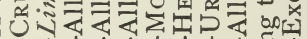

证娄 10111

जी 1111111

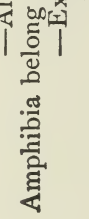

乙) .

3

Q. $\stackrel{00}{\Xi}$

Z.

4

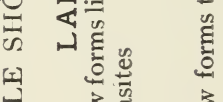

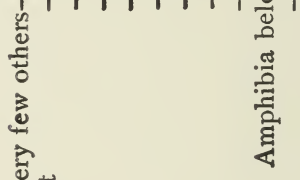

on

它苋

त

:

के

可

ฯ 苋边

ฐ ते ส

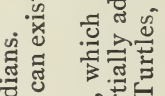

०

运选

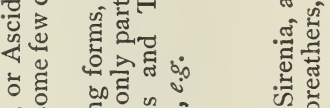

ข

तु चु

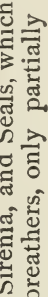

ขิ.

สี่

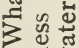

$+\overline{0}$ 원듕

(I)

1 
mal Life in the Sea" tells about the present inhabitants of the ocean. It is therefore unnecessary to say much in this volume regarding the distribution of animal life. A table is, however, appended, which is not without interest. It shows how the chief great groups of animals are divided between land life and water life, whether in fresh water or salt. It will be seen that the terrestrial animals are much in a minority, and that they belong, for the most part, to the higher types. They are, in fact, stragglers, bold emigrants from the early home of animal life, which lies in the more shallow parts of the waters of the sea.

\section{CHAPTER XV}

\section{MAN}

If we are to accept the opinion of Dr. Isaac Watts, man, as a moral being, is distinctly inferior to the "birds in their little nests," who live in harmony with one another; and, again, if we are to believe Solomon, he is by no means always the equal in intelligence of the Ant. Yet somehow it came as a shock to many who had been accustomed to revere both these authors, when they were asked, early in the latter half of the nineteenth century, to regard man, from a zoological point of view, as just a little superior to the Apes.

Then arose a great agitation as to the possibility of finding the Missing Link. We shall see later on in this chapter, that if Research had been content, like Charity, to begin at home, its industry would have been duly rewarded. 
But inquiry, carried far afield in time and place, has not been without result. For it is generally believed that the remains found in 1894 in Java by Dr. Eugène Dubois, are veritably those of the Missing Link. These remains, which consist of the top of a skull, two teeth and a thigh bone, belong either to the oldest Pleistocene age, or to the upper Pliocene; they are found in association with the remains of other animals, among which are included some forms now extinct, or absent from that region. 'These ape-like remains have been carefully compared with those of the lowest races of man which have hitherto been found in a fossil state, and the result of the comparison is as follows: Of twelve experts present at the Zoological Congress held at Leyden, "three held that the fossil remains belonged to a low race of man, three declared them to be those of a man-like ape of great size; the rest maintained that they belonged to an intermediate form, which directly connected primitive man with the anthropoid apes" (Haeckel). To the creature represented by these bones has been assigned the name of Pithecanthropus erectus, the Upright Ape-Man.

Let us now return from the subject of the Java fossil to those inquiries which, as we have above suggested, begin at home. We have already referred to the great principle of modern zoology, that the history of the development of the individual sums up the history of the development of the race. Of late years it has occurred to scientific men to apply this principle in the case of human beings, and to ask, "What can the baby teach us?"

The Baby, for one thing, has a very small nose, 
insignificant compared with the size of its jaw. At least scientists find that this is the case with their babies-it would, of course, be invidious to make such a remark regarding their friends' children; and still more so to add, that in this the Baby differs from the human adult, and somewhat resembles the Ape, in which the nose is still less prominent, and the jaw still more so. Observations have been made, too, regarding the Baby's remarkable power of "holding on "with its hands. While a Baby is, in most respects, a very weak creature, yet its powers of grip have been favourably compared with those of adult human beings. No one who has ever tried to rescue his watch or his hair from the clutches of a friend's Baby, will feel inclined to doubt the conclusions of scientific observers regarding the point in question.

The observations above referred to were made by Dr. Louis Robinson. He drew his conclusions from the study of sixty cases, all of them infants less than a month old; and of these at least half were tested within an hour of their birth.

In every instance except two, says Dr. Robinson, the child was able to hang on by its hands to the finger, or to a small stick three quarters of an inch in diameter, and to sustain the whole weight of its body for at least ten seconds. "In twelve cases, in infants under an hour old, half a minute passed before the grasp relaxed, and in three or four cases nearly a minute." In infants of about four days old, increased strength was shown, and "nearly all, when tried at this age, could sustain their weight for half a minute. At about a fortnight or three weeks after birth the faculty appeared to have attained its maximum, for 
several at this period succeeded in hanging for over a minute and a half, two for over two minutes, and one infant of three weeks old for two minutes thirty-five seconds!" "Thus," says Dr. Robinson, "a three-weeks-old baby can perform a feat of muscular strength that would tax the powers of many a healthy adult. If any of my readers doubt this," he adds, "let them try hanging by their hands from a horizontal bar for three minutes."

In these facts Dr. Robinson finds something to remind us of the ape-babies that owe their safety to their capability of holding on to a treeclimbing mother; and also something to suggest connection with an ancestor which, although well accustomed to the use of its hands, had yet to learn the use of its feet for walking on flat ground.

The same author, in discussing the "Meaning of a Baby's Footprint," has shown that the foot of a young child bears traces of adaptation to a state of existence in which it was used for purposes other than that of walking.

"The toes of infants," says Dr. Robinson, "are much more mobile than those of adults. The great toe is shorter than the second and third, and is often separated from the second by a considerable interval. The four outer toes can be, and frequently are, bent downwards so as to show a distinct knuckle on the upper aspect of the foot at the metatarso-phalangeal joint, and when at the same time the great toe is flexed and turned inwards towards the sole, the front part of the foot makes a very respectable fist. The great and little toes are often made to approach one another beneath the rest, and I have seen orie 
child who could almost make them touch, and who habitually would endeavour to make the great toe oppose the others when any graspable object was brought into contact with the front part of the sole."

Regarding the lines in the sole of the foot, Dr. Robinson says: "The sole is covered with lines of a character exactly similar to those on the hand; and when the toes are bent downwards these become deep creases, showing that they are, like the palmar lines, the natural foldingplaces of the integument to facilitate the action of grasping. . . . The lines are scarcely visible at fourteen months old, and are only present in a few cases after the age of two years. In adults no trace of them can be seen when the foot is at rest, and only the faintest indication at one or two spots when the toes are flexed to the utmost. The obliteration is doubtless owing to the foot being used as an organ for progression rather than prehension, and it will be seen that the most distinct line crosses the sole at the spot where the epidermis is always dense and callous, and the subcutaneous tissues thickened into a cushionlike pad by the pressure and friction consequent on walking. This line undoubtedly marks the place where the chief fold in the skin was situated, when the toes were habitually clasped round some object such as the branch of a tree." It has been pointed out by other writers that the lines of the sole of the foot can plainly be seen in the adult foot of some savage races. It must be added, however, that the survival of the lines in the adult civilised foot is by no means so rare 
as Dr. Robinson's remarks would lead one to suppose. I have seen instances in which they were quite clearly marked. It must be added that anyone who wishes to confirm my observations in this respect must be careful not to mistake lines of disfigurement, caused by the pressure of boots, which are sufficiently common, for the primitive lines of the foot.

The child, as it grows, ceases to remind us of the ape. Its nose gets bigger as its toes cease to wriggle and learn to stand. But, for years of its life, it is only too apt to remind us of the savage. How greedy it often is! How readily it snatches that which does not belong to it! How quick it is to quarrel with its playmates, and to fight! How noisy when at play! How cross when it meets with disappointment! How fond of tawdry things! In all these qualities we see the history of the race, repeating itself in the life of the individual. The savage has preceded the civilised family - the child shows us the faults of a lower race. With the elapse of years they disappear, and are replaced by the more amiable and gracious manners of the adult human being.

Nor do we need to go into the nursery to find links with our inferiors. Much, indeed far too much, has been written of late years about "atavistic degeneracy"; that is to say, degeneracy which imitates the characteristics of our forefathers. Many things which are classed as diseases, whether of the body, mind, or moral nature, may be expiained in this way. Take the gills, which, as we have stated, exist in all vertebrates, but not in the adult of the highest groups. In a sickly individual, even among the highest vertebrates, traces of these are sometimes 
seen existing in the adult, as a gap or open space in the neck, called by the medical man "cervical fistula": this is an instance of degeneracy in the body. Take, for another instance, the kleptomaniac, who snatches up everything he takes a fancy to, although he is not in want. This is degeneracy of the mind, a relic of savage nature out of place in civilised man. Yet the gill-space is an ancestral feature which has its right time to appear, though it is out of place in the adult; and the "want-to-snatch" stage, as we have al. ready seen, is quite natural in the young child. A parallel instance to the last is that of the hysterical girl who invents all sorts of tales about her harrowing adventures, weaving in stories she has heard of other people, with an account of her own life. She is an impostor; but her instinct for weaving yarns is that of the savage, who is the more admired by his fellows the more he can show himself a liar. Even the dangerous criminal, such as the Anarchist assassin, is comparable with the treacherous savage, who stabs his guest, and with the fierce animal that bites the hand that feeds it.

The causes of degeneracy may seem obscure. But if we turn to our gardens, how easily is the process understood! Leave a cultivated plant to look after itself; neither watered, nor manured, nor weeded; and how long will it be before the plant resembles its wild ancestors? The flower will be less fine, the leaves more weedy; the whole aspect of the plant is changed. The causes: insufficient food and water, and the struggle for root space, standing-room, and light, with the weeds around it. Just in like manner the human being, when unfed, unwashed, and 
untaught, begins to degenerate. The want of fresh air and light associated with slum life, and even in the country, associated with the homes of the poor, are factors in the case that are not to be forgotten. Add to these drink, and the other sins of the fathers which are visited on the children. All these are among the causes of degeneracy.

Nay more, the very virtues of the parents, as we account them, may lead to the degeneracy of the offspring. Overwork, either physical or mental, causes the deterioration of the family, and in our days nearly every man successful in any career, either commercial or intellectual, is guilty of overwork. The "haste to be rich," equally with the haste to be famous, tells on the next generation. Those who are fond of moralising at the expense of their neighbours, enjoy pointing out the unsatisfactory careers of the sons of men who have become rich. Almost invariably such a one is idle, we are told, and fond of pleasure. Good cause has he to be so. He comes into the world with weakened constitution, owing to his father's strenuous career; and if he were to work as hard as his father, he would probably soon be dead; or at least his children, in their turn, would be miserable and diseased. Nature guides his inclinations, and whispers " Do not work too hard," "Do not deny yourself too much"; and thus, so long as his father's money maintains him, his life is preserved.

What is the kind of degeneracy that overtakes the family of the brain-worker? The modern world is full of it. We owe to the unamiable genius of Max Nordau a criticism of the intellectual world of the present day, which attributes 
well-nigh all the follies of intellectual cliques to degeneracy. Poetry, which is "full of sound and fury, signifying nothing," rich in rhyme and alliteration, but wanting in sense; art which seeks effect by loud and inharmonious colours; music which rejects "mere melody": in these the critic sees the taste of the savage, fond of a jingle of words, fond of bright colours, and ignorant of middle tints; and fond of noise without a tune.

The so-called æsthetic movement which, a few years ago, wrought such marvels in decoration and in dress, comes in for a share of the critic's analysis. The dull senses of the degenerate cannot appreciate the soft colours which ordinary persons like to look at; to attract his attention and to please his fancy, he must have staring red, or staring blue. Or, if he possesses an object which is of special interest, he must bring this into contrast with a very sombre background, lest by chance it should miss being seen.

I met with an amusing instance the other day which is much to the point. In a remote part of the British Isles, two friends, immigrants from the world of "culture," had been criticising the landscape. It was a pity, they agreed, that everything was so grey and dull; otherwise the neighbourhood might have been pretty. If only the cottagers could be got to grow something in their gardens that would give a touch of colour to the scene! These poor creatures had before their purblind sight all Nature's rich harmony of colour, which affords such pleasure to persons of true taste. Green fields, brown rocks, blue sea, and blue sky, all were dull to them. Wild flowers of a score of kinds, and bright with every colsur -these were too insignificant to be visible. They 
wanted some big patch of vivid colour, perfectly inappropriate to the climate and surroundings. Some exotic plant was needed, in their opinion, to give a touch of brightness. 'The harmony of colour and beauty of form in our native plants, and in the common flowers of cottage gardens, were imperceptible to their unobservant eyes. Their intelligence was on a level with that of the savage, who is impressed by new and striking objects, and delighted by gaudy colours, but finds no beauty in wild nature or in accustomed things. These people were typical specimens of the degenerate of the book-reading classes; dull of understanding and wanting in taste, as the result of mental overwork in several successive generations; immeasurably inferior in æsthetic capabilities to the untaught peasants and fishermen of the district they would fain enlightenfor these appreciate the beauty of their country, and love its flowers.

Much might be added regarding atavistic degeneracy, as an explanation of the mental and moral defects of human beings. Its most frequent form, perhaps, is that of mere laziness. The Ape does not work; nor does the savage, if he can possibly help it. Civilised man, if thoroughly sound in mind and body, likes activity, and activity with a purpose. The poor man takes a pride in his labour; the rich man takes a pride in his skill in games, his learning, or his efforts to benefit others. The idler, disinclined for either hearty work or hearty play, is a Degenerate. Of late there has been much discussion of a plan for treating the confirmed idler as a criminal. It will be seen from the remarks made above, that there are equally good reasons for treating him as an 
invalid. In criticising the plans of would-be reformers, this fact should not be forgotten. He was a wise man who said "You cannot, by passing an Act of Parliament, make a Vice into a Crime."

It must, however, be remarked that the doctrine of degeneracy has lost both in force and in usefulness, by the treatment it has received at the hands of those who have constituted themselves its popular exponents. Some of these writers have made it but too evident that their criticisms are of ten captious, and that their definition of degeneracy includes all human failingsexcept their own. The reader who devotes a little attention to the subject will, however, readily find an explanation of this: for he will easily recognise, in the popular writers on Degeneracy, the characteristics of the Degenerate, as described by themselves.

First, the choice of a disagreeable subject, when the whole field of science lay open to them : for the Degenerate prefers a disagreeable subject. Secondly, the almost universal discovery of causes of dissatisfaction, in every possible direction: for the Degenerate is always vexed with everybody -except himself. Again, the want of principle shown in appealing to the morbid tastes of the public, by laying before it information on disagreeable subjects: for the Degenerate is lacking in principle; what does it matter to him how much harm is done to weak minds by his writings, so long as he sees in such writings a safe means of securing eager readers and liberal pay? Again, the Degenerate seeks notoriety ; and this is easily secured by writing books that discuss the morbid side of life.

Above all, the habit of carrying the war of 
criticism into regions of art and culture with which the writer is obviously unfamiliar: this also marks the tendency of the writer's mind. To criticise the doing of that which he can by no means do; to destroy that which he can by no means make; to leave no margin of leniency in his judgment, for the imperfections which disfigure all human work: these are the familiar failings of youth, of the unripe mind. They are also those of the type of mind that never attains ripeness-of the Degenerate: we are forbidden, on high authority, to apply to our brethren a shorter and less modern term.

But although the doctrine of Degeneracy has thus found its way to the general reader in a form which is often much to be regretted, it is nevertheless a doctrine which, if wisely used, may lead to the most beneficial results. Already it is widely recognised, by the thinkers of all nations, that the theory of degeneracy, when thoroughly understood, must revolutionise our treatment of the criminal classes. Instead of the attempt to punish, civilised legislation must eventually, in many cases, substitute a system of restraint.

It is useless to try to reform the idler or the thief, whose instinct for idling or thieving is as imperative as a cat's instinct for catching mice. So long as he goes free, so long will the instinct reassert itself at every renewal of opportunity. Repeated punishment of the offender, who is powerless against his own impulses; is frequently a mere cruelty; while his repeated release, at the termination of every punitive sentence, is, on the other hand, still more certainly, a cruelty to the community at large, which he afflicts by his presence. Public opinion is gradually becoming awake 
TABLE SHOWING THE PLACE OF MAN IN CLASSIFICATIONS

Grade IV. TRIPLOBLASTIC Animals with a BODY-CAVITY.

Group. CHORDATA; Animals with a Notochord.

Phylum. VERTEBRATA; Animals with a Back-bone.

Class. MAMMALIA; Animals that suckle the young.

Order. Primates.

Genus. Homo, i.e. man.

Species. Sapiens (possessed of sense). 
to the necessity for fresh methods of dealing with these problems; it is by the patient investigations of scientific men that it has been enlightened.

Meanwhile, it must not be forgotten that the theory of degeneracy has its cheerful aspect. It enables us to look at the offending fellow-creature who belongs to the criminal classes, as an incomplete development rather than as a hardened sinner. It reminds us, too, that the criminal and the idler of to-day are now, what in the times of savagery and animalism, every man once was. The degenerate criminal, in fact, stands as a landmark, to point out the progress which has been made by the human race. This was the startingpoint, where now he stands. How great the progress that is measured by the distance between him, and the orderly, kindly-hearted citizen of the present age!

\section{CHAP'TER XVI}

\section{HOW ZOOLOGISTS DO THEIR WORK}

IT is one of the most well-worn of commonplace sayings, that "one half the world does not know how the other half lives." It is equally true that one half the world does not know how the other half works; and especially is this the case when one of the world's halves is its learned, and the other its unlearned, half. The average business man probably has an idea that the man of learning has a pretty easy time of it, and that his most arduous occupation is to enlighten an attentive world by reading papers at the meetings 
of the British Association and the Royal Society. He has a vague idea that the man of learning sometimes uses midnight oil, but it would surprise him to be informed that the man of learning often sets to work at five o'clock in the morning-as is actually the case. And well he may, considering the magnitude of the task he has in hand, and the variety of the odds and ends of labour that it includes.

Firstly, how does he obtain the raw material for his work? The scientist, like the cook, must "first catch his hare" before any further details of work can be arranged. $\mathrm{He}$ does not, as a rule, do this in person, except when an animal of unusual interest is concerned. An army of collectors, all the world over, are constantly busy in searching for material for the zoologists, on land and sea. They look for employment and pay to the museums and laboratories of the learned world. When the specimens arrive, what is to be done with them? Some arrive alive, and may be dismissed from present consideration. The dead specimens give employment to a number of workers who are under the command of the man of learning. There are skins to be mounted and stuffed, bones to be articulated and set up, each practically the work of a different trade. There are drawings to be made of all important specimens, a task which affords employment for the artist and the photographer. There are carcases large and small, to be immersed in preservative fluids until they can be thoroughly examined in detail. And woe betide the zoologist who allows any of these tasks to be performed without his own personal supervision. He will realise, as all careless masters do, that blunders may be made 
in an hour, which cannot be repaired in a day. But when all is done that servants and helpers can accomplish, the real business remains to be done. Is there among the specimens one which has not been thoroughly overhauled by other writers, one whose every detail of structure is not already to be found printed in a book? That one must be examined with the utmost accuracy. If it is big enough, it must be dissected, and every part recorded and figured in diagrams. But suppose it is a small creature, whose parts can only be seen under the microscope, a long series of processes are necessary before it is ready for use. In its fresh state, it contains a quantity of water, and if left to itself would shortly decompose. Even if already immersed during carriage in various preservative fluids, it still contains much water, and, if so, neither will it keep for an indefinite length of time, nor could it be satisfactorily examined under the microscope. It must be soaked in one of various chemical solutions, to harden and preserve it. If very small indeed, a mere speck, it perhaps only needs to be transferred to a fluid in which it can be "mounted" and placed under the microscope. But with the vast majority of specimens, an immense amount of labour is needed before they are ready for inspection under the microscope.

This will easily be understood if we reflect for a moment on the way in which objects are examined under the microscope. For purposes of scientific investigation, they are rarely looked at under light that falls upon their surfaces, that is to say, by reflected light; for this method can show nothing but details which are external and comparatively unimportant. They are seen by 
light placed behind them so as to shine through them, i.e. by transmitted light. If the object is not extremely thin, it will shut out too much light, and thus it cannot be clearly seen, therefore all objects, except the most minute, must be divided into thin slices, technically known as "sections."

If we want to know not only the microscopic structure of organs, but also their shape and position in the body, and their relations with other parts, we must have every successive section carefully preserved, and the whole row arranged in correct successive order ; the physiologist may often content himself with single sections; the zoologist must have rows and rows of them. What a task this was, a quarter of a century ago, for scientists who cut their sections by hand !

Let us, however, describe first the way in which objects are prepared for section-cuttingwhether by hand or by machine. It has already been noticed that animal substances contain a quantity of water, and therefore will not keep. The same circumstance renders them soft and squashy, so that the sharpest razor in the world, in cutting a section, must necessarily do more or less damage to the structure of the delicate tissues. The water is held in the meshes of the tissues just as it is held, for example, in the meshes of a sponge. Now, if we were dealing with the sponge, we could get it to absorb any other fluid substance besides water; we might choose one that would prevent decomposition; we might choose one that would go harder by cooling; so as to change the sponge into a strong solid block that could be knocked about without sustaining any damage. This is exactly what we must do with our animal tissue to prepare it for section-cutting; and the 
most convenient fluid for the purpose is melted wax. But whereas we might take our sponge out of water, squeeze it dry, and dip it straight into melted wax, we can by no means do so with our animal tissues. For one thing they usually cannot be squeezed, and where they can, they would of course be irretrievably ruined by such a rough process. Even the transference of the specimen from one fluid to another of very different qualities and density, would deface the tissues. Cells would burst, or be squeezed out of shape, and organs would be loosed from their right position by the currents set up in all parts of the specimen, under such circumstances. We must, therefore, try to get rid of the water by degrees. This may be done by gradually adding alcohol, a fluid which may be diluted with water in any proportion. We begin with a comparatively weak solution of alcohol, say about fifty per cent., and immerse the specimen in this for some little time. The time required depends somewhat upon the size of the specimen; if a large one, a new fluid will take longer to filter through it. Then we must change this solution of alcohol for stronger ones, say seventy per cent. and ninety per cent. successively, and finally to absolute alcohol. By this time the alcohol will have removed almost nearly all trace of water from the specimen. The latter is now nearly but not quite ready to be imbedded in melted wax; but first we must soak it for a while in a fluid intermediate in thickness between the alcohol and the wax, and capable of mixing in a friendly manner with both. Then it goes into a bath of melted wax, and is kept for hours at a stated temperature until the wax permeates it thoroughly. Then the melted wax and the speci- 
men along with it is poured into a little mould and left to cool. The block of wax containing the specimen is cut down to a quadrangular shape, and is now ready for section cutting. In old days the block was placed in a stand, and successive sections were cut from it by hand with a razor. But this process is much too slow for modern days. Machines called microtomes (i.e. cutters of small parts) have been invented, and of these there are several kinds -in all, however, the razor is worked by machine and not by hand, so as to secure steadiness and a uniform thinness of the sections. The old microtomes threw off each section separately; but now matters

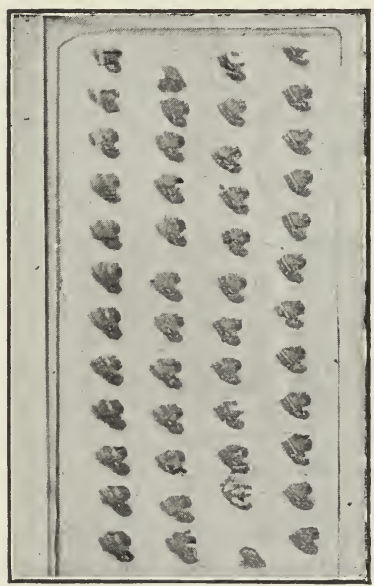

FIG. 47.-Sections of Embryo Chick, eight days old. A slide mounted for microscopic examination, showing sections arranged in ribbons.

are so arranged that the wax of each section adheres to that of the next, and the whole series of sections forms a continuous ribbon of thin wax. A large specimen, affording a number of sections, thus results in a ribbon of considerable length. Further processes are now required to fit the sections for the microscope. The ribbon must be divided into successive pieces of a length determined by that of the slides to be used. These are 
mounted in order on the slides, steps are taken to melt away the wax from the sections, the latter are covered with Canada Balsam surmounted by a glass cover slip, and left for some time to dry. After this they are ready for examination, and it is only now that the work really begins. All that has gone before is mere handicraft; it is time now for science to be called into play.

The sections must be compared with others of the same kind which have been cut before. Do they entirely resemble these, or is there a difference somewhere? Happy the man who finds that his sections represent a fresh stage, perhaps older or younger than any that has been seen before in the history of the particular animal which is under investigation. Happier still the man who has succeeded in getting hold of an animal which has not been described before. $\mathrm{He}$ will make haste to write a full description of it, illustrated by drawings; to found a new theory on it, if that can possibly be done; and to publish it to the world. It will go all over the globe. To every country in Europe; to the centres of learning in the United States; to universities in New Zealand and Australia, and our other colonies; and perhaps even to "Far Japan."

When in his turn he receives publications from all countries, written in all languages, he is in a position to realise the very great advantage (referred to in an earlier page, p. 3I) that results from the use of the learned tongues, in the terminology of zoological science. For the educated classes in all countries are equally acquainted with these; and when half of a sentence consists of words of Greek or Latin derivation, the labour of translation from a foreign tongue 
is necessarily greatly lightened. To no writer is this advantage of so great importance as to the Englishman, who is usually less familiar with the tongues of other nations than his colleagues abroad. It will easily be understood that in the world of zoology, there is no "predominance of the English-speaking races." Far from it. German is the language which supplies the fullest literature of every scientific subject; and in England even our text-books are, for the most part, translated from the German. German, in short, is to the seeker after Knowledge, what English is to the seeker after Money.

Let us now pause a moment to consider how large a number of different industries profit by the labour of the zoologist. First there is the shipping trade; for, of course, all specimens from foreign lands are brought by sea. The chemist supplies preservative substances, and reagents used in the preparation of objects for the microscope. The construction of microscopes is a profession in itself, and one which employs many industries; for the making of a microscope includes not only the work of the optician, but also that of the artificer in brass, and of many other handicraftsmen. The glass-worker supplies "slides," that is to say, the thin pieces of glass upon which objects for the microscope are placed, and "cover-slips," the little sheets of thinner glass which are laid over them; and, besides these, the bottles in which specimens are placed. Then comes the microtome, already spoken of, by means of which sections for the microscope are cut; how many skilled workmen have been engaged in the construction of its parts! Sheffield, perhaps, has supplied the razor which it 
holds, as well as the instruments for the dissection of the larger zoological specimens. We have already spoken of the laboratory servants, and the bone-articulators and skin-stuffers, who are personally and directly employed by the zoologist; and of the artists and photographers who depict his specimens, or perhaps copy his drawings. We must add to the list of the zoologist's helpers, last, but not least, the printer who "sets" the learned treatise in which the final result of his work is usually embodied; and attendant on the work of the printer is that of the bookbinder. With the bookseller the zoologist has but little to do; the general public, even the reading public, has no knowledge whatever of the writings of the zoological specialist. They are addressed to his equals and co-workers, not to critics and reviewers. Their publication is provided for, not by the law of supply and demand, but by the funds of the learned societies and the universities. It is only occasionally that a writer arises who is able and willing, like Huxley or Darwin, to express himself in a book that the general public can read; and it is only after a lifetime of detailed work, such as is understood only by the specialist, that writers like these think it fitting to lay the results of their labour before outsiders.

The librarian, finally, must not be forgotten, in making up our list of the zoologist's helpers. The preservation and cataloguing of zoological literature is obviously a task all the more important, because, as we have already stated, zoological writings are not regulated by the law of supply and demand. A very little paper, read to a very small meeting of a learned society, 
and wholly ignored by the world at large, may contain facts priceless to the world of science. It is on the accurate and painstaking work of the librarian, who preserves and catalogues small things as conscientiously as large ones, that wa rely for the completeness of our record of zoological knowledge. Such work has at a:? times been carried on in the libraries of our universities; but at the present time there are in existence libraries specially devoted to zoological literature alone.

The museum, again, must not be forgotten, in which our man of learning stores his specimens, duly labelled and arranged. Here, again, is a staff of curators and sub-curators; and, under their direction, work for various workmen, and for perhaps even a humble charwoman to dust the shelves.

Turn now to another aspect of the zoologist's work-that of teaching. We should think it very wrong to turn men loose on the world to practise in the professions of law or medicine without a long and careful training to fit them for their task. No less impossible is it for anyone to become a man of science without a similar training; for the profession of the man of science, whether zoologist, chemist, botanist, or expert in whatever branch, if defined in plain English, is the profession of seeking after knowledge of the order of things in which we live; and what profession can be more important to the world than this? To attain a scientific degree of any value, years of study are therefore required, and a series of examinations tests-or is supposed to testthe success of the student. Both the work of teaching and the work of examining must be the 
tasks of the scientist who has attained a position of eminence in the world of learning. The preparation of lectures, with their accompanying illustrations of diagrams and lantern slides: the guiding of classes engaged in the actual work of making acquaintance with animal specimensthese are the labours of the great man who is at the head of things. His task is carried out with the aid of junior helpers of his own professionthe demonstrators, who "point out" detail after detail of the work described in the lectures. Another helper, more esteemed by the students than by the professor who teaches them, is the "coach" who prepares them directly for their examinations. His aid, in the shape of extra teaching, given at the last moment, will often secure for the careless and inattentive pupil, better success than is the lot of the painstaking and industrious one, who cannot afford to pay extra fees.

Few, however, of all the many pupils who crowd the lecture room of the zoologist, will ever become zoologists themselves. A vast proportion of them are students of medicine, of whom some knowledge of the subject is required. Others are preparing to be schoolmasters or schoolmistresses, and seek just such an amount of knowledge as they expect to find useful in teaching pupils of their own. To the students who are preparing to be doctors or teachers, circumstances often assign a limit-" thus far and no farther" - when they would fain bring their knowledge to a higher standard. But the time they have spent already has not been wasted. How keen an observer of animal life is the country doctor! How often, isolated from the world 
of learning, and ill-provided with books, he finds in this his chief recreation! As for the schoolmaster, how is the routine of school-work relaxed, and labour changed into pleasure, when he lets his boys exchange grammar and Euclid for zoology, and the lessons of the schoolroom for lessons in the fields!

The most important part, however, of a zo. ologist's work is not the giving of instruction, but the labuur of original research, to which we have already alluded; not the mere communication of information, but the task of adding to the general store of knowledge; not teaching, but discovery. The work of the man of science is, in fact, within the limits of his own department, the work of seeking after truth. 



\section{N D E X}

A.

Acœelomata, 37 .

Adaptation, I3.

Alternation of Generations, 57, 137 .

Amœba, 35, 45 .

Amphibia, I52-I54.

Ancestors, 40, 42 .

Animalcule (minute animal), 49.

Anisopleura, 29.

Annelids, 72.

Annulosa, 69 .

Ants, 92.

A ppendages, 77 .

Arachnida (spiders), 84 .

Arthropoda, 33, 76 .

Ascidians, 33, 44, I35.

Asexual reproduction, 55 .

Atavistic variation, 27.

Azygo-branchiata, 29 .

\section{B.}

Balanoglossus, 133, 143 .

Barnacles, 79, 80 .

Bees, 9 I.

Beetles, 95 .

Bell Animalcule, 49 .

Birds, ${ }^{56}$

Bivalve shell-fish, 23, 27, 107 .

Body-cavity, $34,37,3^{8}$.

Body-cavity (diagrams), 38,139 .

Body-rings, or "segments," 69 .

Brachiopoda, 33, 43, 44, II7.

Bryozoa, 33, 44, II 9 .

Buds, 55 .

Butterflies, 89, 93 .

\section{C.}

Cat, fur of black, 160.

Cell, ir.
Cell-types, 49.

Cephalodiscus, $\mathbf{1 4 5}$.

Cephalopoda, Ir 3 .

Centipedes, 77 .

Chætopoda, 7 ז.

Chalk, 46.

Chordata, 33, 44, I35, 143-146.

Cilia, $42,43,48,65$.

Classes, 33.

Classin̂cation, 30 .

Classification, tables of, $30,44,52$, $62,67,75,116,118$, 121, 134, 146, 164,179 .

Cœlenterata, $33,44,53$.

Cœlomata, 37, 44.

Cockle, ir 1 .

Colony, 57.

Corals, 59 .

Corallines, 56, 58 .

Corticata (or Infusoria), 47 .

Crabs, 8r.

Crocodile, I r.

Crustacea, 78-83.

Ctenophora, 60, 62 .

D.

Degeneracy, 28, I72-180.

Development by metamorphosis (change of form), 4I, 89.

Development, direct, 45.

Dicyemidæ, 34 .

Diploblastic (two-layered), 34, 36 .

Diploblastic larva, 4r.

Duck-mole, r6o.

E.

Earthworm, 74:

Earthworm, diagrammatic section of, to show position of body-carity, $3^{8}$. 


\section{THE STORY OF ANIMAL LIFE}

Echinodermata, 33, 43, 44, I22.

Ectoderm, outer or skin-layer of adult animals and larvæ (corresponding with the epiblast of embryos in the egg), 34, 37, 4I, 139 .

Eleutheroblasteæ (hydroid animals which throw off "free buds"), 56 .

Embryology, 45.

Encrinites, I3I.

Endoderm, inner or digestive layer of adult animals and larvæ (corresponding with the hypoblast of embryos in the egg), 37, 4I, 139 .

Enteron, 36.

Environment, 26.

Errantia, or Wandering Annelids, 72.

Euthyneura, 100.

Families, 33 .

F.

Fertility, 32 .

Feathers, 157 .

Feather-stars, $\mathbf{I}_{32}$.

Fishes, $150-152$.

Flagella, 65 .

Flat-fish, 23.

Foraminifera, 46 .

Frogs, 38, 152 .

G.

Galeodes, a spider-like animal, 85, 86.

Gasteropoda, 29, 98-107.

Gasteropoda, classification of, 29.

Gastræa, 40.

Gastrula, larva, 4I, 150.

Genus, 32 .

Gills, 45, I4I, I49.

Grades, 34, 35-38.

Gregarina, 49.

H.

Heliozoa, 48.

Hemichordata (or Adelochorda), 33 , 43,145 .

Hermit Crabs, 80.

Holostomata, 105.

Hybrid, 32.

Hydra, 36, 4I, 54, 59 .

I.

Infusoria, 10, 47

"Infusorial earth," 47.

Insects, true, 88-97.

\author{
J.
}

Jelly-fish, 57,58 .

$\mathrm{K}$.

Kangaroo, 163.

L.

Lamellibranchiata, 107.

Lamp-shells, IIg.

Land Animals, 166.

Larvæ, larval forms, 40, $4 \mathrm{I}$.

Larvæ of Brachiopods, rig.

Larvæ of Insects, 90.

Larvæ of Molluscs, II5.

Lancelet (Amphioxus), 4I, I4O, 149. Leeches, 7 I.

Limpet, Common, 17, 19, 20, 29, 30.

Limpet, Semi-transparent, 15-20. $^{-20}$

Liver-fluke, 7 I.

Lobsters, 80.

Lophophore, II7, 122.

Lustre, metallic, of feathers, ${ }_{57}$.

M.

Mammalia, 160.

Man, $13,26,167-180$.

Mantle (of bivalve molluscs), 108.

Marsupialia (or Metatheria), I6r.

Marsupium or nursery-pocket, I6I.

Mesoblast, 38 .

Mesoderm or middle body-layer, 37 , $6 \mathrm{r}$.

Metameric symmetry, 70 .

Mesozoa, 35.

Metazca, 35.

Microscope, 9, 10, 182.

Microscope, Sections for the, 182.

Microtome, 185 .

Mites, 87 .

Mollusca, 29.

Mollusca (classification of Gasteropod), 29.

Moths, 93 .

Monoblastic, 34 .

Moss-Corals, 33.-39, II

Mule, 32.

Mussel, Common, r03.

\section{N.}

Nematodes, $7 \mathrm{I}$.

Notochord, I35, I39, I45, I49, I5 1 .

Nucleus, 35 .

Nummulite, 46 . 


\section{O.}

Odontophore, roo.

Operculum (of univalve molluscs), I05.

Opossum, r6r.

Orders, 33.

Orthonectidae, 34 .

\section{P.}

Pelecypoda, ro7.

Perforating gills (of vertebrates and other chordata), $1_{42}, I_{44}$.

Peripatus, 88.

Periwinkle, Common or Edible, I9, 26, 105.

Periwinkle, High-tide-mark ( $L$. rudis), I9, 105, II4.

Periwinkle, Yellow, 19, 21, 23, 25, 3०, 105.

"Persons" of a colony, 58.

Phoronis, I22.

Phylum, pl. phyla, 33 .

Placophora, 113.

Planarian Worms, 37, 70.

Planula Larva, 4r.

Platyhelminthes, 44, 7x.

Polycystina, 47 .

Polyzoa, irg.

Porifera, 33, 63, 68 .

Protective Coloration, 15, 25.

Protophyta, 50 .

Protoplasm, 35.

Prototheria, 16r.

Protozoa, 33, 44, 45.

Pseudopodia, 36 .

\section{R.}

Radial Symmetry, 53 .

Radiata, 53 .

Radiolarians, 47.

Rainbow Worm, 72, I59.

Reptiles, ${ }_{54}-156$.

Rhabdopleura, I45.

Rhizopoda, $36,46,48$.

Rodent, Teeth of, 163 .

Rotifers, 76 .

\section{S.}

Sand-hoppers, 83 .

Sauropsida, I54.

Scales of fish, I42, I43.

Scallop, ro7-II2.

Scorpion, 87, 88.

Sex, Io.
Sea-Anemone, 54, 59 .

Sea-Cucumbers, 129, 130.

Sea-Fan, 59.

Sea-Mats, IIg.

Sea-Mouse, 72, I 59.

Sea-Urchins, $23,33,122$.

Shell-fish, 33 .

Siphonostomata, I02, 106.

Skin of Vertebrates, 142.

Snail, 98, II4.

Snake-Stars, or Brittle-Stars, I28.

Species, 30.

Spiders, 84

Spiny Ant-eater, I6o.

Sponges, $33,44,63,68$.

Sponges, Parasitic, 68.

Starfishes, 127.

Streptoneura, 29, 100.

Symbiosis, $4^{8}$.

\section{T.}

Teeth, I47, I6 3 .

Tentacles (arms or feelers), 54 .

Ticks, 87 .

Trichina, $7 x$.

Triploblastic (three-layered), 37 .

Trochophora, 43.

Trochosphere larva, 42, 43, 72 .

Tubicolous (tube-dwelling) Annelids, 72,74 .

Tunicata, 33, 44, 135 .

Turbellaria, 70 .

Two-layered animals, 34,36 .

U.

Unicellular animals, II, 34, 3539 , 44 .

Univalve shell-fish, 98 .

Urochordata, 145 .

\section{V.}

Vacuole, contractile, 35 .

Variation, 24, 26, 28, 32 .

Varieties, 29.

Vermes, 33, 44, 68.

Vertebrae (joints of the backbone), I38, 139.

Vertebrata, 33, 44, I38.

W.

Water Animals, I66.

Wheel-ball larva, 42, 43 .

White ants, 93. 


\section{6}

\section{THE STORY OF ANIMAL LIFE}

Wood-lice, 83 .

Worms, 33, 44, 68 .

Z.

Zooids, $5^{8}$.

Zoologists (see below).

Zoophyte, 53 .

Zygobranchiata, 30.

Zoologists, names ofBuffon, $r$ I.

Caldwell, 160.

Chamisso, 137.

Cuvier, 54 .

Darwin, 24, 76 .

Dubois, Eugène, 168.

Forbes, 17 .
Gadow, 157.

Gosse, P., 54 .

Grant, Robert, 65 .

Hæckel, 40, 168 .

Hertwig, O., 50.

Huxley, 37, 78, 136, 154.

Kowalevsky, 136 .

Landsborough, W., rog.

Lang, A., 39 .

Linnaeus, 32, 68.

Leuckart, $7 \mathrm{I}$.

Morgan, Lloyd, 20.

Parker, T. J., 32.

Roberts, G., 2 r.

Romanes, G. J., II.

Sharp, D., 92.

Sollas, 65 .

Woodward, rog. 



